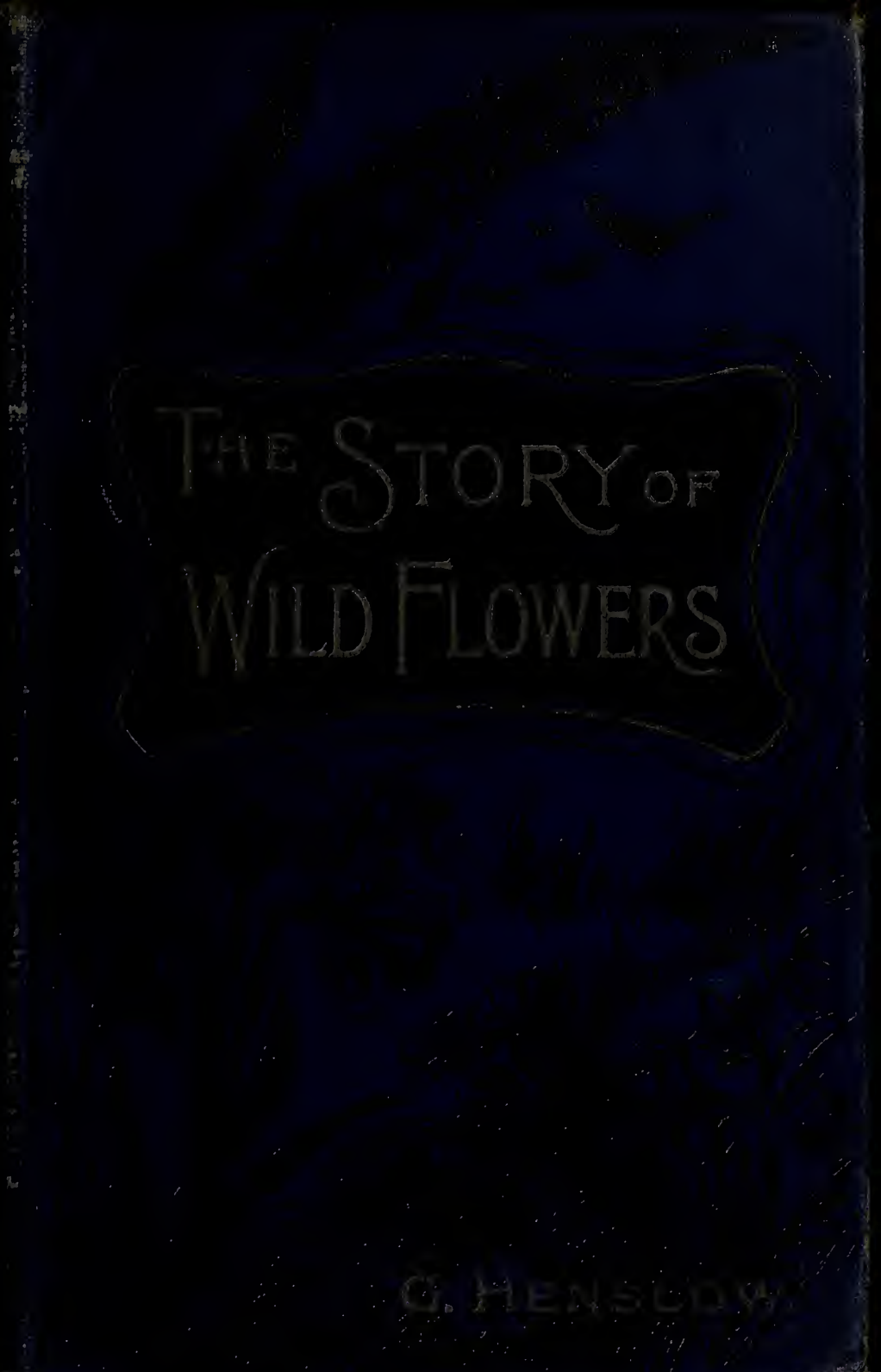




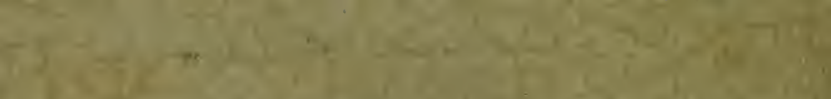

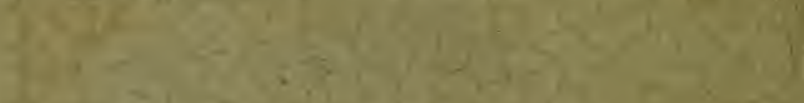

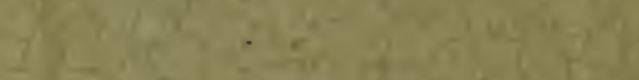

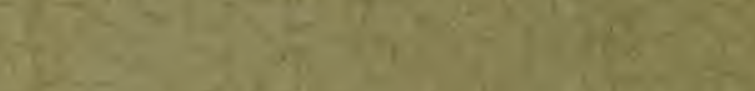

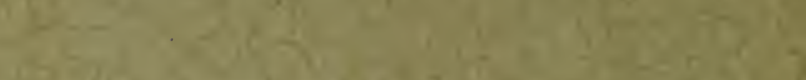

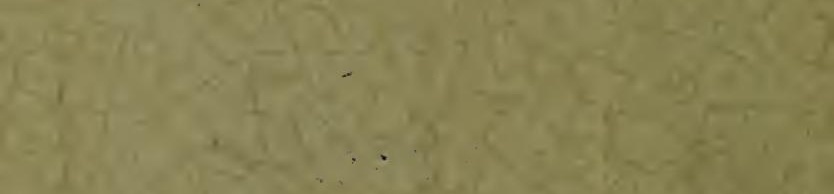

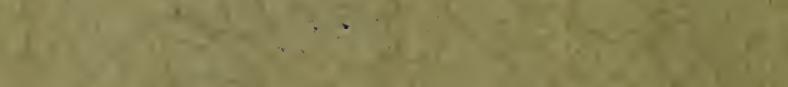

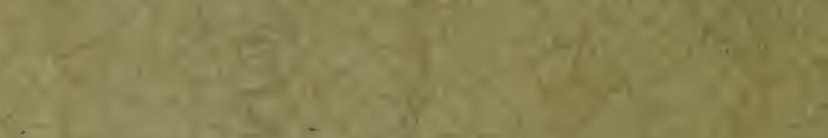

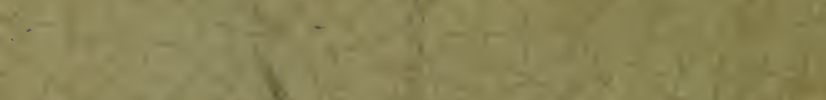

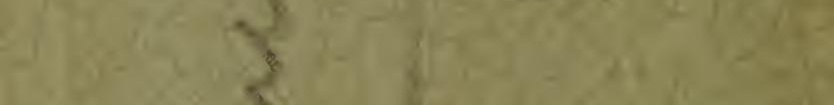

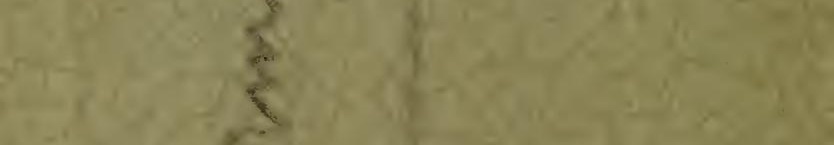

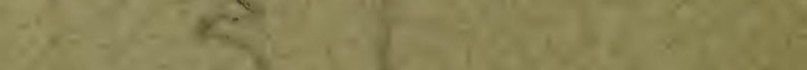

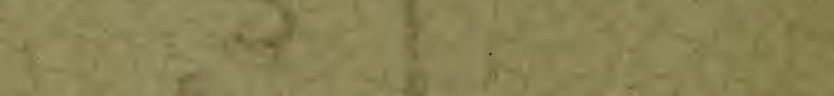

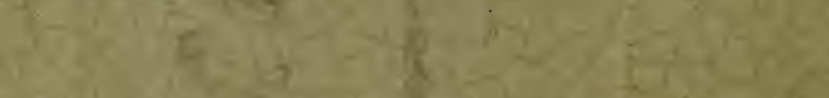

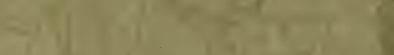
a.

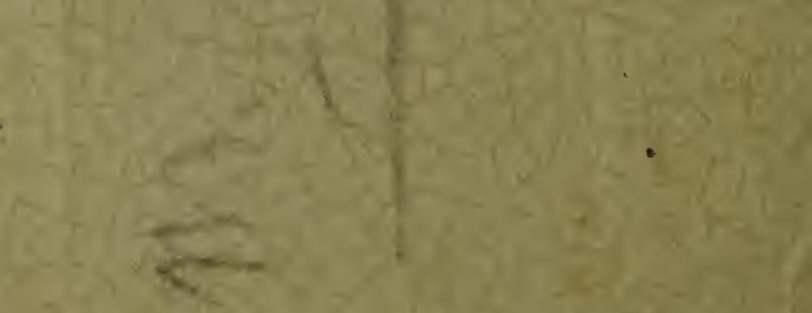


WRuito

123 Ealquaren:

Hrow Mrother 1020

B,cteivits

13. Ducts

13 NoV 1921 



\section{THE STORY OF}

\section{WILD FLOWERS}

BY

Rev. Professor G. Henslow

M.A., F.L.S., F.G.S., \&c.

WITH FIFTY-SIX FIGURES IN TEXT

LONDON

GEORGE NEWNES, LIMITED

SOUTHAMPTON STREET, STRAND

1901 



\section{P R EF A C E.}

In treating of wild flowers generally, the reader may ask-How are you going to do it? Now, if we turn over the pages of any text-book on Structural Botany, or of any "Flora," describing all the plants of some country, little else than descriptions of the actual structure of plants, that is, of stems, leaves, flowers, etc., will be found.

In the present work I have tried to add something additional by putting life into those dry bones of mere structure.

We now know that all plants have arisen by descent with variation. That is to say, every plant has had a history, in that it has descended from a long line of ancestry. This is why we can arrange them like the branches of a tree, all having sprung from a single stem. In other words the great doctrine of evolution teaches us that a plant, besides carrying a hereditary likeness, has the power within itself of varying, provided its external conditions of life are changed.

The living bond, therefore, which unites the following chapters together is the principle of evolution.

I should like my readers to keep this steadily in view; for they will then see how classification, the origin of forms of leaves and flowers as well as of special plant-structures, are. 
entirely based on adaptations to surrounding conditions of life, using that phrase as including everything with which plants come into contact.

Secondly, to interpret the distribution of species, this same power of "self-adaptation to the environment" explains not only the peculiar forms of plants on high mountains, in tropical countries, dry or moist, as of deserts, in marshes and in water; but also why it is that different and not usually identical species of the same kind of plant "represent" one another in similar climates but of widely separated regions.

Here I must say a word about "Natural Selection ;" for Mr Grant Allen in his "Story of the Plant" speaks of adaptations of flowers to insects as " the result of two great underlying principles, known as The Struggle for Life and Natural Selection."

He follows Darwin in this remark ; but Darwin has been proved to be wrong. He assumed without any evidence, that when seeds are carried away from their homes and grow up in a distant and different kind of place, that the new external influences caused the seedlings to vary in all sorts of ways, or " indefinitely," as he called it. Then, in the struggle between them and others, i.e. the native plants, any one or more which happened to have varied in harmony with its new surroundings, survived, and all the rest of the seedlings are supposed to have died.

Unfortunately for his theory, no single instance has ever been found of such indefinite variation, since he wrote his book "On the Origin 
of Species by Means of Natural Selection," in 1859.

On the other hand there is abundance of evidence that plants vary in direct adaptation to new conditions of life. Darwin admitted that this was sometimes the case, and said that if a plant varied "definitely" in this way, a new variety would arise without the aid of natural selection. Now we know that this is an invariable law of nature.

Where then, does Natural Selection come in?

Nowhere at all, as far as the Origin of Varieties or Species is concerned; but it plays a most important and universal part in the Distribution of Plants. Wherever plants struggle together, or with inhospitable, inorganic environments, the many die out and the few survive, and that is the province of Natural Selection.

As illustrations of the evolution of forms and of their having become dominant species, I shall describe some of the plants of our Colonial Floras in the Southern Hemisphere ; but must postpone them for a second volume.

With regard to our cultivated vegetables, the reader will see how in these evolution has been at work; and it is to this marvellous power of self-adaptation, to the artificial conditions of cultivation, that we possess our vastly "improved" plants, so utterly different as they often are from the original wild flowers from which they have descended.

Lastly, to meet frequent inquiries about the sources of our commoner garden flower: I have added an Appendix, in which is enumerated the 
majority of the better known flowers, giving the country from which they came, and the approximate dates ${ }^{1}$ of arrival, when known, into these islands.

Hothouse and conservatory plants, as well as cultivated species of our own native wild flowers are not given.

1 These are mostly taken from Paxton's "Botanical Dictionary." 


\section{CONTENTS.}

CBAP

PAG B

I. INTRODUCTORY .

II. EVOLUTION AND CLASSIFICATION OF WILD FLOWERS • . $\quad$. $\quad$. 15

III. EVOLUTION AND CLASSIFICATION OF WIL1) FLOWERS-continued . . . . 28

IV. GERMINATION OF WILD FLOWERS • • 41

v. ROOTS OF WILD FLOWERS AND THEIR WAYS • • . $\quad$ - . $\quad$. 54

VI. LEAVES OF WILD FLOWERS AND THEIR MODIFICATIONS . . . .

VII. STIPULES OF WILD FLOWERS AND THEIR USES . $\quad$. $\quad$. .

VIII, VEGETATIVE MULTIPLICATION OF WILD FLOWERS . . . . . .

IX. VEUTATIVE SPORTS IN WILD FLOWERS . $\$ 9$

X. MOVEMENTS OF THE ORGANS OF WILD FLOWERS • • • . . . 98

XI. ClIMBING WILD FloWERS . • . . 110

XII. INSECTIVOROUS WILD FLOWERS . • . 121

XIII. AQUATIC WILD FLOWERS • • . . 133 
CHAP.

XIV. THE ORIGIN OF FLORAL STRUCTURES OF WILD FLOWERS . . . . . . 143

XV. ADAPTATIONS FOR POLLINATION AMONG

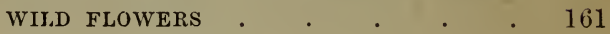

XVI. FREAKS OF WILD FLOWERS . . . . 183

XVII. ORIGIN AND PRESENT DISTRIBUTION OF BRITISH AND IRISH WILD FLOWERS • 193

XVIII. WILD FLOWERS IN THE KITCHEN GARDEN : OR EVOLUTION OF OUR VEGETABLES • 209 APPENDIX-WILD FIOWERS IN THE GARDEN ・ 225 INDEX . 


\section{THE STORY OF WILD FLOWERS.}

\section{CHAPTER I.}

I N T R O D U C T O R Y.

BEFORE proceeding to discuss Wild Flowers and their ways, it is necessary to give some account of the general structure of a Flowering Plant, in order to explain their means of multiplication and how new forms or "species" of plants arise, as a result of their spreading into countries of different characters, etc. For these results depend upon the peculiar nature of their "organs," using this word to mean generally all parts of a plant which have special functions assigned to them to perform.

It is a matter of common observation that, besides the production of offspring resembling their parents in every way, they can, and often do, vary more or less greatly in certain aspects from them. How such variations arise has to be accounted for.

As the late Mr Grant Allen has done a good deal for my readers in his volume "The Story of the Plant," I shall avoid going over the same ground, by referring them to his work when 
necessary for further details than I can give in this book, beyond a general outline, which I will here supply.

Any ordinary flowering plant, say, a buttercup, may be regarded as possessing two classes of organs, "Vegetative" and "Reproductive." The former embrace the Roots, Stems, and Branches (subterranean and aërial), and, lastly, Leaves, with or without Stipules.

The reproductive organs are Flowers with or without Bracts, and the subsequent Fruit containing the Seed.

The former group is concerned in maintaining the life, and securing the development of the plant; while the latter is occupied in reproducing and multiplying the individual. The vegetative organs can, however, often act as additional means of propagation; as a tulip bulb will produce bulbils, and a tuber of a potato develops a plant which again bears many potatoes for future multiplication. This subject will be discussed in chapter viii.

The next point is to understand the uses or functions of these organs. First, then, with regard to the vegetative, there are two kinds of roots; one consisting of simple or branching fibres, which absorb water and whatever salts, etc., may be dissolved in it; the others are thickened or fleshy, their function being to store up organised products as reserve food-materials for future use, such as starch, sugar, oil, and other matters. These two kinds of roots are well seen together on a plant of the Lesser Celandine (Fig. 3). 
The stem and branches convey the water to the leaves, which "transpire" or "exhale" the superabundance; so that the salts necessary for the plant can be sufficiently concentrated.

The leaves absorb carbon-dioxide (carbonic acid), composed of carbon and oxygen, from the air; and, under the action of light, decompose it, exspiring the oxygen, and "fixing" the carbon. This, in combination with the elements of water (hydrogen and oxygen), form the first visible organic product or starch, the first important result of the process of "assimilation"; so that the two great functions of leaves are transpiration and assimilation. For further details of these functions I will refer the reader to chapter iv., "How Plants Eat," and chapter v., "How Plants Drink," in Mr G. Allen's book.

Of the reproductive organs, Bracts are the first to be noticed. These are rudimentary scalelike leaves, generally green, but not infrequently taking the colour of the flower; when they may be white or brilliantly coloured. They are usually single, i.e. one below each flower, which arises from its axil. In the blue-bell there are two, and if the Hlowers are crowded together, as are the "florets" of a daisy or dandelion, then they form a dense mass underneath the "head" of "florets" and are called an involucre.

A typical flower consists of four series or "whorls" of parts, the outermost, or Calyx, is generally green, as in a rose, sometimes coloured as in the marsh marigold (which has no corolla). The individual parts are called Sepals. The Corolla is usually white, or coloured other than 
green, and is composed of Petals. The third whorl consists of Stamens; each stamen having a stalk or Filament with a two-celled Anther at the summit. Each anther-cell contains the fertilising powder called Pollen. The last and central organ is the Pistil. This is composed of one or more Carpels. Each carpel consists of a bag-like structure below, called the Ovary, which contains one or more Ovules. Above the ovary rises the Style, terminating with one or more Stigmas at the summit.

These four sets of organs, Calyx, Corolla, Stamens and Pistil, constitute the four Floral Whorls.

The uses of these parts are briefly as follows:The calyx protects the interior parts when immature. The corolla attracts insects by being white or coloured or scented. The stamens shed the pollen, which must fall on to the stigmas of the pistil either of the same flower or of some other like it in order that seed may be borne by the latter. The minute grains of pollen then send down "pollen-tubes" through the style into the ovary. They ultimately reach the ovules, one entering a minute pore in each ovule called the "micropyle." The fertilising matter, called a " nucleus," passing out of the pollen-tube, unites with a "germ-cell" or nucleus already prepared within the "embryo-sac" within the ovule. These two nuclei, i.e. the "germ-cell" and "spermcell," now united, grow into an "embryo," or young plant of the future, as is seen in the almond, bean, or pea, when the skins are removed.

For further details of the process of "fertilisa- 
tion" and of the "crossing" of flowers, I will again refer the reader to Mr Allen's book; for he enters into particulars about "How Plants Marry" in chapter vi., and on "Various "Marriage Customs" in chapters vii. and viii.

I shall have several occasions to refer to "Marriage Customs" among plants in the course of our travels over the world in search of wild flowers; so I shall assume my readers to quite understand what I shall have to say on this subject.

Now what does the term "Wild Flowers" embrace? Not only all flowering plants that are wild, but such as have been introduced into cultivation and remained unchanged.

In these days "forced marriages" between different "species," or what is called "hybridisation," has probably given rise to by far the greater number of our garden plants, both in the open border and in greenhouses and conservatories; so that the truly "wild" originals of our garden rhododendrons, roses, fuchsias, pelargoniums, begonias, pansies, narcissus, etc., etc., are quite unknown to the general public. On the other hand, the purple foxglove, snapdragon, blue and white irises, Alpine plants, etc., are just as they are found in their native homes.

Now, every country has, and if it be a continent, various parts of it have their own peculiar wild flowers : and if we travelled to all our colonies and if I were to try to enumerate all the wild flowers of each, I should require many volumes; so that I shall be compelled to limit myself to a selection, especially such as are better known, or 
which are characterised by having some special points of interest.

Another feature of importance is that in comparing the wild flowers of one country with those of another, one notices that certain "families" and groups called "genera" (which will be explained hereafter) often prevail. Thus the "scrub" of Australian forests is largely composed of various "species" of Acacia. Visitors to the Riviera will be familiar with them, for they grow so well there. The flowering branches are often sent over to London under the name of "Mimosa."

Another feature is that when the "floras" of two widely separated countries of like conditions, say, hot, rocky and dry, are compared, at first sight many plants of the one would be thought to be the same as those of the other ; but a closer inspection of the flowers reveals the fact that while their general vegetative systems are closely alike, their flowers betray totally different families, genera or species as the case may be. Hence botanists call them "representative" plants. I shall have occasion to give several instances of this remarkable fact, among foreign wild flowers. The explanation is simple enough. It is that like external conditions have induced the plants to assume like forms, which are best adapted to live under the conditions in question.

Such are the lines on which I propose to treat of wild flowers ; and to add chapters dealing with special peculiarities of certain plants such as have acquired the habits of climbing, of parasitism, of catching insect-prey, of going to sleep, etc.

In this way we shall be able to take a pretty 
general survey of wild flowers and their ways and so compile their story.

As it will be quite impossible to deal with so vast a subject as the wild flowers of the world in one book, it is proposed to continue the subject in a second, if the present one meets with approval. As this will treat mainly with plants of England and the European continent, the second volume will be more concerned with tropical regions and their peculiar plants, as well as the floras of our colonies in the southern hemisphere and elsewhere.

\section{CHAPTER II.}

THE EVOLUTION AND CLASSIFICATION OF WILD FLOWERS. ${ }^{1}$

IN looking at any nosegay of wild flowers, the eye rests upon a great variety of forms and colours in the blossoms; and it might be thought what a difficult thing it must be to reduce the mass of beauty one sees in nature to anything like a simple system of classification. Yet, so it is. All plants can be placed in two sections, containing those which bear flowers and those which do not. The former are called Phanerogams ; a word signifying " visible marriages or unions," as the stamens and pistil are conspicuous. The latter are called CRYPTOGAMS ; and as the unions are produced by organs, representing stamens

1 "Wild Flowers" must be allowed to include all plants growing wild, whether they bear flowers or not. 
and pistils, which are microscopic in size, thi word is invented to signify " concealed unions.'

At present we are only concerned with plant which have flowers. These are grouped into tw classes, called Dicotyledons and Monocoty LEDONS, according as the "embryos" of the seed have two or one cotyledon or seed-leaf, respectively.

There are almost always a few exceptions tc

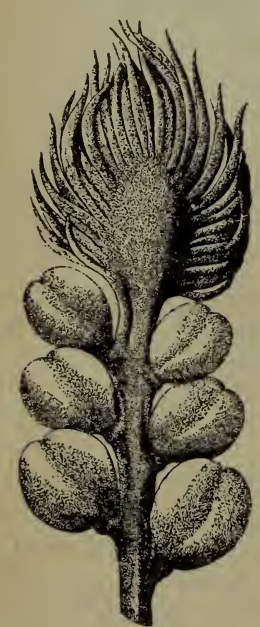

Fig. 1.- "Carpellary" scale of Cycas, with six marginal and naked seeds. (From the Gardener's Chro-

nicle.) the edges of altered leaves (Fig. every group, and so some of the former have only one, whil some of the latter have at leas a rudimentary second cotyledon We shall understand the signi ficance of this hereafter.

The first class has two Sub Classes. The first is callec ANGIOSPERMS, as the "seeds" are in "vessels," as the wor implies. In other words, they are contained within a fruit of some kind, as peas are in a pod The second sub-class is called Gymnosperms, for the "seeds" are "naked."

This is a comparatively smal group, at least compared with the two classes, but remarkable for having no "fruit," only seeds exposed to the air and borne on the edges of altered leaves (Fig. 1 ), or by the stems. We have but three in Great

"The structure of seeds will be explained later on. The two cotyledons are the "halves" of an almond of of "split" peas. 
Britain - the Srotch Fir, the common Juniper, and the Yew. They, however, represent a very ancient "flora"; for such plants once formed a large proportion of the vegetation, which now constitutes our coal.

The next classificatory terms are the FamiLies or Orders. These consist of Genera, and these last, of SPECIES, with or without VARIETIES.

How shall we attack this subject? The best way is by seeing how Nature herself has brought about such "Diversity from Unity"; for the above classification has been made by comparing plants, and noticing their points of similarity, as well as of difference. Thus, if, e.g., we collect some buttercups, one would soon see that while the flowers strike one as being all alike, yet one kind would have runners like a straw-

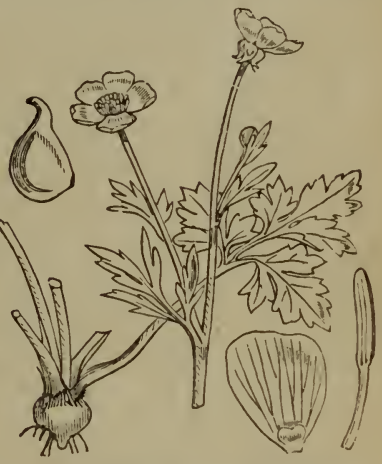
berry plant; another FIg. 2.-Bulbous Buttercup (Ramun-

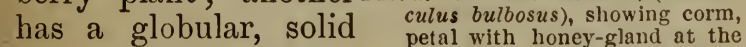
stem, called a "corm"; base, a stamen, and an achene. a third in corn-fields is an annual, not a perennial, as the former, and has prickly, and not smooth fruit; a fourth kind lives in water, and has white, instead of yellow flowers. Linnæus, who gave latin names to them, called the first Ranunculus repens; the second, $R$. bulbosus (Fig. 2); the third, R. arvensis; and the 
fourth, $R$. aquatilis. Why are they all called Rununculus? Because the structure of the fiower and fruit is essentially the same in all, viz, consisting of five free sepals, five free petals, many free stamens, and many free carpels, each of which when ripe, becomes a "seed-like" little fruit, called an " achene." No child would hesitate to gather the first three kinds, at least, as buttercups; so Linnæus called them all, and a great many more, by the "generic" name Ranunculus. That is to say, this is the "genus," but each kind has its "specific" name, which indicates the "species."

I have only alluded to one specific character, taken from the stems, but the reader must clearly understand that a species should al ways be known, not by one only, but by a collection of constant characters, taken from any or all parts of the plant. They may be supplied from the roots, stems, leaves, flower-stalks, parts of the flowers or fruits ; these may all form "specific" characters; but they must be constant, year after year, and therefore to be depended upon.

It often happens that some one or two characters belong to two or more species. That is why one, two, or even a few characters are often insufficient to define a particular species; but as many as possible taken collectively are what one can trust as indicating a species. Thus the sepals are reflexed, both in $R$. bulbosus (Fig. 2) and $R$. hirsutus, but spreading in $R$. repens and $R$. acris.

It is very desirable for the reader to clearly understand what is meant by a "species," as this, lies at the whole basis of classification. 
A certain difficulty comes in here, because there is no hard and sharp line by which we can always sever one species from another. Often it is possible; but the differences may, in the eye of one botanist, be sufficient to separate two plants, to which he would give two distinct specific names; but to another botanist the resemblances seem to overbalance their differences, and he would call one a "variety" of the other.

The greater the knowledge of plants the more often does this happen, and "transitional" forms are found connecting, sometimes by almost insensible gradations, what would otherwise be regarded as well-differentiated species. But not only may species, but genera, that is groups of "allied" species, are often linked to other groups, called by a different generic name.

Thus the late Mr G. Bentham, one of our greatest of systematic botanists, says, that of ninety genera of the "Tribe" or larger group, Asteroidece, of the great family of Compositce, he could find no decided break between any of them. That means, that nearly 1000 species were linked together.

It is this almost universal feature in both kingdoms, animal as well as vegetable, that seemed to militate against the old idea of every species being a distinct entity created just as we see it now. How, then, has this, so to say, intimate connection between species come about? It is a true alliance by relationship.

Although a species is known by its group of characters, yet, as far as we know, no plant has 
them so absolutely fixed that they can never change. It was thought so once, but now we find that although, when plants have grown for long periods within any particular surroundings, great fixity becomes a characteristic feature ; yet if the seeds be sown in a garden border, or be transferred to a widely different locality, as by birds, wind, etc., then the plants, as they grow up, begin to change their features more or less, so as to be in better harmony with their new environment. Plants will often stand a considerable amount of external changes without much, if any, appreciable alteration. Some are very refractory under cultivation, and seem to resist it; while others change very rapidly. Thus bulbs of tulips, etc., imported from Asia Minor and elsewhere, sometimes bear flowers and foliage very unlike that of their original parents after three or four years' cultivation only. So, too, the seed of the wild parsnip, common in many places of England, when sown in a richlyprepared soil, may become a good kitchen vegetable in about four or five years. The root and leaves become enormously enlarged. The latter loses its dense hairiness and becomes smooth and what is of prime importance, these "acquired" characters, as they have been called, become hereditary, and the enlarged form of root is perpetuated by seed. It was thus that the "Student" parsnip was raised as an experiment by Prof. James Buckman at the gardens of the Royal Agricultural College, Cirencester, between 1847 and 1852. It was "brought out" by Messrs Sutton and Sons, and is still 
the best in the trade at the present day (1901).

Similarly is it in nature. Though we cannot see nature's experiments as a rule, as we can our own, yet we find that if a particular plant is abundant in a certain locality, the further we travel from that centre, the more do we find it passing into other varietal forms; at first differing but slightly, till we find quite different species in districts widely separated. The reason is simply that the further they travel from the original home, the greater are the differences in the environment or surroundings, which act upon the plant and induce it to vary in the right way; so as to render it suitable to its new conditions of life, whatever they may be. ${ }^{1}$

As this is so important a subject, as explaining the Origin of Species, I will take the following illustration from Sir J. D. Hooker's Student's Flora of the British Isles, to show how various "forms," whether we choose to call them "varieties," "subspecies," or "species," arise. The common knotgrass is a familiar wild flower by roadsides. He thus describes them:-First there is the knotgrass "proper" or the typeform; secondly, a littoral form, being the passage to a true, maritime one ; thirdly, a field form ; fourthly, a sand loving form; fifthly, a small fruited form; sixthly, the wayside form; seventhly, a second maritime form in sandy shores.

${ }^{1}$ In giving some account of the wild flowers of our Colonies, I shall draw attention to this fact; "pointing out how genera and species are "represented" but not identical in different localities widely separated. 
It is pretty evident that all these forms are the result of living in the special soils where they are found.

The reader will now understand how simple is the process by which new species arise, i.e. through varieties from old-established ones. It all depends upon a certain power which resides in the living "protoplasm" contained in the cells of the plant. Any explanation of the process is at present impossible. All we can say is that the prołoplasm, together with its still more important "nucleus," can form two cells out of one. The cells then assume definite forms according to their positions in the plant. A certain number go to form an organ, such as a root, a leaf, a petal, etc.; and if the protoplasm be unaffected by external agencies, it will go on perpetually forming cells of the same kinds, in the same places, and so build up organs of like kinds. But, if it be affected by a new set of external agencies, then cells build up a differently shaped organ. Thus, if a leaf lies horizontally, the protoplasm constructs a broad leaf-blade, with a different structure on the upper from that of the under side. If, however, it be erect, as a blade of grass, or of a carnation or thrift, the form is totally changed. The leaf is narrow, and has both sides alike. How the trick is done, nature keeps secret to herself, for she has never told us what life is, how it acquired its properties, nor whence she obtained it.

The individuals of a species, then, are actual entities but a genus is not; for it means all the species derived from some common ancestor and 
taken collectively. Thus any buttercup one gathers in the field is a species; but the genus Ranunculus is the collective name for all kinds of buttercups and does not stand for any one in particular alone. Sometimes it does when it includes only one species, then of course the species and the genus are the same thing, as, e.g., the British water-plant called the Horn-wort, or the little Australian pitcher plant, ${ }^{1}$ a solitary species of a solitary genus.

It may be added that when such a plant occurs, it is now recognised as the lingering relic of a long line of lost ancestors. Since, having abandoned the Idea of separate creations and accepted evolution, we cannot look upon it as having come into existence without a previous line of descent. But they have all disappeared. There are many other "survivals" as they are called, both in the animal as well as the vegetable kingdom. Sometimes it is a single genus with many species that stands all alone, without any near allies, as the true pitcher plants, ${ }^{2}$ and the horse-tails. ${ }^{3}$ Of this last we do know something of its lost ancestry, as numerous kinds are found among coal-plants. All but one genus having died out. We do not know when or where the different species of buttercup arose one from another; but the accumulative evidence is so great, that no one now who has paid a little attention to it, disputes the doctrine of evolution; which asserts that all existing animals and plants have arisen by "Descent with Modification" from pre-existing ones.

${ }^{3}$ Cephalotus follicularis. ${ }^{2}$ Nepenthes. ${ }^{3}$ Equisetum. 
Perhaps it will not be amiss to give another illustration to show the line of argument adopted. It is called "Inductive reasoning." That is, it is based on an accumulation of a vast number of coincidences; so that the probability of the result being as supposed becomes so great, that the alternative is unthinkable.

Now it is in this way "certain" that the water-crowfoot is descended from a land buttercup. Why do we believe this? It has finely divided submerged leaves. It is "certain" that this feature has resulted from being under water; because, not only is it so in this plant, but it would be easy to mention a dozen others, of no relationship between them, which have precisely the same feature. In almost every case, as with the buttercup, other species living on land have not their leaves finely divided. This widely spread coincidence of submerged leaves being finely divided convinces us that it is a result of the submergence.

Now this line of reasoning can be applied to hundreds of particulars among plants.

Sometimes we can adopt an even more satisfactory proof that our inferences are correct ; for we can actually produce the anticipated result by experiment, though the previous line of arguing in a vast number of cases is quite sufficient. Thus, the fleshines: of many seaside plants is a general characteristic, as in the samphire. That it is due to the presence of salt is an inference based on coincidence. Now experiments have been made with garden plants, watering them with salt and water, which has induced them to 
acquire a similar fleshiness. Conversely, when maritime plants have been grown inland, they have been known to lose it, and become thinleaved. All this "experimental" proof, therefore, corroborates our original "inductive reasoning."

We thus see how species and varieties, which last are but incipient species, have arisen in nature, and that such are collectively grouped under the term genus.

How did the group of species forming one genus come to differ from the group of species constituting a second genus of the same family?

Here we must concentrate all our attention almost entirely upon the structure of the flowers, and sometimes on the fruits, and we have to travel back in Frg. 3.-Lesser Celandine (R. Ficaria), imagination into the past history of plant life.

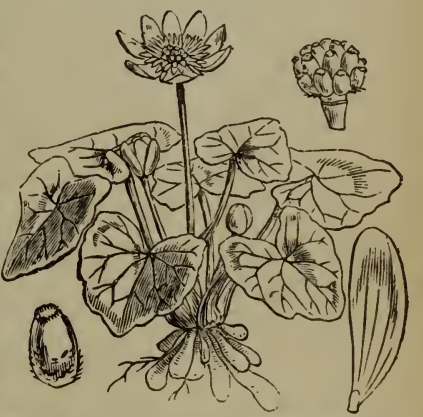
showing tuberous and fibrous roots, a petal with honey-gland, the pistil of many carpeis, and a single carpel.

As we have taken buttercups to illustrate the origin of species, so I will take the lesser Celandine (Fig. 3) to illustrate the origin of a new genus; for this is also one of degree, and - botanists have differed as to whether it should be called a Ranunculus or not.

As a rule, there is a greater difference between 
the forms of the parts of the flower of species of different genera than between those of different species of the same genus.

Thus, if a child were told to gather buttercups, it would have no hesitation in collecting flowers from $R$. acris, $R$. bulbosus, and $R$. repens; but it might hesitate to gather flowers of the earlier flowering Lesser Celandine or R. Ficaria, or as some have called it Ficaria ranunculoides.

The flower has 3 instead of 5 sepals. There are 7 or 8 petals instead of the constant number 5 . It has, however, numerous stamens and carpels, which become achenes, exactly like those of other species of Ranunculus, if they ripen at all, which is not usually the case in the Lesser Celandine, in England. Moreover, it flowers much earlier than the true buttercups, and the whole plant is smooth, and the leaves round and not divided; so that its general appearance does not seem to associate it very closely with the true buttercups.

How came these differences, and what is its history? The leaf resembles in shape that of the Marsh Marigold, or that of the water-lily in miniature, or even that of a monocotyledonous plant called the Frog-bit, all the preceding being dicotyledons.

If we cut the stem or leaf-stalk we find "aircanals," characteristic of all water-plants. Again, if we examine its leaves microscopically, we should detect a predominance of "stomates" on the upper surface as occurs in floating leaves, which, however, have none on the under side, as the Lesser Celandine has. 
Again, if we let the seeds grow, we find that they possess only one seed-leaf, not two cotyledons. What do these features indicate, but that we must infer that the Celandine's ancestors were aquatic plants? Such had descended from some lost ancestral buttercup which took to the water, just as the Water-crowfoot did. Many years ago it returned to the land again, and readapted itself to terrestrial and aërial conditions, though it could not throw off all its "acquired aquatic characters."

The plant has thus retained so many of its features originally adapted to an aquatic life, and it has lost so much of the appearance of a buttercup, that it is no wonder there should be a doubt as to what it should be called. Sir J. D. Hooker, however, still retains it as a Ranunculus.

Having thus obtained a new genus-for whether we call it a species of Ranunculus or of Ficaria, it is only a question of degree-the two genera need a fresh common name, and that is "Natural Order" or "Family."

At the present day families contain from one to, it may be, hundreds of genera, all linked together by some common characters taken from their flowers or reproductive organs, generally.

They are believed to have descended from some common ancestral stock. They contain many "doubtful" forms, which systematists arrange as genera in different families or species in different genera, according to their ideas as to how many and what sorts of different characters go to make the genus or species respectively.

The greater number of genera and species, 
however, are well defined, and one has no hesitation in recognising a plant as belonging to a particular genus and family.

As families and orders are now so many, botanists have grouped them on the same principles into "Cohorts," these again into "Divisions," and the last into the two Classes already mentioned.

I do not, however, propose to trouble the reader much with descriptions of Cohorts and Divisions; but shall have a good deal to say about the Classes ; but I prefer to point out their characters by degrees, as I have to treat with the natural causes which produced them.

\section{CHAPTER III.}

THE EVOLUTION AND CLASSIFICATION OF WILD FLOWERS-(continued).

IF the classification of plants can be shown to be simpler than one might expect from a general survey of the immense variety in nature, the next question is-Can the various structures of flowers be also reduced to some simple system, dependent upon a few causes, or perhaps a single cause, to which we can attribute their multitudinous shapes and colours?

I believe they can; but here we cannot avoid being somewhat speculative, as actual proofs by experiment as to how flowers have been, and perhaps are still being, made, is difficult to obtain. Still we can depend upon much induc- 
tive evidence, or the accumulation of coincidences giving rise to probabilities of a very high order.

Of course we do not know what the first flowers were like, but the Gymnosperms appear to supply a link between Cryptogams, such as Ferns and their allies, and Dicotyledons. If, therefore, that of a fir-tree is to be trusted, as illustrating a primitive type of flower, we find stamens, but no corolla or calyx; and $¥ i t h$ regard to the female flower, for the two kinds are distinct on these trees, if it be asked how or when nature passed from constructing a simple naked ovule, either on the margin of an open scarcely modified leaf, as seen in the Cycads of South Africa (Fig. 1), or at the base of a flat scale as in pines, and began to fashion a pistil with an ovary, in which to include the ovules, we are still unable to reply.

That petals were formed out of stamens seems an obvious fact, from water lilies, in which the transition is retained; but other links are unfortunately lost, so that at present we must fill up the gaps by our imagination.

In dealing, however, with existing flowers as we find them, we observe that the simplest condition is represented by an entire freedom among all the parts, so that a buttercup may be taken as representing a flower of this character, since it has five free sepals, five free petals, numerous free stamens, and many free carpels. The last two whorls being arranged spirally, after the manner of leaves.

The whorls, too, are all "regular," in that their parts are of the same shape respectively 
While considering how flowers are constructed, I will here introduce some subsidiary classification. Thus all plants of the Class Dicotyledons which have both a calyx and a corolla, and their petals free, come under the "Subclass" Dichlamydece ${ }^{1}$ and "Division" Polypetalce. ${ }^{2}$

The first advance in structure is seen in one or more of the four floral whorls having the parts coherent; as familiar examples are the sepals of the calyx and the petals of the corolla forming tubes, one within the other, in the primrose, deadnettle, gentian, etc.

The ten stamens of the Laburnum and of the Broom are united into a tube surrounding the

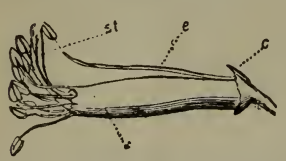
pistil, but in most flowers of the Pea family, or the Order Leguminosce, to which these belong, one (the uppermost) Fig. 4.-Stamens of Pea: of the ten stamens is free, nine coherent, one free. in order to allow access to the honey within the staminal tube (Fig. 4).

Lastly, a poppy-head is a pistil composed of some ten or more carpels united together. ${ }^{3}$

All Dicotyledons which have their corollas composed of coherent petals form the Division

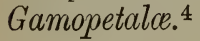

1 Literally "two-cloaked," i.e., in reference to the presence of a calyx and a corolla.

2 Poly-petaloe literally means "many-petalled"; but Poly here stands for " free."

3 The reader should always make a point of examining everything described in this book, in nature, himself, whenever possible.

"Gamos, literally signifying "wedded," means here "coherent." 
Another kind of union among the parts of flowers is called "Adhesion." As co-hesion means "united together," and refers to the parts of any one whorl without respect to others, so ad-hesion always refers to the union between two or more different whorls. Thus, when the petals cohere to form what has been called a "gamopetalous" corolla, it is almost an invariable rule that the stamens should be adherent to the corolla-tube, as in a primrose, deadnettle, gentian, etc. Two orders or families supply exceptions, they are the Canterbury Bell and the Heath families.

Another curious modification results from a growth of the Hower-stalk. The end of this is usually somewhat enlarged

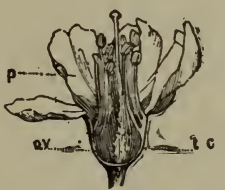

FIG. 5 .

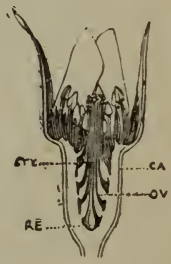

FIG. 6.

FIG. 5.-Flower of Apricot (vert. sect.). $p$. petal; ov. ovary of the pistil of one carpel; $t c$. the cup formed by the receptacular-tube. into a knob or cone, Fig. 6. - Flower of Rose (vert. sect.).
ov. ovary of carpels, arising from the and occasionally takes on a great ininner surface of the receptacular-tube $(r e)$; sty. styles of free carpels. crease, as in the fruiting stage of the strawberry, the succulent, edible part being entirely flowerstalk. It is called the Floral Receptacle. It sometimes happens that when a flower-bud begins to be developed, the middle point, where the pistil is, ceases to grow, while the circumference continues to do so. The final result is that a cup is formed, having the pistil at the bottom, while the sepals, petals, and stamens now spring from the rim of 
the cup. This is well seen in the apricot (Fig. 5) and cherry-blossom, which has only one carpel to form the pistil. In a rose, however, there are several free carpels within it, which can be easily picked out if the swollen urn-shaped extremity (which becomes the scarlet hip in autumn) be cut down the middle (Fig. 6).

This "receptacular-tube" takes various shapes. In some, as the raspberry, it forms more of an expanded, dish-like structure, with a sort of little trough running round the base of the pistil. The use of it is to secrete honey, which fills the trough in the raspberry. In the rose it appears to bave lost this function of secreting honey, the flowers only supplying pollen for food to bees.

About one-half of the group Polypetalce are without this receptacular-tube; while the other half have it represented in some way or another; so that while the former constitute the subdivision Thalamiflor ${ }^{1}{ }^{1}$ the latter are included in Calyciflorce. $^{2}$

There is yet another modification to be mentioned with regard to the receptacular-tube. In the apricot and cherry-blossom there is one carpel only, constituting the pistil, and quite free within the tube. When ripening the latter articulates at the bottom and falls off, leaving the cherry at the end of the stalk.

1 These are fanciful and somewhat misleading terms; for Thalamos is a Greek word signifying "chamber," but here must be understood to mean the "corolla on the thalamus," i.e. the floral receptacle.

${ }^{2}$ Calycifloree would mean "corolla on the calyx," for it was invented when the now recognised "receptaculartube" was thought to be a "calyx-tube." 
In many cases, however, the receptacular-tube becomes adherent to the ovary during growth. In such flowers the pistil is usually composed of two or more coherent carpels. In apples and pears, however, there are five free carpels forming the star-like core when the fruit is cut across. But in such flowers as a currant (Fig. 7), fuchsia, any flower of the umbelliferous family, as of the carrot and parsnip, the swollen part below the flower if cut across will reveal the united ovary-cells.

The interpretation is that the ovary is imbedded within the receptacular-tube which is adherent to it, and so forms the superficial covering. This is evidenced by the sepals, petals, and stamens standing on the top of the ovary, i.e arising from the elevated rim of the recepta-

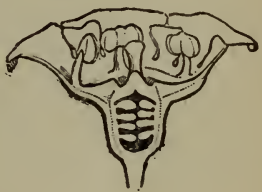

Fig. 7.-Flower of Currant (vert. sec.), showing inferior ovary and superior calyx; with petals and stamens arising from the expanded top of the receptaculartube. cular-tube, which is now adherent to the ovary.

Two words are used to signify these conditions, and may be described as follows :-If the caly $x$ or perianth 1 be apparently inserted upon an adherent receptacular-tube (the old "calyx-tube" of authors), it is called "superior" (i.e. above the ovary), and the ovary is "inferior," i.e. not only enclosed within, but adherent to the receptaculartube.

1 The "perianth" is the equivalent of the calyx and corolla taken together, when they are both alike. It is the usual condition with "bulbous" plants, e.g., of the crocus, lily, narcissus, blue-bell, tulip, etc. 
On the other hand if the ovary be free, and above the calyx or perianth, it is called "superior," the calyx or perianth being "inferior." 1

It is only in a few families or orders of the Calyciflorce and a few of Corolliflorce which have "inferior" ovaries. In Monocotyledons the two divisions are based on these differences as the words Epigynce "on the ovary," and Hypogynce, " under the ovary," imply.

To make this a little plainer, suppose we take an apple. First notice the tuft at the top composed of sepals, withered stamens, \&c. This often indicates an "inferior" fruit, as on a gooseberry and currant; whereas a cherry, a peach, a grape, and an orange have no such remains of the flower and are "superior" fruits.

Sometimes the tuft articulates leaving a clean scar; so that one may be easily deceived, if the flower had not been examined. Thus gourds, cucumbers and melons are all true "inferior" fruits ; but shew no withered tuft at the top.

The structure of inferior fleshy fruits, as e.g. an apple (Fig. 8) is as follows :-An ovary, if free and superior as a peach, has three parts, viz., the inner lining or skin (fibrous in a pea-pod, stoney in a peach or plum), the middle and soft tissue, and an outer skin or epidermis.

On the other hand a free receptacular-tube as of a rose, reveals three similar layers.

Now, if the tube be adherent to the ovary, then the inner skin of the tube and the outer skin

${ }^{1}$ It is important to note that there must be adhcsion between the ovary and calyx or perianth for these to be "inferior" and "superior" respectively. 
of the ovary, are not developed at all ; so that the two soft middle layers are fused into one mass. While the leathery core of an apple, or stoney covering to the seeds in a medlar and hawthorn, enclosing two pips or seeds, represents the inner skin of the ovaries, the outer or "peel" belongs to the receptacular tube or flower-stalk; and the thick fleshy edible part is a combination of the two inner layers, half being of the ovary, and half of the receptacular-tube.

We thus see how flowers pass from entire freedom to various states of union; and botanists consider such differences represent the lines of evolution of flowers, cohesions and adhesions being of later introduction into the world than the earlier state of freedom.

Similarly it may be added that all irregularities in floral

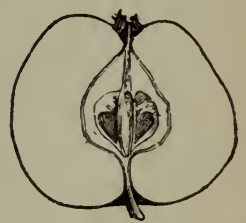

Fig. 8.-Apple (vert. sec.), showing fleshy receptacular - tube, with core and seeds; inner boundary (double lines); and withered stamens, etc., on the summit. whorls, which are special adaptations to insect agency, ${ }^{1}$ are later additions to regularity which marks a primitive condition.

A flower is said to be complete when it has all four floral whorls; but it often happens that one or more are wanting. This may be either a primitive condition as in Gymnosperms, which have only stamens and ovules wherewith to represent flowers; or a flower may have become de-

${ }^{1}$ How irregular corollas, \&c., have come into existence in consequence of insects visiting flowers for honey or pollen as food, will be fully explained hereafter. 
graded from a complete to an incomplete state; and so lost one or more of its parts. A large number of plants are in this state among Dicotyledons; and botanists have placed them together under the term Incompletee as a "sub-class." It is doubtful whether some few among them be not of a primitive or very early type $;^{1}$ but the probability is that the greater number are really "degradations ;" for they often show points of affinity with plants of orders which have complete flowers.

Incompletce are mostly destitute of corollas, so they are sometimes called apetalce, i.e. "without petals"; and the group has been divided into two divisions according as a calyx is present; Monochlamydece, i.e. "one-cloaked" or when there is none, Achlamydece i.e. "cloakless." In this latter case the flower consists of stamens alone or a pistil alone as in the willow; or they may be together, to form a flower. Thus in the common spurges, a male flower is reduced to a single stamen.

This sub-class Incompletce furnishes a good illustration of what occurs under evolution; for this word not only includes "advances" with more and more complicated structures as animals and plants have risen in the scale of life ; as, e.g., in passing from a buttercup to a daisy, or from a fish to a mammal; but accompanying progressive complexity, there are always degradations in some organ or other; because they are no longer required. Hence many an animal and plant is

${ }^{1}$ Such as the Sweet Gale (Myrica); perhaps, too, willows and poplars and the Australian Beefwoods (Casuarina). 
far simpler in structure than its ancestor may have been; either in certain parts of its body or wholly. ${ }^{1}$ We shall see this well illustrated in such plants as have acquired parasitic habits.

Much degeneration is to be seen also in aquatic plants ; for water has a very obviously degrading influence upon vegetative structures, as compared with those of allied plants growing on land; as will be more fully explained hereafter.

Similarly the structures of flowers, even when highly complicated, having adaptations in correlation with the visits of insects, are often coupled with degenerations in certain parts. This is very conspicuously so with orchids. Although these plants have remarkable and highly differentiated flowers, their seeds, the most important part of all, are in an extraordinary arrested condition, which renders them very difficult to germinate, not one out of thousands of seeds ever giving rise to a new plant.

Again, if flowers which have previously been adapted to insects, such as orchids, come to be self-fertilising and independent of insects' visits, all the elaborate machinery may become degraded, and the flowers reduced in size, the honey-secreting organs become honeyless, till even the flower-buds cease to expand; but in compensation fertility is greatly increased, and an abundance of seed is made; for the stamens and pistil remain perfectly $\in$ flective, the anthers being applied directly to the stigmas, the pollen often pours out its tubes into the latter while

1 The reader is referred to Prof. Ray Lankester's work on "Degeneration" (Nature Series). 
remaining within the anthers. Such fertile buds are called "cleistogamous," i.e. "concealed unions," and may readily be seen on the violet. If the leaves be uplifted in the summer, numerous buds in all stages will be found on runners proceeding from the root-stock. More will be said about these hereafter.

We thus discover the clue wherewith to explain the secret of the origin of the structures of flowers upon which classification is based.

Hence the groups called Divisions stand in the order of evolution, as from a buttercup with all parts freely inserted upon the thalamus (Thalamiflorce) to a strawberry with its parts free but inserted upon a receptacular tube (Calyciflorce). We then reach a coherent corolla (Corolliflorce), then finally degradation sets in, and we have the Incompletce.

It is to be observed that one step is omitted, namely, all flowers with "inferior" ovaries. These are to be found in a certain number of orders of both Calycifloree and Corollifloree, eight of the former and seven of the latter among British plants ; or out of all known plants, these numbers must be raised to eighteen of the former, and ten of the latter; i.e. comparatively few out of the 163 orders of Dicotyledonous flowering plants known.

Let us now have a few words on the classification of Monocotyledons. This class, as I shall endeavour to prove by collecting our evidence at different stages of our progress in the study of wild flowers, is derived from aquatic Dicotyledons. The "proof" lies in the great accumula- 
tion of coincidences, i.e. it is based on inductive evidence; for we cannot test it experimentally.

Now, Monocotyledons are readily divisible into two sub-classes. One has a calyx and a corolla, as in the Water Plantain, but it usually happens that these two whorls are both alike and "petaloid," i.e. "petal-like." Hence botanists substitute the word "perianth," as already observed, for the two whorls collectively, and speak of the outer and inner whorl (describing their parts as "leaves") as representing the calyx and corolla of Dicotyledons. All such constitute the subclass Petaloidez.

The other sub-class has no perianth, but the stamens and pistil are included in dry boat-shaped scales or "glumes"; 1 such constituting the chaff of threshed wheat. These make up the sub-class GLUMIFER E, i.e. glume-bearers. ${ }^{2}$ Of British plants, we only possess two families of this sub-class, viz., grasses (Graminece), and sedges (Cyperacece); but there are three foreign orders in addition.

Looking at the adjoining table of Classification the reader will observe that species, genera, and orders are omitted. It has been already insisted upon that any one of these three groups must be known by "a collection of constant characters," and not by one, two, or very few. For we should soon find ourselves in difficulties if we trusted to one, two, or few characters, however important, wherewith to recognise a group. Because, as

${ }^{1}$ From the Latin word gluma, chaff. Mr G. Allen has illustrated a sedge, fig. 13 , p. 79 ; and the wheat, fig. 30 , p. 145 ; both being glumiferous.

2 See "The Story of the Plants," fig. 13, p. 79. 
stated, it often happens that one or two out of the "collection" belongs to two or more species or genera, as the case may be.

Now, this explains the difference between what has been called the "natural" system and an "artificial" system of classification.

The latter depends upon one, two, or at most a very few characters alone, as will now be seen to be exemplified in the divisions of the subclasses. Hence, these must be regarded as purely "artificial" and "unscientific." They are only introduced for convenience to break up an enormous number of orders into groups, i.e. the socalled "divisions."

The classes, however, are based on a number of characters, five being here given in the table below; but there are others not mentioned, because they are taken from the minute microscopic anatomy of the interior tissues.

The general conclusion, therefore, is, that in the present system of classification, nature made the species, genera, orders, and classes; but botanists have, so to say, intercalated the divisions.

It will assist the reader to have the above classificatory terms arranged in a tabular form, as follows-

\section{Classimication of Phanerogams or Flowering Plants.}

CLASS I. DICOTYLEDONS.

[Chars. - Embryo, with two cotyledons; Axial root, present; Stem, with wood in annual cylinders; Leaves, with reticulated 
THE GERMINATION OF WILD FLOWERS. 41

venation; Floral whorls, in twos and fives, or their multiples.]

SUB-CLASS I. ANGIOSPERMAE.

DIVISION I. POLYPETALE.

SUB-DIVISION 1. Thalamiflorce.

$$
\text { " 2. Calyciflorce }\left\{\begin{array}{l}
\text { Hypogynæ } \\
\text { Epigynæ. }
\end{array}\right.
$$

DIVISION II. GAMOPETAL $\left\{\begin{array}{l}\text { Hypogynæ. } \\ \text { Epigynæ. }\end{array}\right.$

$"$ III. INCOMPLETE.

SUB-DIVIsion 1. Monochlamydece.

",

2. Achlamydece.

SUB-CLASS II. GYMNOSPERME.

CLASS II. MONOCOTYLEDONS.

[Chars.-Embryo, with one cotyledon; Axial root, arrested; Stem, with woody bundles scattered; Leaves, with parallel venation; Floral whorls in threes.]

DIVISION I. PETAloide $\left\{\begin{array}{l}\text { Hypogynæ. } \\ \text { Epigynæ. }\end{array}\right.$

" II. GLUMIFER E.

CHAPTER IV.

THE GERMINATION OF WILD FLOWERS.

THE natural history of wild flowers ought to begin at the beginning, so let us observe what takes place when seeds germinate. But, first, we must understand of what a seed consists, as they are by no means all alike. If we strip off 
the brown skin of an almond, after having soaked it in water, the white edible Embryo or young plant remains. This is easily separable into two halves united at one point. These are the first two leaves modified to store up reserve foodmaterials. Lying between them is a little bud or Plumule, and at the lower end of this is a tail-like body called the Radicle. The two leaves are called Cotyledons. A similar embryo fills the seed-skin in beans and peas. "Split peas" are so-called because the two cotyledons have been separated.

If, now, we examine a grain of wheat or of Indian corn, we shall find that the embryo only occupies a small space at one end, at the wrinkled spot in the wheat. All the rest is filled with a tissue of cells filled with starch or oil, and a nitrogenous substance called aleurone. In these cases, the embryo lives on these nutritious matters outside itself until it has roots, and leaves when it can assimilate mineral food.

In order to germinate there must be a fitting temperature, according to the nature of the seeds; they must be well moistened throughout, and have access to air ; for as long as they are perfectly dry they will not germinate. Wheat is particularly short-lived, from four to twelve years being the maximum period which may be allowed; but all stories of "Mummy wheat," extracted from the tombs of Egypt, and supposed to be some thousands of years old, having grown, are utterly false. As, however, this impossibility is still accepted as a positive fact by many persons, it may be advisable to give 
more fully some details about it, and at the same time explain the difference between "Mummy" and "Egyptian" wheats, for a popular error of confounding "Mummy wheat" with "Egyptian wheat" has lasted for at least half a century, and is not extinct yet! Perhaps, therefore, a brief resumé of the subject may not be uninteresting to my readers. In 1840, Mr M. Farquhar Tupper received twelve grains from Sir G. Wilkinson, who, it was said, took them with his own hands out of a vase in an Egyptian tomb. Of these twelve Mr Tupper asserted that he raised one plant, which bore two poor ears, one of which was figured in the Gardeners' Chronicle (1843, p. 787). Mr Tupper's account was reported in the Times (Sept. 1840). In the second and third years the wheat was described as having recovered its vigour, so that it bore ears seven and a half inches long, and was so like a good sample of Col. le Couteur's variety called "Bellevue Talavera," that even the experienced eye of that gentleman was unable to detect any difference. The eminent botanist, Dr Lindley, then editor of the Gardeners' Chronicle, in a leading article expressed his belief in the truth of the survival of the wheat after some 3000 years.

Suspicions, however, were raised; and a writer, signing himself "Este," suggested that there had probably been some tampering by the Arabs (Gardeners' Chronicle, p. 805).

In 1846, Sir W. Colebroke is said to have raised several plants from "two grains of mummy wheat, received in 1842 ;" but it is not stated whether they were of the original sample, 
or of the produce of those raised by Mr Tupper. After cultivating them, Sir W. Colebroke remarks- "I cannot resist the impression that this is a winter wheat; and if so, it cannot be a production of the soil of Egypt; for whence could the ancient Egyptians draw their supply of this grain?" In 1846 the late Professor J. S. Henslow received six grains from Mr Tupper, from the plant raised by him. He grew them with several other varieties of wheat in an experimental border in his garden; the following are his observations_-."This variety was specially remarkable for its exceeding length of straw and for flowering much earlier than any of the other varieties in my garden. In this and in all other particulars I could not observe the slightest difference between an ear of the Bellevue Talavera and that of the supposed mummy wheat. Both were also attacked more vigorously than others by rust and mildew." Suspecting some flaw in the testimony, application was made to Sir G. Wilkinson himself for a genuine sample, that it might be tried among a series of experiments on the vitality of seeds, which were at that time in progress under the superintendence of a committee of the British Association.

On receipt of the sample, great surprise was felt at the discovery of fragments of grains of maize (of American origin) intermixed with the grains of mummy wheat! This, of course, led to further inquiry; and the conclusion arrived at was that the sample had most certainly been vitiated by the wheat having been placed in the common corn jars of Cairo! 
THE GERMINATION OF WILD FLOWERS. 45

It may be added that whenever on other occasions the actual grains of true mummy wheat have been carefully sown, they have never germinated. Thus, M. Denon, who accompanied Buonaparte's expedition to Egypt, tried to raise them in many ways, but he never succeeded. A Dr Steele also utterly failed in 1857. In fact a microscopic examination proves that the embryo is always destroyed, a section crumbling to powder under the microscope, though the starch grains are not decomposed, and still colour violet as usual with iodine.

The popular confusion between "Mummy wheat" and "Egyptian wheat". is easily explained. There is a not very rare variety of "Revets' wheat," which is "proliferous," that is to say, it bears two or more additional smaller ears at the base, in consequence of the lower "spikelets" growing out and becoming supplementary ears. This is supposed to resemble the ears described in Genesis (xli. 5), and has consequently received the popular name of "Egyptian wheat." The reports of "Mummy wheat" from Egypt having been grown in this country has thus given rise to the idea that this variety of Revets' was actually raised from the old grains brought from the tombs of Egypt. But as Professor Henslow remarked, if Mr Tupper's experiments were trustworthy, the old Egyptian wheat must have been identical with the Bellevue Talavera, and not at all like our modern "Egyptian" or the proliferous variety of Revets'.

Finally, it may be noticed that wheat, in this country at least, is well known to agriculturalists 
to be particularly short lived. "An old farmer," writing to the Gardeners' Chronicle (1848, p. 787), remarks that, "We all know that the seed of the year is always preferred for sowing; that the seed of the year before would never be equally productive; and that if seed five or six years old were sown, not half of it would come up." And I can add, that of apparently sound grains seventeen years old, not one germinated.

Lastly, it may be added that Arabs impose upon tourists by taking fresh wheat, rolling it in Nile mud to give it the same mouse-colour which characterises mummy wheat, and then passing it off as such! So ends the story of Mummy wheat!

The materials stored up as food consist of starch, sugar, oil, cellulose, and aleurone ; but as long as they are such they are useless. They must be converted into substances in a soluble condition, and capable of being assimilated; starch and oil have to be changed into a particular form of soluble sugar, and the aleurones into "peptones," as they are called. Now, the way this is done is exactly like the process in our own bodies, for these substances stored up are the white "endosperm," as botanists call it, but everybody else "flour," when ground, have to form our own flesh and bones and nerves, etc. As starch, for example, passes through the mouth a ferment is secreted, which partly changes it into sugar ; and when I say starch, I mean such familiar things as sago, tapioca, corn-flour, arrowroot, etc., for these are all precisely the same thing, and have the same use to the plants from which they are extracted. 
Whatever the reserve food material may be, nature supplies a ferment to convert it into something which the embryo can take up and utilize to make fresh cell-walls and renew its living substance, protoplasm. Water and the oxygen of the air must enter the seed; then these, with a suitable temperature, incite the embryo to breathe and to bring about the chemical changes mentioned. Respiration is as necessary for plant-life as for human beings, and the effect is the same. It breaks up certain chemical compounds, as starch, causing the oxygen of the air to unite with the carbon, forming carbonic acid gas, which is expired ; but in so doing force is liberated which can now convert other things into assimilable substances for growth. A very simple experiment will illustrate this respiration. If some well-moistened peas be put into a closed wide-mouthed glass jar, and placed in a warm place in the dark; after some time, if sufficient carbonic acid gas has accumulated, a lighted taper quickly thrust in goes out; or if a little lime-water be poured in and well shaken, it acquires a milky appearance ; because the carbonic acid has united with the lime and made chalk-like carbonate of lime.

We will now follow the life-history of a germinating acorn. This, like a bean or almond, has no flour or endosperm, but the embryo lives upon itself at first, having two massive cotyledons full of starch, etc.

If an acorn be suspended over water in a widemouthed glass jar, the radicle will be seen to protrude, and will at once grow downwards. 
If the acorn be inverted, the radicle will curl over, and again grow downwards. As seeds do precisely the same thing at the antipodes, it is presumably under the influence of gravity or the attraction of the earth. It has been found by Darwin and others that the influence of gravity only directly affects the "growing point," immediately behind the dead and protecting root-cap. That is, for a distance of two to three hundredth parts of an inch. If after the radicle has grown to some length, the seed be placed horizontally, then the end will curve downwards, but the bend is at some distance behind the growing point. This proves that the influence at the growing spot near the tip is conveyed up the radicle to a more or less distant point.

If the 02 to 03 of an inch be removed, gravity then has no effect.

Besides the influence of gravity, the radicle will curve under that of pressure, vapour of water and light as well ; moving away from light and pressure; but towards moisture, as well as the earth.

While growing in a vertical and downward direction, the radicle "circumnutates," i.e. it moves round, making, or trying to make, ellipses or circles, resulting in a more or less zig-zag motion. This enables the tip to find a place of least resistance in entering the soil.

To penetrate the soil, the radicle must have some purchase or means of overcoming the resistance of the soil. Apart from being accidentally covered with earth, it at once begins to throw out root-hairs. These are simply epidermal cells 
which elongate, and by a sort of gluey matter fasten themselves to the particles of the soil. They thus are like tent ropes, and hold the radicle firmly while the apex grows. It is found that only a space of half-a-line grows at a time, all behind it soon ceases to elongate. The root now penetrates by means of the forces due to the longitudinal and transverse growths. Darwin tried some experiments to ascertain this strength. He cut a hole in a cleft stick, and allowed the radicle of a bean to grow through it. After six days the stick and bean were dug out of the damp sand, and the fissure, which at first was closed, now stood open. On removing the radicle the fissure closed, and it was found necessary to apply a weight of $8 \mathrm{lb}$. $8 \mathrm{ozs}$. to open it to the same extent as when the radicle was in it. This weight, however, does not express the really much greater amount of force used; because the bean had split the stick on the other side of the hole to a distance of half-an-inch. So that the force exerted must have been actually greater.

If a minute radicle can do this, it is not surprising to find roots of trees uplifting walls and bursting masonry asunder. Sir J. D. Hooker writes in his "Primer" on Botany that in shrubs and trees "the root-fibres as well as the tap-root thicken as they grow, become woody, and displace the earth laterally as well as in front; moreover, with such force does growth go on that stones of walls are frequently displaced by roots. In tropical countries the destruction of buildings is often caused by the power of growing roots; 
and neither conquering nations, nor earthquakes, nor fires, nor tempests, nor rain, nor all put together, have destroyed so many works of man as have the roots of plants which have all insidiously begun their work as tender fibres."

Darwin refers to Sachs' experiment on taproots, that while they descend vertically, secondary roots are much less affected by gravity, for they branch off at various angles from the main root; but if the end of the primary radicle be cut off, one or more of the nearest secnndary fibres now grows perpendicularly downwards instead of it. Darwin found that it was not necessary to amputate the tip ; it is sufficient that the flow of sap into it should be checked, and consequently directed into the adjoining secondary radicles. He observes that this change in the nature of the secondary radicles is clearly analogous to that which occurs with the shoots of trees, when the leading one is destroyed and is afterwards replaced by one or more of the lateral shoots; for these now grow upright instead of somewhat horizontally. Darwin also notices that this power must often be of great service to the plant, when the primary radicle has been destroyed by the larvæ of insects, burrowing animals or any other accident. He goes on to observe that from this manner of growth of the various kinds of rootfibres they are distributed, together with their absorbent hairs, throughout the surrounding soil, in the most advantag ous manner ; for the whole soil is thus closely searched.

The next point to notice is the extreme sensitiveness of the tips of roots to moisture. Sachs 
invented a simple experiment to illustrate it (Fig. 9). A trough is made of wire gauze filled with wet moss, in which are some beans. It is suspended not horizontally, but at a high angle. As long as the radicles were within the wet moss and moistened all round, they grew vertically downwards and their tips protruded from the meshes. Now, however, there was a contest between the attraction of the earth and the moisture of the moss on one side of the radicles, as the radicle made an acute angle with the sloping trough. The result was that the tip turned aside and re-entered the trough. But now finding itself again surrounded by a moist medium, the tip turned

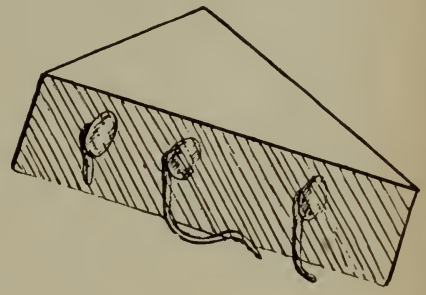
downwards and made its second exit. This process was repeated FIG. 9.-Diagram representing a wire giuze trough with germinating beans. two or three times; so that the radicle actually threaded the wire guaze.

It is a popular belief of gardeners that roots of trees, etc.; go in search of water; but the simple interpretation is that the vapour, arising from, it may be underground water at a considerable distance off, penetrates and reaches the tips of the roots, which now being influenced grow in the direction from which the moisture comes.

Radicles and roots are also sensitive to mechanical irritants, such as stones or other obstructions, which cause the tip to bend away from them. 
Darwin made some interesting experiments by fixing a small piece of card to one side of the tip of a radicle suspended in mid-air. Instead of continuing to grow downwards it curved away in an opposite direction to the side on which the card was fixed, as if trying to get away from it. The tip, thus, not only completed one circle but a second, and actually passed through the loop, thereby tying itself into a tight knot. ${ }^{1}$ A long radish was once dug up and found to be thus tied. It could not be accounted for until Darwin's experiment gave the most probable explanation. A remarkable difference appears to exist between the sensitiveness of the apex, and that at a point a little above it, viz., from $\cdot 12$ to $\cdot 16$ inch. For when this part was touched, the radicle turned towards the object, just as tendrils do. This accounts for the fact that certain plants which have aerial roots, as epiphytal orchids crawl round their means of support. In a subterranean root this curvature round an obstruction is somewhat abrupt, so that the root at once resumes its downward direction.

We must now observe what takes place with the plumule, which is destined to develop into the stem above ground. It would seem that the original determining cause was light; and as illumination is from the sky the plumules rise in response to it, ${ }^{2}$ and if the incident light comes from a lateral source, the shoot bends and grows

'See Darwin's "Movements of Plants," p. 179, fig. 69.

2 If the reader desire for the evidence in support of this conclusion, I must refer him to my "Origin of Plant Structures," ch. x. p. 197. 
THE GERMINATION OF WILD FLOWERS. 53

towards it, as in an ill-lighted room. Plants may, indeed, be induced to grow upside down. An experiment has been made by growing seeds on a perforated shelf near the bottom of an inverted box, only lighted from below by a mirror reflecting light upwards into the box. Under these conditions the plumules grew downwards.

There are two ways adopted by germinating seeds. In the case of the acorn the cotyledons remain below ground and the plumule rises at once and grows up, but in the mustard and cress, beech, etc., the cotyledons are elevated into the air by the lengthening upwards of the radicle, which now becomes a stem. The cotyledons then turn green and perform the functions of true leaves. The plumule remains dormant as a bud between them; and when it subsequently develops in mustard, we consider it too old to be edible.

Whether it be the plumule which first rises out of the ground or the radicle, they always commence in the form of an arch in preparation for freeing themselves from the superincumbent soil ; and the way they do this is well described by Darwin in the following illustration. $\mathrm{He}$ says - "We may suppose a man to be thrown down on his hands and knees, and at the same time to one side, by a load of hay falling on him. He would first endeavour to get his arched back upright, wriggling at the same time in all directions (i.e. in imitation of the circumnutating plumule during its growth) to free himself a little from the surrounding pressure; still wriggling 
he would then raise his arched back as high as he could; and this may represent the growth and continued circumnutation of the arched stem before it has reached the surface of the ground. As soon as the man felt himself at all free, he would raise the upper part of his body while still on his knees and still wriggling; and this may represent the bowing backwards of the basal leg of the arch, which in most cases aids in the withdrawal of the cotyledons from the buried and ruptured seed-coats, and the subsequent straightening of the whole stem-circumnutation still continuing." 1

We have thus traced the history of a wild flower through its first stage from the embryo in the seed to the period when it has developed roots in the soil and has elevated its plumule above ground, which we will suppose has now produced its first year's leaves.

We must now proceed to consider what the roots are about, to maintain the life of a plant.

\section{CHAPTER V.}

ROOTS OF WILD FLOWERS AND THEIR WAYS.

Roots assume a great variety of forms according to circumstances under which the plants grow, and to their requirements; and when we see how they change their forms under cultivation, we can understand how they were acquired in nature.

1 “The Movements of Plants," p. 106. 
ROOTS OF WILD FLOWERS AND THEIR WAYS. 55

Thus of our root-crops, radishes, turnips, parsnips, carrots, etc., the wild flowers from which they are derived have long, spindly or wiry and tough roots utterly unsuited for food. Tl.e ancients did not know much, if anything, of the art of "selecting," now practised by all horticulturists, by which our vegetables are "ennobled;" but they used to bring the wild plants from the fields and plant them in a rich soil; so that they became a little better in the second year; but they complained that they could not get rid of the "strong" flavour, as of the parsnip.

As I shall have an opportunity in the last chapter to speak more at length of the origin of garden "roots," I will not do so at present. The obvious advantage to us is that the tap-root becomes greatly enlarged under cultivation and supplies us with valuable root-crops.

Conversely, the effect of growing in water, is an arrest of the primary or tap-root; so that it may be feebly developed only, or even not at all. This can be well seen if the seeds of our Watercrowfoot be grown in a glass bowl of water with earth at the bottom. As soon as they have germinated, various conditions of arrest of the roots will be found on the little plantlets. This feature is elsewhere discussed, to show how the permanent condition of an arrest of the primary root is one of the numerous features of Monocotyledons, that lead us to the inference that this Class is descended from aquatic Dicotyledons.

Moisture, however, will often have an opposite effect, namely, it stimulates, not only the axial but secondary and other rootlets into vigorous 
growth. I have, for instance, a turnip plant, the primary root of which entered a field drain-pipe and spent all its energy in elongating, being stimulated to do so by the moisture, so that when extracted it was upwards of six feet in length. Sometimes such pipes get completely choked up with a dense mass of fine root-fibres of trees, etc., stimulated to multiply by the constant presence of moisture.

Other illustrations of greatly elongated taproots are seen in many plants of the deserts. These only grow along the wadys or watercourses, but they are dry for nine or ten months of the year. The annuals and others, too, send down very elongated slender roots to reach the deep-seated water. Thus Dr Aitchison observed in Beluchistan that several of the Astragali (the genus, the gum of which is called Tragacanth), have long whip-like roots, the bark of which is employed as twine by the people. In the desert, near Cairo, a plant of Monsonia nivea (allied to Geranium), of one year's growth may be seen between July and January to have a small rosette of three or four leaves, while the roots may be twenty inches in length. Again, the Colocynth has an enormous length of root, in order to maintain its existence. It stands singly, has large herbaceous leaves, without any means of preventing an excess of transpiration, as a cut shoot fades within five minutes, and yet it flourishes unshadowed through the whole summer.

The cause of the long tap-roots of so many desert plants is, of course, the responsive power of the apices to moisture, or hydrotropism. 
ROOTS OF WILD FLOWERS AND THEIR WAYS. 57

Another adaptation to the arid conditions of a desert is the capability of storing water in all parts of plants. In some cases this is done by the roots, as in the cortical regions of grasses. In three species of the Stork's-bill there are tuberous enlargements on the roots, which are water and not starch-bearing structures. Similar structures occur on the lowest internodes of the culms, or shoots of grasses, in other countries. It is interesting to note that they only occur in dry seasons, and not at all in wet ones. When experiments were made in growing Poa bulbosa in moist soil, it almost lost its bulbous character, clearly proving, therefore, that these productions are the direct result of drought.

These tuberous swellings on the subterranean stems are, therefore, clearly analogous with those on the roots of Stork's-bill, some being potato-like tubercles, others finger-shaped or spindle-like. They all contain a storage tissue protected externally by a strong many-layered cortical coating. Their position being between the absorbing rootapices and the foliar transpiring surfaces, they act as reservoirs, and regulate the supply of water.

Other reservoirs in the leaves and stems will be described in speaking of tropical and other plants in the next volume.

Many plants have what are called contractile roots. These have for their function to draw the plant into the soil. They are especially well seen in tubers and corms, etc. For the depth at which these thrive best is characteristic of its kind, and so the tubers, etc., have to be taken down to the proper level underground. 
The shortening of the contractile root, by means of which the process is effected, is seen in the transverse wrinkling on the surface, say, of a carrot. It begins on the oldest and uppermost part of the root after elongation has ceased, and follows the growth to the apex. It may be readily observed in garden roots of parsnip,

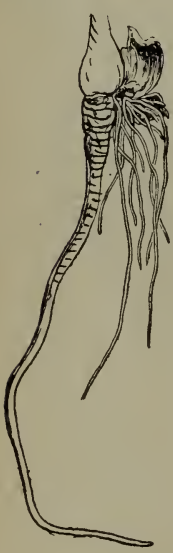
etc. It is due to a change in the forms of the cells of the surfacetissues. They undergo a contraction in a longitudinal direction, accompanied with radial extension. There is a simultaneous absorption of water. The root though now shorter increases in bulk.

The amount of shortening may vary from 5 to 40 per cent., the result being that the whole plant is more or less pulled down into the ground.

If the corm of a crocus be examined they will be seen to have two sorts, fine, absorbing roots, and Fig. 11. - Fine, thicker contractile ones (Fig. 11). absorbing, and thick, contractile root of Crocus. in the tips of bramble stems, which arching over a hedge, ultimately reach the ground. They then strike root, and the roots pull the tip of the shoot well into the soil.

It is not all plants that bear contractile roots, for they are wanting in the colchicum; but this is compensated for, as we shall see presently.

If a seed of the Lords and Ladies be sown at the surface, it develops a little globular tuber at 
ROOTS OF WILD FLOWERS AND THEIR WAYS. 59

a depth of about one inch. Next year this is carried down by contractile roots to a depth of two inches. When full-grown, the tuber, in the third year, will be at a level of four inches below the surface.

If it be now raised and placed just under the soil, new contractile roots are formed, which at once begin to set to work to try to lower the tuber to its proper depth.

In the case of the crocus, the new corms will be found growing from the summit of the old one, which decays after sending up the flower. Each cormlet produces a large contractile root which sometimes penetrates the old corm. By its means the young corm is ultimately dragged down to the level of the old and now flattened and decayed parent corm.

The colchicum, however, as stated, has no contractile roots. These are compensated for by a curious provision of the stem. The depth to which the corms attain in the colchicum is somewhat considerable, after it has been growing for several years. The downward growth is effected in the following manner. The new corm always rises laterally at the base of the old nne; but when a corm has not yet reached its nornal level of about 6 inches; as, e.g. after germination, or if a full-grown corm be planted too high in the soil, the portion of the corm, which, of course, is stem-structure, from which the new corm develops, does not project horizontally, but points downwards, so that the new corm is formed slightly below the level of the old one. This procedure is continued year 
after year, till the corm finds itself at its proper subterranean level. In this plant, therefore, roots have nothing to do with the descending series of corms (Fig. 12).

Besides contractile roots on tubers, etc., many other cases occur in which this phenomenon may be observed, as, for example, on the runners of strawberries; these root at the joints where the young plants are formed, and the roots will draw
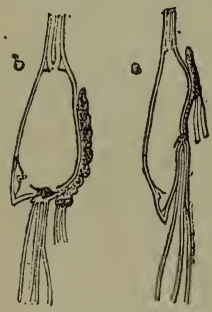

FIG. 12.-Corm of Colchicum. $a$. with descending bud; $b$. with lateral bud (after Oliver). the little tuft-like plants halfan-inch below the soil.

Rock plants, again, as primulas, etc., with their roots in crevices, are thus drawn into them; for, if it were not so, as the stem increases annually in length, producing a fresh tuft of leaves every year, in ten years there would be at least four inches of stem projecting; but the last year's growth occupies the same place as the first, because freshly-formed contractile roots continually pull the year's portion of stem into the same place occupied by the former, as this decays away.

The elevation of roots and stems of trees out of the ground may often be noticed. It is caused by the continual increase in size of the woody roots. The tap-root of the seedling tree soon ceases to grow, for all the moisture as a rule comes from above. Strong secondary roots run under the surface of the soil, radiating in all directions; as may be seen when a tree has 
ROOTS OF WILD FLOWERS AND THEIR WAYS. 61

been torn up by the roots in a gale, and blown down.

These roots increase annually in an exogenous manner, layer after layer just as the stem does. This growth exerts a lateral pressure on the soil above, thrusting it upwards; while the compressed soil below the root prevents its sinking, and acts as a means of resistance in raising the superficial soil.

The thick woody root ultimately becomes visible as the soil gets loosened and washed away by the rain, till it is entirely stripped of the earth from above.

Now, as all the roots grow alike, the stem of the tree becomes raised, and thus is explained the peculiar appearance of many old pines, oaks, ashes, etc.

The elevation of the trees called "Mangroves" in the tropical swamps at the mouths, etc., of rivers, has often been noticed by travellers. They are not, however, supported by secondary roots arising from the primary or tap-root; but by means of "adventitious roots" issuing out of the base of the stem, just as occurs in all monocotyledons, though the mangroves are dicotyledonous trees. As these roots lengthen and thicken, the young trees are raised above the mud, and then look as if supported on stilts.

It may be noted that the mangroves are trees of two very distinct families of no affinities whatever. One kind of the true mangroves, ${ }^{1}$ as they might be called, belong to the Division Calycifloræ. The others to the Verbena family, belonging to the

${ }^{1}$ Rhizophorca. 
Gamopetalæ. In both, the characteristic feature of the arrest of the primary root takes place, as in other aquatic plants. Then, there are the screwpines, which are true monocotyledons, and supported in a precisely similar manner. Hence is the justifiable inference, that growing under the sime conditions similar results have followed in the structure and habit of those trees.

Another, but exceptional, function of roots is the propagative. They do not, as a rule, produce leafy buds; but there are

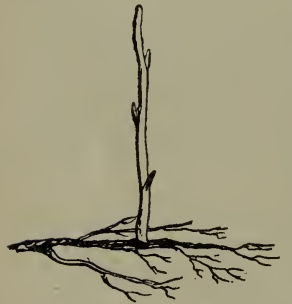

FIG. 13. - Shoot arising from horizontal root of Raspberry. many exceptions. A rather general one is, that when roots of trees are exposed to the air and light, they often do so; and as it frequently happens that elm-trees have been planted in a hedge, as the earth from the bank gets washed away their horizontal roots become exposed. Then a whole crop of elm-underwood springs up, and, in fact, not infrequently it makes a complete elm-hedge. Plum trees and their allies, as apricots and peaches, are very prone to be exceedingly troublesome in sending up quantities of shoots from their roots. While the raspberry will spread to a considerable distance, not by suckers, which are shoots from underground stems, but by budding from the slender roots (Fig. 13.)

Of course, such shoots really represent Nature's method of vegetative propagation, because any shoot can grow into a new herb or tree as the case may be. 
THE LEAVES OF WILD FLOWERS.

Gardeners take advantage of the facilities offered by peaches to propagate them by means of their roots. They take off spare roots, and placing them on a gentle bottom heat, they will start into leafy growth, and then begin to form new roots, thus together laying the foundation of a new plant.

In speaking of roots, we must not forget a use to which Nature puts them, viz., as instruments for climbing. The ivy is the most familiar example with us. These roots naturally arise on the shaded sille of the stem, i.e., towards the wall or tree against which the ivy may be growing. When the roots reach the wall, the contact excites the superficial cells-as also it does with the aerial roots of epiphytal orchids-to secrete a gummy matter which fixes them very firmly, so that they cannot be removed as a rule, at least when young, without tearing them to pieces.

Foreign plants have far more elaborate methods of utilising roots growing in the air; some of which I shall consider in the second volume of "The Story of Wild Flowers," which will be more especially concerned with plants of foreign countries.

\section{CHAPTER VI.}

THE LEAVES OF WILD FLOWERS, AND THEIR MODIFICATIONS.

Like flowers, the forms of leaves seem to be infinitely diverse; but they too, are reducible to a simple arrangement, based upon their evolutionary history. Indeed, we can see, even now, 
how many can change considerably, when the environment is altered, both in external form and internal anatomy. Thus, one of the most powerful agents in effecting changes is the amount of light received by leaves, coupled with their positions in regard to it.

A leaf usually consists of two parts, the leafstalk or petiole and the blade or lamina.

Many leaves have also appendages situated at the insertion of the petiole, called stipules. These are either entirely free from it as in the lime, in which they form bud-scales and soon fall off in spring-time; or they may form wing-like appendages to the petiole, as on the leaf-stalks of the rose, strawberry and clover. What is called the skeleton of the leaf, when all else has decayed, is the woody framework upon which the green tissues are spread out to receive the light. It is a network constructed of what has been foolishly called "ribs," "veins," and "nerves," according to their size, the leaf being said to have a reticulated "venation" if it belong to a Dicotyledon, and a parallel, at most a "curvinerved" venation, if it be a Monocotyledon, allowing for exceptional cases.

The fibro-vascular-bundles ${ }^{1}$ of which the skeleton is composed are derived from the cylinder of wood in the stem. This is really, at least in most cases, composed of isolated cords, but close together, with only a single layer of cells called the medullary rays, between them. One, three, five or more of these cords, pass outwards through the cortex or outermost tissue of the stem and enter

${ }^{1}$ For shortness I will call these "cords." 
the leaf-stalk. They then run up it, parallel to one another till they reach the blade, in which they either form the mid-rib, which gives off lateral branches, i.e. "pinnately-nerved," or diverge, to form a "palmately-nerved" blade; the finer branchlets "anastomose" i.e. unite together, leaving ultimately very small interstitial places. It thus forms a stiff framework, in order to make the large surface for exposure to light. They also carry the fluids up and down which are concerned in the processes of "transpiration" and "assimilation."

The reader will find it an interesting subject to pursue, to notice how the mechanical difficulties of supporting heavy leaves are overcome. In many, the lower end of the petiole widens into a triangular broad and thickened base of attachment called the "pulvinus." The leaf usually articulates at the bottom of the pulvinus when it is time to fall, as may be seen in the Horse-chestnut. As the whole weight of the blarle and petiole has to be supported at this point, the strain is, of course, entirely felt there, and the longer the petiole and the greater the biade, the stronger must be the base of the petiole so that the leverage may overcome the weight due to gravity. If a young growing leaf be found capable of breaking with a certain additional weight suspended from the petiole, and a slightly less weight be attached to a petiole of a similar size, i.e. just insufficient to snap it off; after some days, it will be discovered that this petiole will be able to bear a much greater strain than if it had not been subjected to an artificial weight at 
all. In other words, just as an athlete's muscles increase by use, so do plants respond by making efforts to meet strains of all sorts put upon them. This effort is seen in the increase of the so-called mechanical tissues, such as woody-fibre, liberfibre, hardened cellular tissue called "sclerenchyma," and "collenchyma," etc. But, besides this, the arrangement of the cords is strictly adapted to gain this end. When the leaf is very large, the base of attachment increases and gradually, so to say, spreads and clasps the stem more or less all round it as a sheath. In some plants the two ends of the horse-shoe-like base almost meet. In others they do so entirely and so make a complete sheath. The former is common in "Umbellifers," the latter is usual in palms. Moreover the sheath is, in palms, provided with additional means of strength in having a double set of fibres interlacing one another diagonally. They thus form a powerful aid to the enormous petiole which often has to carry at its end a gigantic blade.

The petiole will be often observed to be grooved on the upper side, as in large leaves of umbellifers, the ash, etc., a section giving a horse-shoe shape or that of a $U$ thickened at the bottom. Now, the use of these upper edges is precisely the same as flanges to a girder, they resist a transverse fracture; for a round, horizontal rod will be found easier to break with a weight than one provided with these flanges. It will be remembered that Fox's umbrella-stays are made on this principle.

The usual distribution of cords in a petiole is 
to have the two "lateral" ones taking a rather higher position in a grooved petiole than the central and larger one, below. The reader will now see the significance of this arrangement, the flanges being extra growths over these cords. The interpretation of this arrangement is to acquire strength so as to resist the tendency of the petiole to break under the weight of the leaf itself.

Some petioles are quite round like a stem. When this is the case the cords are arranged in a complete circle, i.e. precisely as in a stem, nature having found that arrangement to be the best under the circumstances. This occurs in the Sycamore Maple.

As a readily observableinstance of change, it FIG. 14.-Climbing flower-stalk of may be noticed that when a petiole of a Clematis,

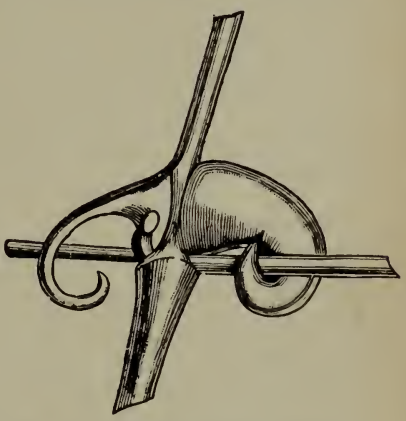
Uncaria, thickened after catching a support. etc. (Fig. 14), has caught hold of a neighbouring shoot, it coils round it and then begins to thicken and strengthen itself, as it has now to bear a portion of the weight of the plant. To do this the space between the isolated cords is filled up by others until a complete cy linder of wood is made.

The general law, therefore, is that in proportion as the weight of a leaf increases, so does the mechanical machinery develop itself to meet the strain, and even more tissue than is actually required for safety; and nature can always 
adopt various contrivances to meet individual cases.

Now, let us consider the origin of the various kinds of leaf-blades among wild flowers.

The simplest form of leaf has a single cord running up the middle of the blade, called the "mid-rib," with an uninterrupted or "entire" margin. An ivy leaf arising from the free shoot from the top of a wall or high up a tree-trunk will illustrate this ; but not only may the margin be "toothed" or "serrated" like the leaflets of a rose-leaf, but it may be deeply indented so to become "lobed," as is the ivy leaf of the stem when adherent to a wall, etc., by means of adhesive roots.

The indentation producing the projecting lobes may be of various depths in different leaves, till the mid-rib is reached. ${ }^{1}$ But as long as the parts are united at all at their bases along the mid-rib, the blade still remains "simple." If, however, they are completely separated, then the leaf is called "compound," and the separate parts are now called leaflets. Such is very characteristic of the Pea-family ; thus clover and melilot have three leaflets, and are called "trifoliate," hence the name "trefoil " is a synonym for clover. The garden acacia has two rows of leaflets, and is then said to be "pinnate."

That all compound leaves have been evolved from simple ones is obvious from the existence of numerous transitional conditions to be found in many plants. Thus a good search on blackberry bushes will reveal simple leaves situated near the

1 All sorts of degrees may be seen in oak-leaves. 
flowers, then leaves with three leaflets and also with five may be found; as well as leaves in which the lower pair are lobed, foreshadowing the separation of the basal portions into distinct leaflets. In the common cinque-foil all states from a single, simple blade to three, five, and even seven, leaflets can readily be found.

If the leaflets radiate from the top of the leafstalk as in the last-mentioned, or as in a Lupin or Horse-chestnut, the origin is precisely the same, only instead of the original simple leaf having a strong mid-rib, several of equal strength radiate from the top of the petiole at the base of the blade. Then each of these supply mid-ribs to as many leaflets, when it forms a compound "palmate "leaf. Such is due to an arrested condition of the mid-rib, supplemented, however, by several ribs instead, as in a geranium leaf.

Compound leaves, therefore, of both types are referable to simple leaves of corresponding forms.

A good illustration of the origin of the primary lobing process may be seen in a long, vigorous, annual shoot of the common snowberry of our shrubberies. At first, when vigour is only in its initial stage, the shoot bears small oval and entire leaves. When it arrives at its maximum degree of strength the leaves are large and lobed. But at the end of growth the leaves are once more small, oval and entire.

This shows that lobing is correlated with the most vigorous condition, when the struggle between vigour in developing the stem, and "assimilation" to supply material for development of the leaves as well, are not equal. The result 
being that the entire outline of the leaf, i.e. by joining all the apices of the lobes, cannot be fully completed.

Now, everything, as it has been said, tends to become hereditary. Whatever was the primary cause of "lobing," it has become a "fixed" character in all plants in which it is at present a characteristic feature.

We cannot always trace the hidden causes of outward forms, but we may reasonably speculate. Thus, the difference between the large mostly five-lobed leaves of the ivy when climbing and the small oval leaves on freely growing branches of the same, seem to be correlated with the energy displayed in making the stems. In those stems which are supported by adhesive roots, more pith and less wood is found than in those which have to support themselves in the air, in which the woody cylinder is relatively thicker in stems of the same diameter as in the former condition. It would seem, therefore, that as materials are required to strengthen the stem, leaf-producing energy is lessened, and it only produces the more primitive type of foliage.

Let us now trace the causes of some other types of foliage. It is readily seen that when leaves can place their blades horizontally, so as to be well illuminated from above, they have a more or less considerable amount of breadth.

When they stand erect from the habit of living crowded, as of grasses and sedges, pinks and carnations, thrift, stitchwort, and many others, the leaves are more or less of a narrow or "linear" form, as has been already observed; and experi- 
THE LEAVES OF WILD FLOWERS.

ments show that plants can be more or less actually induced to make variations in the breadth of their leaves, according as they are made to grow more or less illuminated. Hence we obtain a clue to, at least, a general cause to account for differences in breadth. This also explains the ribbon-like form of leaf of so many submerged leaves, especially of Monocotyledons, as water cuts off a very considerable amount of light, especially laterally, the chief and only source, of course, being from above; so the leaves, or rather "phyllodes," i.e. flattened petioles, continue to grow upwards till they reach the surface of the water; and it is not till then Frg. 15.-Potamogeton heterophyllus. that a horizontal and broad blade is made, as of a Pond-weed, which possesses linear leaves below the surface, and broad elliptical blades floating upon it (Fig. 15.)

It is not in the outward form only that the difference is observable, but it lies in the anatomical structure as well. As a rule, e.g. the breathing pores or stomata are mainly or entirely on the underside of aërial and horizontal blades. In a vertically growing blade, however, they are 
equally distributed on both sides, while the adjacent cells of the epidermis may take on the same characteristic shapes in plants of widely different families, as of thrift, a Dicotyledon, and a grass, a Monocotyledon.

All the details, which I need not further specify now, show how readily structures will change, as soon as external conditions are altered. The changes, be it observed, are always for the benefit of the plant, by putting them in better adaptation with their environment.

\section{CHAPTER VII.}

STIPULES OF WILD FLOWERS AND THEIR USES.

Many families, as those of the Rose and Pea, as well as of the lime, Elm and Oak, are regularly provided with stipules, as the two appendages at the base of the leaves are called. They assume a great variety of forms, and may all be regarded as basal portions of the leaf itself. For just as the usual lowermost pair of leaflets of any pinnate leaf are provided with a petiole and mid-rib, the woody cords of which issue from the main petiole of the leaf ; so, too, the fibro-vascular cords which enter the stipules always arise from the lateral cords which enter the petiole of the leaf. Since, however, they issue out of the stem itself, before the petiole is entirely external to the stem, the twn stipules often appear to have nothing to do with the leaf, other than always taking their rise close to the base of it, one on either side. 
STIPULES OF WILD FLOWERS AND THEIR USES. 73

Still there are so many cases in which the stipules form a sort of wing to the petiole itself, as in the rose, that the origin, in such cases, seems to be clearly appendicular to the petiole, and issuing out of it.

The stem of a Dicotyledon has, of course, a cylinder of wood composed of numerous distinct cords only separated by single layers of cells, called the medullary rays. One, three, or more of these enter the petiole of the leaf. They do not pass from the cylinder in contiguity; but while the central cord goes directly into the petiole, a pair issue at a little distance from it; and, it may be, another still further off, till, in some cases, a whole series pass into it. When that is the case, the petiole is seen to widen out at the base, and make a sheath, more or less grasping the stem.

Now, when there are stipules, the cords which enter them invariably branch off from the lateral cords which belong to the petiole of the leaf, and never issue directly out of the cylinder of the stem itself.

This is easily observable in some soft-wooded stem, as of a geranium. If it be cut across at a node, and a few thin sections be made through the base of the stipule and below it, and then held up to the light, the origin of the stipular cords can be traced without much difficulty.

If there be two, i.e. opposite leaves at a node, then a horizontal cord runs completely round the stem, external to the cylinder joining the outermost cords of the petiole. This is called the stipular zone, because the stipular cords-usually 
four in number, as there are two stipules to each leaf-issue out of it.

This zone is easily seen in the common cleavers ; for if a thin section be made just above and below the whorl of so-called leaves, and held up to the light, it will be readily seen that true stem-cords only enter two of them (Fig. 16.) One of these can usually be recognised as a true

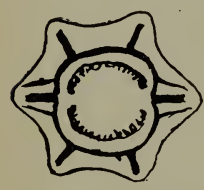

Fig. 16. - Transverse section of node of Galium, showing three lateral cords for each leaf; and four for four stipules arising from the stipular zone. The in. ternal semicircles form the stem:cylinder of cords.

leaf by the bud in its axil; the other true leaf will be situated exactly opposite to it. All the rest, though assuming the exact form, and, of course, the functions as well, of leaves, have their cords, which make the mid-ribs, issuing from the zone, and never from the stem-cylinder itself. Hence all but two of the "leaves" are really stipules.

Having thus made the stipular zone to supply stipules with cords, Nature sometimes takes advantage of it, and increases the number of stipules. Thus while the dwarf species found commonly in heaths has the right number of two to each leaf, the Lady's Bedstraw or Yellow Galium has from eight to twelve in a whorl.

The family to which the galiums belong contains the coffee and cinchona trees. These have only two stipules; but our four genera, the woodruff, madder, blue sherardia, and galium, have at least four, so that, as they are all leaf-like, they look like a radiating leafy star. Hence botanists make a tribe of them, which they call Stellatee. 
Botanists place the Valerian family as immediately following the Madder family. Now this never has stipules, yet if the stem of the Red Valerian (which grows abundantly on walls and rocks, and is in fact quite naturalised, though really being an escape from cultivation) be examined as explained with the cleavers, a stipular zone will be found, and four or five short cords radiating from it, but they do not reach the surface, and there are no stipules at all. This means that the plant's ancestors had stipules, but they have disappeared and nothing but rudimentary cords which formerly entered them are retained. Other rudiments are common in plants, and are always interesting as pointing to former structures which are now no longer of use. Analogous cases occur in the animal kingdom; thus serpents, the slow-worm-which is really a kind of lizard and not a snake at alland, again, whales have rudiments of hind legs beneath the skin but not visible externally; showing that all those animals have been descended from quadrupeds. Having, however, become adapted to a different method of progression, either one pair, of both pairs of limbs have atrophied and all but disappeared.

In some of the pea family the stipules are large and leaf-like, or foliaceous, as it is said, as of the garden pea. The two stipules are when young pressed together in a vertical direction, forming a sheath for protecting the bud between them. Subsequently they acquire all leaf functions in compensation for the loss of some of the leaflets which are turned into tendrils 
for climbing purposes. In our Yellow Vetchling, ${ }^{1}$ the whole of the leaf has become a fine threadlike tendril; so the large triangular-shaped stipules have to do the entire work of the leaves.

Stipules are also foliaceous in the pansy and hawthorn tree.

In the oak, beech, lime, elm, etc., the stipules acquire a totally different function, for they are employed as bud-scales. Being formed in the autumn for protecting the delicate parts of the next year's shoots; so as soon as the buds expand in spring, the brown stipular scales fall off.

In many cases-perhaps it may be regarded as their chief function-stipules protect the bud in the axil of the leaf. In severat species of plants in the deserts they are almost rudimentary, being like a thin white, membranous, nearly dry scale; and as the internodes are very short, they seem to clothe the whole plant with silvery scales. They shield the plant's buds from the intense heat and glare by reflecting them. We have allied plants in England called the SandwortSpurreys. In these stipules the converse to the Valerian has taken place; because although the stipule has remained in a very degraded form, it has no mid-rib at all. The same remark is applicable to the rudimentary stipules of the common Dog's Mercury.

In some trees and shrubs, the stipules have assumed a spinescent form, and often of a very formidable character; so that when they are ${ }^{1}$ Lathyrus Aphaca. 
used as hedges they are very effective as protections. There are two species of Acacia used for this purpose in S. Africa, the Kaffir bush and the "Wait-a-bit" thorn bush (Fig. 16.)

One of the most curious uses to which these stipular thorns have been put, is by ants as a domicile. $\mathrm{Mr}$ Belt, in his work "The Naturalist in Nicaragua," thus writes:- "There is a species of Acacia with bi-pinnate leaves, growing to a height of fifteen to twenty feet. The branches and trunk are covered with strong curved spines, set in pairs, from which it receives the name of the bull's-horn thorn, they having a very strong resemblance to the horns of that quadruped. These Fı. 17.-Acacia with spinescent stipules. thorns are hollow, and are tenanted by ants, that make a small hole for their entrance and exit near one end of the thorn, and also burrow through the partition that separates the two horns; so that the one entrance serves for 
both. Here they rear their young, and in the wet season every one of the thorns is tenanted; and hundreds of ants are to be seen running about, especially over the young leaves. If one of these be touched, or a branch shaken, the little ants swarm out from the hollow thorns and attack the aggressor with jaws and sting. They sting severely, raising a little white lump that does not disappear in less than twenty-four hours.

"These ants form a most efficient standing army for the plant, which prevents not only the mammalia from browsing on the leaves, but delivers it from the attacks of a much more dangerous enemy-the leaf-cutting ants. For these services the ants are not only securely housed by the plant, but are provided with a bountiful supply of food; and to secure their attendance at the right time and place, this food is so arranged and distributed as to effect that object with wonderful perfection. The leaves are bipinnate. At the base of each pair of leaflets, in the mid-rib, is a crater-formed gland, which, when the leaves are young, secrets a honey-like liquid. Of this the ants are very fond; and they are constantly running about from one gland to another to sip the honey as it is secreted. But this is not all ; there is a still more wonderful provision of more solid food. At the end of each of the small divisions or leaflets there is, when the leaf first unfolds, a little yellow fruitlike body united by a point at its base to the end of the pinnule. Examined through a micro scope, this little appendage looks like a golden 
pear. When the leaf first unfolds, the little pears are not quite ripe, and the ants are continually employed going from one to another, examining them. When an ant finds one sufficiently advanced, it bites the small point of attachment; then, bending down the fruit-like body, it breaks it off and bears it away in triumph to the nest. All the fruit-like bodies do not ripen at once, but successively, so that the ants are kept about the young leaf for some time after it unfolds. Thus the young leaf is always guarded by the ants, and no caterpillar or larger

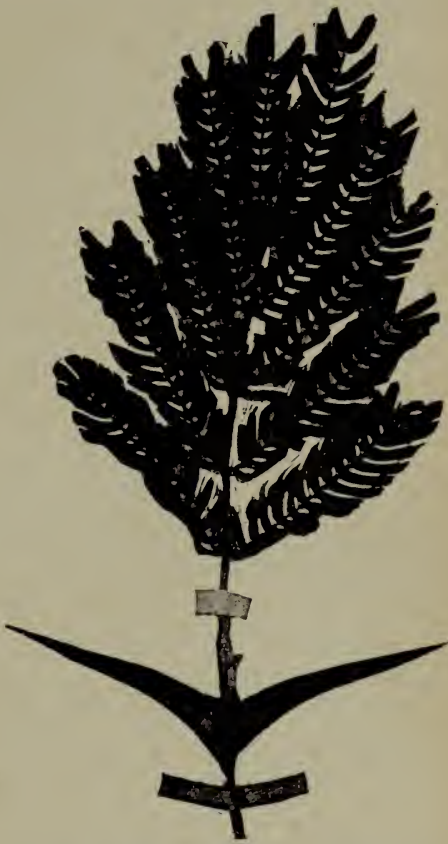

FIG. 18.-Acacia cornigera. (Photo. of leaf $\frac{1}{2}$ nat. size.) The honey-gland is situated just above the horn-like stipules. The fruit-like bodies appear as terminal points to the leaflets. animal could attempt to injure them without being attacked by the little warriors. The fruitlike bodies are about one-twelfth of an inch long, and are about one-third of the size of the ant, so 
that the ant bearing one away is as heavily laden as a man bearing a large branch of plantains" (Fig. 18).

Stipules, as well as petioles, may be nectariferous, as for example is the case with our common tares which secrete honey in sunny weather from glands on the stipules.

The "Crown of Thorns" was probably made of the flexible shoots of a plant common in the east, known to botanists as Paliurus, and allied to our buckthorns. The "thorns" are stipules. In another species the stipular thorns are all curved downwards like those of brambles, and for the same purpose, that of scrambling over the hedges, etc.

The tendrils of the bryony have been regarded as stipules, since they issue from the stem close to a leaf ; but the origin is a little anomalous. If a section be made, it will be found that the cords do not form a perfect cylinder, but are somewhat scattered, as occurs in the leaf-stalk of the rhubarb, and in all Monocotyledonous stems. In these, transverse cords are formed at the nodes uniting them together, and forming a sort of network from which cords enter the leaf, and also the tendril in the case of the bryony ; so that it may be really called "stipular," though its origin is a little anomalous.

I have alluded to the rhubarb, and the stipules of this plant, as of all its allies of the same family, viz., that containing the docks, knotgrass, \&c., are united so as to form a complete sheath round the stem. This encloses the petiole, and so, as it were, binds it to the main stem, and gives it 
great support. This support in the case of palms is secured in a similar way, only it is in these the sheathing base of the petiole itself, which completely wraps round the trunk of the tree.

It may be noticed how remarkably weak the leaf-stalk of the rhubarb is, in that a slight pressure causes it to snap in two. This is due to the fact that the cords are not arranged as in most leaves, but scattered throughout the petiole, just as in all Monocotyledonous stems. There is no union between them to impart strength. A walking-stick made of coconut wood, or other palm, though much stronger, often breaks with comparative ease, for the same reason; as the wood consists of isolated cords penetrating pith, which last, though harder than in the soft tissue of a leaf-stalk of the rhubarb, is in reality the same thing, and therefore of a treacherous material for a staff.

\section{CHAPTER VIII.}

VEGETATIVE MULTIPLICATION OF WILD FLOWERS.

BESIDES the propagation of plants by seeds, the various methods adopted by the vegetative system of plants for multiplication is very curious. I propose to discuss some of them in this chapter. Buds, in the form of bulbils or cormlets, are sometimes formed, and readily detached from the aërial parts of plants. Thus in the so-called bulbiferous lily and coral-wort, little bulbs are produced in the axils of the leaves, and fall off 
as the stem is swayed by the wind, and so get scattered to some distance.

Species of polygonum and onion produce bulbils instead of flowers, and these can be easily separated in a similar way.

In every case there must be a sufficiency of nutritive matter stored up for the little plant to live upon until it has made roots and leaves of itself. It is sometimes in the form of a corm or solid axis. This is the case with the viviparous polygonum and the lesser celandine, when growing in shady places, where it produces no flowers. After falling off these little buds, rest during the winter and at the next period of growth, send out little roots at the expense of the starch, etc. stored up, when green leaves soon follow, and it develops into a new plant.

Similarly viviparous grasses, as they are called, are very common in Arctic and Alpine regions The sprouting leaf-buds of these, issuing from the place of florets in the panicle, may be thrown off, or the weight may be sufficient to bring the whole inflorescence down to the ground, when they strike root and become independent plants.

Rock-plants of the genus of house-leeks furnish another peculiar method of multiplication. The plant consists of a rosette of thick fleshy leaves. New small rosettes are formed in the axils, from these thread-like runners grow to some distance, and terminate with another little ball-like rosette. When the runner decays the little plant is freed from the parent, and the wind rolls it along the slopes of the rocks, when it may fall over to another resting-place, and as soon as it finds a 
suitable spot, roots are formed, and it becomes fixed in the soil of the crevice.

There is a rare British stone-crop, which, besides bearing viviparous buds in place of flowers, propagates by aid of its leaves. It has three ways, or rather three stages of development, each of which can give rise to an independent plant. Minute buds arise in the axils of the uppermost leaves of the stem, which become embedded in the base of the fleshy leaf. In
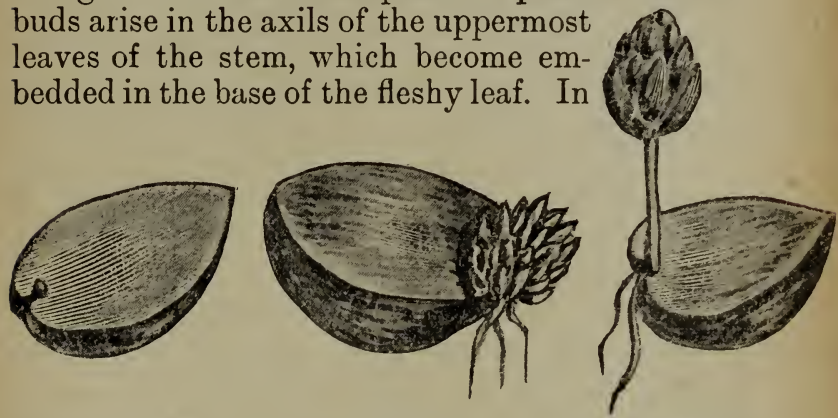

Fig. 19.-Sedum dasyphyllum. Leaves with buds detached from the plant for natural propagation ( $\times 4$ times, after Kerner).

lower leaves the bud has grown to a tiny rosette, while in the lowest it develops a footstalk.

On the withering of the stem, the leaves fall off carrying the buds with them, and being nearly hemispherical in shape they roll away. When come to rest the buds strike root, while the fleshy leaf to which they adhere, supplies the little plant with water and nourishing material until it has its own roots in the soil (Fig. 19).

Subterranean bulbs give rise to numerous bulbils, which are in time separated from the parent bulbs, and so form new plants. These are particularly common in Monocotyledons, but com- 
paratively rare in Dicotyledons. A British species of saxifrage, called Saxifraga granulata, from the numerous little bulbils it produces at the base of the stem, propagates itself by means of them. A double-flowered form of this plant is in cultivation. Species of South African woodsorrels, or Oxalis, multiply in this way. A few bulbs of O. cernua, so called from the tall umbel of drooping yellow flowers, were sent to Malta in 1806 . It never bears seeds, but since that date it has spread not only over Malta and Gozo, but through the traffic in orange plants and by other goods, it has established itself from Egypt to Morocco, and from Gibraltar to the Greek Islands ; being found in the Riviera, Naples, etc.

Many water-plants propagate themselves in various ways by their vegetative systems. Thus, the duckweeds, which cover ponds, etc., in summer, form little expansions or a "thallus," as botanists call it ; for there is no distinction between stem and leaf. These in autumn become detached, and having their cells full of starch grains, they sink to the bottom, and there rest. When warm weather arrives the plants begin to grow. The starch grains are used up and air fills the cells, so the plant rises to the surface and floats.

A similar change takes place in the frog-bit (Fig. 20). Its long roots hang down in the water but do not reach the bottom. It throws out numerous runners on the surface, which bear little plants, like a strawberry plant. The surface of the water is soon covered with them, sometimes as many as twenty offsprings are strung together by the horizontal runner. 
Though the frog-bit bears flowers, these seldom seed. Autumn buds are subsequently produced on shorter stems. These buds remain wrapped up in close fitting scale-leaves. As soon as it has laid up a sufficient amount of starch, etc., the bud becomes detached and sinks to the bottom; when the floating plants all die.

These winter resting buds rise to the surface on the approach of spring, just as the duckweed does on becoming filled with air.

In the bladderwort, a rather different procedure takes place. The leaves are always submerged, and, as is so often the case with dicotyledonous aquatic plants, finely dis-

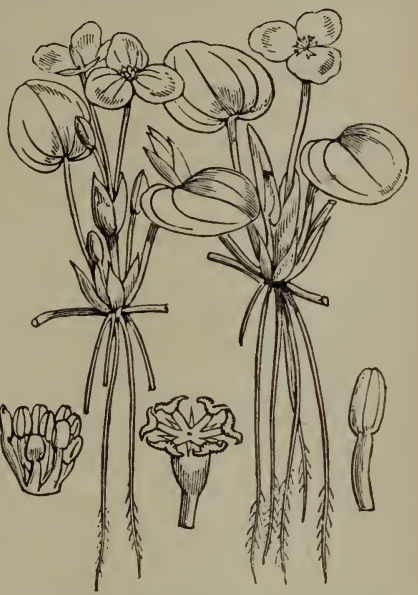

FIG. 20.-Frog-bit. Floating male and female plants, with dependent roots and horizontal runners (cut off short). A male flower on left, and a single stamen on right; female flower in middle.

sected. The stem develops special buds for winter use, consisting of the abbreviated axes or ends of the shoots, with the leaves so crowded and fulded together that they form a little compact green ball. This then sinks to the bottom to rise again in the following summer. This method of making a new plant out of the ends of the branches explains why this plant has no roots. 
The pond weeds differ in that the buds detached in autumn sink to the bottom, but then strike root in the mud ; so that they grow up into wellrooted plants which can produce a stem long enough to reach the surface of the water. They also extend themselves by means of stolons, which creep along the bottom.

Besides complete buds consisting of axis and budscales, single leaves can multiply plants. Many habitually do so. Thus there is a fleshy leaved plant of warm eastern countries, off which the leaves fall before decay, and if it be damp soil, roots soon appear at all the indentations on the margin. Then follow leaves and a complete new plant, so that a single leaf may be surrounded by a ring of plantlets.

Several kinds of ferns habitually produce little plants on their surface or at the tips of the fronds.

Gardeners take advantage of this property and so propagate plants, such as begonias and gloxinias, which readily lend themselves to this method of multiplication.

There is one species of fern which grows on the bark of trees, the long tips of which avoid light and creep along the surface till they find a fissure in the bark, in which they become fixed. Every tip thus situated at once develops a bud at the point of contact. This bud gives rise to fronds, one of which develops vigorously and in turn searches for a new suitable crevice in which to insert itself: and so the process is repeated indefinitely.

Some British plants have acquired this habit 
of developing buds on the leaves, as the lady's smock, and the little bog-orchis, the watercress, celandine, cabbages, etc.

Buds can also be formed on the scale-leaves of bulbs. This is the usual method of propagating hyacinths in Holland. The base of the bulb is scooped out or the bulb is slashed crosswise ; it is then stimulated by heat, and little bulbils soon appear along the cut edges of the scales. When large enough they are detached and grown. More than a hundred bulbils have thus been taken from a single bulb.

These methods of multiplication by the vegetative system are often in compensation for the want of propagation by seeds; or it would be more correct to say that flowers surrender their function of reproduction to the vegetative system when this has been perpetually resorted to. It often happens.that this occurs not only in the wild state, but also under cultivation. Thus the lesser celandine, which habitually multiplies itself by means of its root-tubers underground, as well as by axillary corms, rarely sets seed. In fact, the pollen is not formed, but remains in an arrested condition. We have seen how Oxalis cernua has propagated itself all round the Mediterranean; and is never known to set seed there. Similarly the frog-bit, which multiplies extensively by runners, also fails in this respect.

The horse-radish which spreads largely underground, often blossoms, but no seed is ever made. The saffron crocus, formerly extensively cultivated, as at Saffron Walden in Essex, and possibly on Saffron Hill in London, failed 
to seed, being always multiplied by fresh corms.

The production of bulbs and corms at the expense of flowers, as in lilies and onions, crocus and horse-radish, is of course compensatory for the loss of the reproduction by the legitimate means of the flowers. But some interesting experiments with potatoes show that the power to produce them is a general one pervading the whole plant. For when potato-tubers are never allowed to be formed, being removed as soon as they begin to appear, then the "tuber-bearing energy," if we may so call this habitual tendency, finds vent above ground in developing tubers instead of elongated branches in the axils of the leaves. Of course an ordinary tuber is only an arrested subterranean branch, and swollen in diameter to store up reserve food-material for next season's growth.

There yet remains another method, by means of which some plants can be multiplied, viz., by swollen internodes of the branches, when they have stored up sufficient food-stuffs. They then become disarticulated and fall to the ground, readily striking root, and so giving rise to new plants. There is, e.g., a fleshy stemmed groundsell called Kleinia, of hot countries, and a vine which multiplies itself in this way. 


\section{CHAPTER IX.}

VEGETATIVE SPORTS IN WILD FLOWERS.

Changes in structure are sometimes comparatively slow and slight when plants adapt themselves to new environments, at others marked adaptations occur at once. They then resemble "sports," which appear suddenly, with no traceable cause; as can be seen, if a shoot of the water-crowfoot is crowded out of the water; when all the tissues in the air are at once adapted for living in it; while all below the surface are very different, but equally fitted for living submerged.

We shall hereafter see how freaks occur in flowers, but they also are to be found among the vegetative organs of plants.

Thus among branches there is the so-called "fastigiate" form, as of the erect-growing Lombardy poplar, the Irish yew, the common cypress, etc., in which, instead of being spread out horizontally, which is the normal or typical condition of their branches, these all run up vertically. When this is the case, a different disposition of the leaves sometimes occurs. Thus, in the common yew, though the leaves are "inserted" on an imaginary spiral line, which can be drawn through their "points of insertion" successively round the stem, the leaves are all twisted at the base so as to make them lie in one and a horizontal plane.

In the Irish yew (all plants of which have 
been derived from one plant still growing in Ireland), as well as on the short vertical shoots of the common yew, the leaves are not twisted, so that they bristle all round the shoot.

In the common laurel, however, the leaves on the horizontally growing branches are actually inserted in two parallel ranks on opposite sides; but on a vertically growing shoot, which may issue from the top of the bush, the leaves are in five vertical ranks.

Another sport among branches consists in their "weeping." It is not usually hereditary, but can be propagated by cuttings. Thus, all the weeping ashes in the kingdom are said to have been derived from one tree, but the seedlings show no tendency to weep. The weeping willow, if growing away from water, often ceases to bear pendulous branches. The deodar cedar, a native of the Himalayas, does not bear drooping ends to its branches, but resembles the cedar of Lebanon in its native home. This habit of the former species has been acquired in the climate of England.

With regard to leaves, one of the commonest forms of sports is the so-called cut-leaved type of foliage. Several trees have sported in this way, the branch being removed and struck can establish the sport. This type has been thus perpetuated in the beech, birch, maple, elder, blackberry, and many others.

A curious result happened in grafting a sport of the cut-leaved beech upon a tree of the ordinary kind, in that all the shoots which subsequently appeared above the graft on the 
VEGETATIVE SPORTS IN WILD FLOWERS. 91

same side of the tree were affected by it, and bore this "laciniated" form of leaf (Fig. 21).

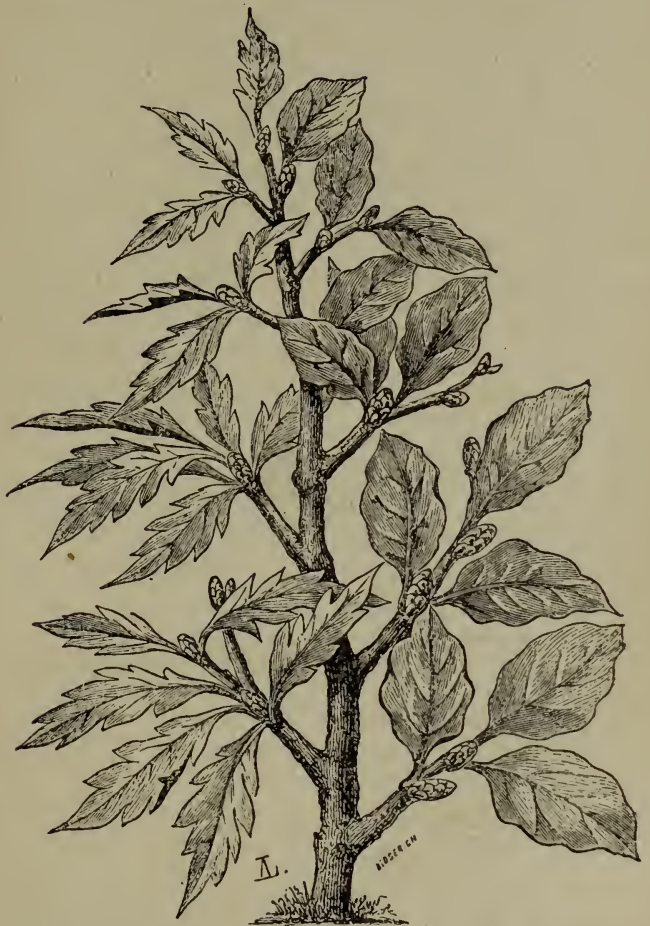

Fig. 2:.-Beech. Lowest branch on left, the original graft. All subsequent branctes on left bore cutleaved foliage (after Carriére).

A cut-leaved tree will not infrequently revert and bear a branch with the ordinary form of leaf. 
Thus two sorts of leaves are sometimes borne normally by a plant. E.g., the musk-mallow has both almost completely formed leaves, and much divided ones as well. There is a cultivated variety of this plant with white flowers, on which the leaves are much more deeply dissected. This comes true from seed.

Under cultivation other changes may be hereditary. Thus, savoy cabbages and other plants, through excessive nutriment, develop too much tissue between the ribs or veins of the leaf, so that it will not lie flat but bulges upwards. On the other hand, the "dissections" of parsley have become so fine that it looks more like fennel.

Reversions sometimes give the appearance of sports. Thus, acacias of Australia are usually devoid of the compound blade at the end of the flat phyllode. But now and then they suddenly reproduce them, giving a quite different appearance to the tree.

Veronica cupressoides, a small Alpine plant of New Zealand, so-called because its minute, adpressed leaves resemble those of a cypress, under cultivation produces dissected leaves, which were undoubtedly an ancestral form (Fig. 22). A juniper will often bear two kinds of leaves, one like the cypress, another long and sharp-pointed. The latter is the ancestral form, and appears as the younger on a bush.

Another cause of sporting is the dissociation of hybrid characters. Thus, when a Barberry was crossed with the genus Mahonia, the oval leaves, with a toothed margin of the former, 
VEGETATIVE SPORTS IN WILD FLOWERS. 93

appeared on the same shoot, with the spiny, holly-like leaves of the latter.

A similar dissociation often occurs in flowers. Thus, a chrysanthemum not infrequently has

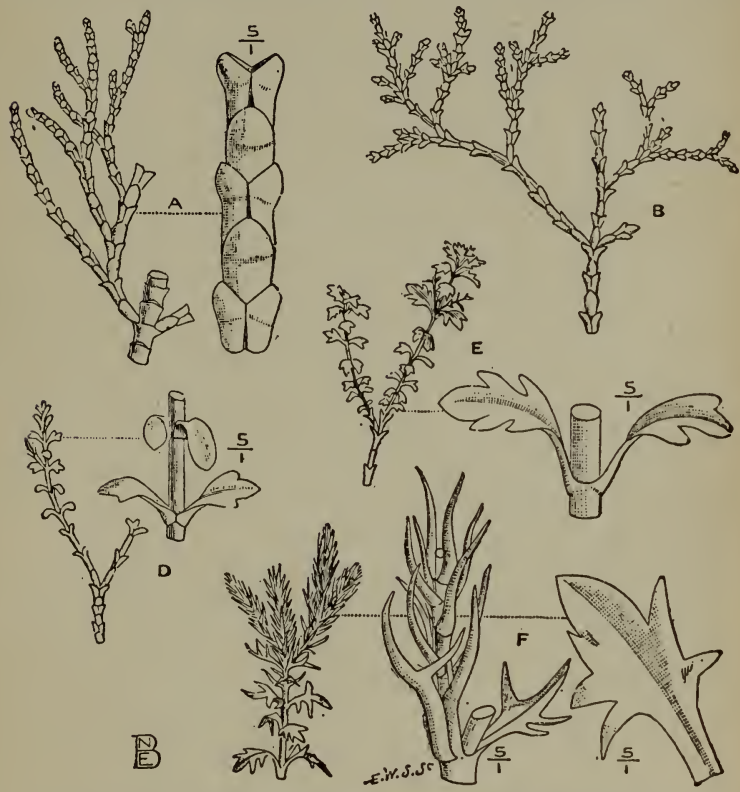

Fig. 22.-Veronica cupressoides, illustrating different forms of foliage on the same plant (fr. Gard. Chron.).

the flowers sharply divided into two colours. Petunias are frequently striped white and purple. This is because the two parents of all our garden petunias bore purple and white flowers respectively. 
Lastly, in fruits sports and dissociations occur. Thus the peach is a sport from the almond, and a nectary from the peach. A fruit of these two may be shared between them, one-half or other portion being of one kind, the rest of the other. And if the seeds be sown of either, it cannot be foretold what kind of fruit the tree will subsequently bear.

This power of sporting, which is only a sudden and striking condition of variation, leads us to consider how one organ can not only change its form, but put on all the appearance, and assume the functions as well, of another. We may call this power of adaptation the "mutual accommodation among plant organs"; it also illustrates the meaning of the words "homology" and "analogy," which have been applied to plants.

I will now give some account of this, and summarise instances in illustration of this curious practice among wild flowers.

First, let us remember that plants are entirely composed of cells. These contain the so-called living matter or protoplasm, and though it is thus apparently isolated in each cell from its neighbours yet protoplasmic threads keep up a communication through the cell walls, which themselves also probably contain it; so that a plant is not quite built up of entirely independent cells, as was once supposed to be the case ; but is one whole living thing, of which any part can, however, be separated and become an independent organism. Hence as this is true of those plants which are regarded as the highest of the vegetable kingdom, this as a whole stands no higher in the 
VEGETATIVE SPORTS IN WILD FLOWERS. 95

scale of life than, or is on a par with, corals and sponges in the animal kingdom.

Besides this general power of a fragment reproducing the whole, as a necessary consequence almost any part or "organ" can, if required, take on the functions of some other organ, with or without undergoing much alteration of structure. This is what I have called " mutual accommodation" among plant organs.

All plant organs may be classified under the terms axes and appendages; the former bring stem and root structures; the latter, leaf structures, being appendages to stem structures.

HOMOLOGY asserts, first, that root and stemaxes are fundamentally the same; and secondly, that all leaf-appendages are fundamentally the same thing. So that organs may be homologous though their forms and functions may be very diverse.

ANALOGY is applied to organs of normally different natures, which, however, perform the same functions. Thus regarding a leaf as an appendage, it can become a tendril in the pea; whereas the tendril of the vine is an axis, being homologous with a flowering stalk.

I will now collect together some cases of interchange of functions between roots and stems. As a rule roots being subterranean do not bear leaf-buds; i.e. a means of propagating the plant; but the raspberry, as we have seen, produces them in abundance. That stems can produce roots is familiar to everyone. Hence gardeners can propagate by cuttings, etc. Roots miy be produced from the branches of trees, descend to 
the earth, and then act as supernumerary trunks, as in the banyan or Indian fig. One form of root is to be tuberous in order to store nutriment as in the peony and dahlia; tubers also appear on subterranean stems, as the potato. Stems often acquire the power of climbing as the hop, by twisting round some support. A species of Dissochceta utilises its aërial roots in the form of tendrils; while the ivy has both subterranean and aërial roots, the latter being adapted for climbing only.

Stems can imitate leaves, the use of the latter being to assimilate the carbonic acid gas absorbed from the atmosphere. Thus many plants have some of their branches flattened out imitating the blade of a leaf, as in the butcher's broom and other species of that genus. Some have no leaves at all, the stem being flattened, thick and fleshy, the green tissue of which is the sole assimilative structure of the plant as of the prickly-pear.

Stipules which are basilar adjuncts to a leaf and really belong to it, assume various forms and functions. They may be leaf-like as in the pea; spinescent as in acacias; as a tendril in Smilax; or as bud-scales in the lime, elm, oak, etc.

Regarding a leaf as the type of all appendages, we may recognise the following modifications of the two parts-stalk or petiole, and the blade or lamina.

The leafstalk or petiole may assume any of the following characters:- It may be foliaceous and therefore assimilative as in the phyllodes of acacias; it may be spinescent as in Astragalus; it may be sheathing and thereby mechanically 
VEGETATIVE SPORTS IN WILD FLOWERS. 97

strengthening the petiole, while protecting the bud in the axil. It may become a climbing structure and sensitive to touch as of a Clematis, or a store-house of nutriment as the scales of bulbs of lilies, etc.

The blade may be altered, as seen in the tendrils of the pea; in the insectivorous structures of pitcher plants; in the development of buds for propagative purposes, as in the lady's smock, etc.

Bracts form a transition from vegetative organs to the reproductive, being assimilated to leaves when they are green and to the flowers when they are coloured or "petaloid" in character.

The homology of bracts is various. They may be stipular as in Magnolias, more generally are they petiolar as in Hellebore, which affords a completely graduated series from the true pedate leaf to an oval acute bract, by the gradual suppression of the segments, and a dilatation coupled with a shortening of the petiole.

In buttercups and geraniums, bracts are homologous with the blade, the petiole being suppressed.

Petaloid bracts may be grouped conveniently under three heads. (1) Assisting in the colorisation of the inflorescence. (2) A number of bracts may together mimic a flower, the true floral perianth being insignificant. Lastly (3) bracts may pass by insensible graduation into the true floral whorls, there being no break between true bracts and true petals. Euphorbias are good examples of the first; Darwinia, Cornus, ${ }^{1}$ and "Ever-

${ }^{1}$ See Index for illustrations. 
lastings" well illustrate the second class; while Cactuses are types of the third.

Inflorescences consist of the flower stalks or Peduncle, with smaller branches carrying the flowers, called the Pedicels. These may undergo changes of form and assume other functions than carrying flowers. Thus they may become climbing organs, as the tendrils of the vine, passion flower, and virginia creeper; they may become "hook-climbers" as in Uncaria (Fig. 14), in which the peduncle curls round after flowering. They may be reservoirs of nutriment to nourish the fruit and seeds. Such are the thick receptacles of some composites, as of the artichoke, the pseudocarp of the strawberry, apple, etc.

All the above mentioned instances and many more might be given would have been called sports, "imitative sports," perhaps, had they occurred suddenly. But since they are now constant features in the plants possessing them, they cannot be classified as such, though possibly originating in the same way.

\section{CHAPTER X.}

THE MOVEMENTS OF THE ORGANS OF WILD FLOWERS.

THE old distinction between plants and animals, that the latter can move and the former cannot, has long since been abandoned as untrue to nature; but that all plants, even when perman- 
ently fixed to the soil, have their stems, leaves, flower-stalks, etc., in almost perpetual motion, is a discovery of recent times, and notably due to the investigations of Darwin.

The majority of the movements can be embraced under the single term circumnutation, and its modifications ; it signifies "bowing around." The stem or other organ bends to all points of the compass successively with a sort of rolling action, so that the side which is uppermost in any direction becomes the lowermost when it points in the opposite one. The circles or ellipses thus described by the apex of the moving organ are most perfectly seen in the stems of climbers; other organs for the most part move more irregularly; consequently when they are represented by diagrams they show most complicated figures. Darwin illustrated a great many of these "projections." 1

We have already had occasion to discuss the peculiar movements of radicles and plumules of germinating seeds; and we saw how Darwin proved that the former will turn away from mechanical obstructions which irritate the tip by pressure. He also discovered that stolons and runners, which consist of much elongated flexible branches, which run along the surface of the ground and form roots at the joints, are similarly able to pass over obstacles by circumnutation, and so manage to wind about between the stems of surrounding plants. Erect stems continually circumnutate. In the case of climbers

${ }^{1}$ See his work entitled "The Power of Movement in Plants." 
or stem-twiners, to be described in the next chapter, the circumnutation is most perfect, so that if any erect object stands within the circle the twiner on touching it must necessarily twine up it; as can be readily seen by using a piece of string fixed below, and imitating the

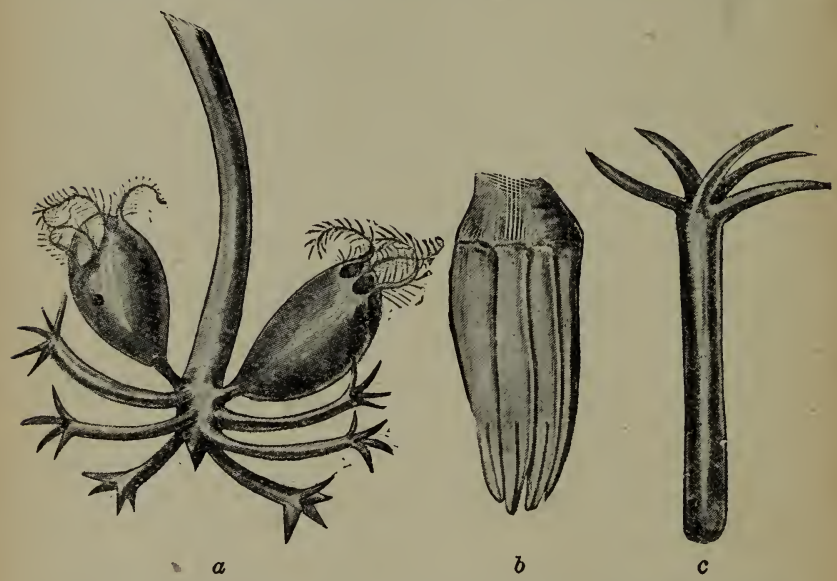

FIG. 23.-Subterranean clover; $\alpha$. flowerhead after liaving been buried and ripened its seeds (one in each pod); $b$. abortive flowers, closely adpressed, before penetrating the soil; $c$. abortive flower with clawlike sepals spread out for raising the soil.

bowing stem by moving the upper end in a circular manner. Flower stems form no exception to axial structures circumnutating; but the effect is curiously modified by gravity in the case of the "subterranean clover," and by turning away from light in the cyclamen. In both plants the object in view is to bury the unripe pods beneath the soil. 
The flower-buds of the first-named (Fig. 23) produce but two or few perfect flowers at the base of the head, all the others consisting only of cylindrical calyces with stiff spreading lobes, forming claw-like projections. As soon as the perfect flowers wither, they bend back upon the peduncles. While these are thus moving the whole peduncle curves downwards and increases in length, even from 6 to 9 inches if necessary, until the flower-head reaches the ground. At this period the younger, imperfect central flowers are still pressed closely together $(b)$, and form a rather rigid conical projection. It then buries itself to a depth of $\cdot 25$ inch. After the heads are buried, the central aborted flowers increase considerably in length and rigidity. They gradually curve, one after another, upwards or towards the peduncle. In thus moving, the long claws on their summits carry with them some earth; hence a flower-head which has been buried for a sufficient time forms a rather large ball, the aborted flowers, having caught up the earth with the claw-like sepal-lobes $(c)$, act somewhat like the claws of a mole, which force the earth backwards and the body forwards.

The calyces of the perfect flowers are provided with hairs, which, on absorbing carbonate of ammonia presented to them, exhibited all the evidences of being thereby nourished; hence this seems to be Nature's use for the hairs; as Darwin found that only those pods which bury themselves, produce a full complement of seeds.

Movements in flowers may be slow or rapid; an illustration of the latter may be seen in the 
petals of the genista, a pea-like blossom which, when an insect alights on the front petals in which are concealed the stamens and pistil, the
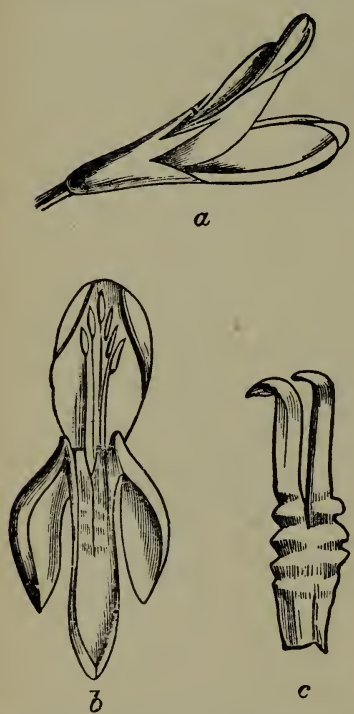

FIG. 24.-Genista. $a$. flower expanded, side view; $b$. front view after "explosion"; $c$. "claws" of keel petals showing curvature at the base and contraction higher up where the petals cohere, causing them to drop.

while the staminal tube curves upwards with great force (c, side view, petals removed) and cannot be replaced without fracture.

In several flowers of different species the filaments retire slowly after the anthers have shed 
the pollen, or fallen off, when the pistil comes forward, and occupies the same position. This may be noticed in the lemon-scented or oakleaved pelargoniums, and in our wild wood-sage and bugloss.

Enough has now been said to show how extensive and varied are the movements effected by the different organs of plants, and the advantages accruing to them by possessing such powers of motion.

In the preceding cases the movements are more or less perceptible after the organ has been fully constructed. But growth under external influences gives very similar results. Thus Fig. 25.-Lucerne (for description roots, as we have seen
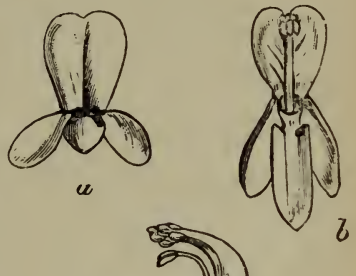
in the case of radicles of germinating sfeds, are very sensitive to moisture, which explains many curious instances of root growth.

Roots of trees have been found growing to great distances to reach water, even diving under a hard road to a ditch on the opposite side.

The attraction of warmth has a peculiar influence on stems and leaves.

If the temperature of the ground be higher than that of the air above it, shoots will grow flat upon the ground and become creeping stems. This accounts for so many high Alpine plants being prostrate, and never tall and erect. The 
creeping willows, so common there, illustrate this fact.

Similarly leaves of blue-bells in early spring, as well as of plantains and daisies on lawns, lie flat on the ground, but they grow erect among long grass by road sides.

It may be noticed how even usually tall plants, like the common mallow, which grows erect when in the midst of other plants, if the seed happens to fall by the roadside, will give rise to a prostrate plant.

Plants grow upwards under the influence of light, and if the source of illumination be lateral, they grow and bend in the direction of it.

Roots, on the other hand, grow away from light, or towards the darker side. This may easily be seen, as stated elsewhere, in the climbing roots of ivy, etc. But other organs may do so, if necessary, thus the tendrils of the Virginia creeper being adapted to climb a rough wall, turn towards it, being, of course, away from the illu minated side.

The sleeping movements of leaves take place when they are quite full-grown, but when buds expand in spring, the leaves grow in various directions to secure the same end as in sleep; namely, the avoidance of injury by radiation of heat, as long as they are young and unformed. Subsequently they assume a permanent horizontal position when mature.

If leaves grow in pairs they stand erect and face one another, having their upper surfaces in contact. This may be seen in veronicas, St John's Wort, and periwinkle. 
THE MOVEMENTS OF THE ORGANS. 105

If leaves be alternate, as of the Portugal lanrel, they may be erect, but now each leaf is folded like a sheet of notepaper or "conduplicate" (i.e. "folded together ") (Fig. 26). If it be pendulous a more complicated process may take place. In the case of the lime, as soon as the bud expands and escapes from the winter (stipular) scales, the inner stipules develop

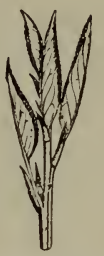
considerably; those on the upper side Fig. 26.-Portuare concave and ovoid, and cover the gal laurel; upturned edges of the leaves, which duplicate in at once take a position in a vertical bud.

plane; the stipules at the sides elongate much more than the former, furnishing some lateral protection to the whole bud, which now curves rapidly downwards. As the bud continues to de-

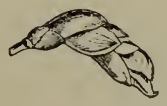

$\alpha$

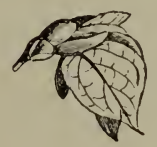

$b$

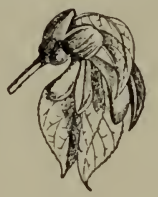

c

FIG. 27.-Lime; buds unfolding.

velop, the branch becomes more and more strongly curved downwards, so that the leaves are held vertically; but as the lower and older ones increase in size, they assume a horizontal position, and undertake to protect the younger ones which are concealed beneath them. Thus the protecting care is handed on to each leaf as it arrives at maturity, until the whole series are developed, 
and the branch and leaves become horizontal (Fig. 27, $a, b, c$ ).

Compound leaves behave in a similar manner. Thus in a rose or laburnum leaf the leaflets are at first both pendulous and conduplicate, as well as tightly pressed together ; they then expand in order from below upwards. In the

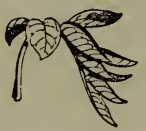
walnut (Fig. 28), the petiole curves strongly downwards at a very early stage, thus placing the pairs of conFIG. 28.- duplicate leaflets in a vertical plane. Walnut. As they increase in size the basal pair is the first to become spread out, then the others in succession as the petiole rises into a horizontal position. In the ash leaf, which somewhat resembles the walnut, the petiole curves upwards instead of downwards, but the leaflets are in a vertical plane all the same.

The horse-chesnut has a "digitate" leaf of several radiating leaflets (Fig. 29). As soon as it issues from a bud all the leaflets curve downwards, exactly in the same manner in which some lupins go to sleep. . They subsequently rise up and become horizontal. The Virginia creeper when growing close to a wall develops the leaflets like a

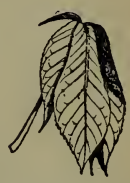
vertical star, as other species of lupin Fig. 29.-Horsewhen asleep; but if it grow over a chesnut leaf. trellis, it not only climbs like a vine with its tendrils (no longer in adaptation to a wall with adhesive disks), but its young leaflets all drop vertically as in the horse-chesnut, resembling a shuttlecock. 
A clover leaf has its petiole at first arched, with the three conduplicate leaflets closely adpressed together, so that they hang vertically. This arrangement is exactly the same in the wood-sorrel when very young (Fig. $30, a$ ); but in these plants the position of the leaflets in sleep is very different.

I have spoken of the movements undergone during the grow th of leaves in spring, in order to avoid the chance of injury from frost and radiation; but this is Frg. 30.-Woodalso effected in many plants by

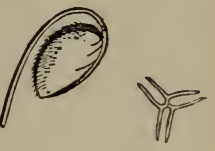
the process of sleep, as it is called, of leaves when full grown. It is particularly well seen in the compound leaves of the Leguminous or Pea family; though it is by no means confined to it. Darwin has written an elaborate treatise on the suhject of Nyctitropism, i.e. the "nightturning" of leaves in sleep, to which the reader is referred should he desire to study the peculiarities of the process in detail. ${ }^{1}$

I propose giving a few instances of plants which are easily observed. If a clover plant or one of the common medicks be observed on any fine day, all the leaves will be seen having their three leaflets spread out horizontally. At sundown, it will be noticed that they are closely packed together. In order to acquire this position the two basal leaflets rotate on their short stalks till they stand in a vertical plane. They then swing round till their upper surfaces come into contact. Lastly, the terminal leaflet rotates 1 "The Movements of Plants." 
upwards, passes through an entire semicircle, and comes down like a sloping roof over the upper edges of the lower pair of leaflets (Fig. 31,b). This position, it will be noticed, is a very different one from that in which the conduplicate

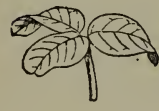

$a$

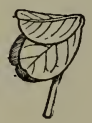

$b$

FIG. 31.-Clover. leaflets were all pressed together in the earliest condition, like that of the wood-sorrel (Fig. 30, a).

The object is to protect the upper surfaces, which in the clover are entirely concealed, as well as to place the surfaces of the leaflets in a vertical position, if possible.

The trifoliate leaf of the wood-sorrel resembles that of a clover, but it prepares itself for sleep in a different manner; for the three leaflets drop down and slightly fold the two halves, so that the mid-ribs touch the petiole. The upper surfaces are not protected at all, but now stand in a vertical position (Fig. $30 \mathrm{~b}$, trans. sect.).

The melilot agrees with the clover in having three leaflets, but it sleeps in yet another way. The three leaflets twist through an angle of $90^{\circ}$, so that they all stand vertically at night. The two basal leaflets then move towards the terminal one. This, in turn, bends towards one side, and invariably to the side towards which its upper surface lies, until it presses against its neighbour on that side.

The seat of the movements resides in the swollen base of the petiole called the "pulvinus." This retains its tissue in an elementary condition, and 
so remains pliable and not rigid, as it would be if the woody tissue were fully developed.

Lupins have " digitate" leaves, being composed of several radiating leaflets, like those of the horse-chesnut. After having been spread out horizontally by day, they go to sleep in at least three different ways in as many species. In one the leaflets all drop vertically down like a shuttlecock, the leaves partly covering one another (Fig. 32). In

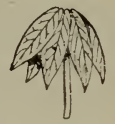
another they are reversed, like a shuttle- Frg. 32.cock standing on the cork head. In a Lnpin. third, while the lower leaflets fall down the upper become erect, so the whole leaf stands like a vertical star, all the leaflets being in the same plane.

There are many kinds of leguminous plants which have pinnate leaves of two rows of leaflets. In some they all drop down, and each pair has the leaflets pressed together; in others they are all elevated; the same result, of course, is gained either way. In the logwood tree, the leaflets, while placing themselves vertically, lie with their mid-ribs parallel to the main petiole. Yet another plan is adopted in Cassias which also has pinnate leaves. It is the little leaflets of certain species which is senna. In this, the petiole rises up and stands at an acute angle with the stem. Thus by the leaf dropping vertically, all its leaflets more or less overlap one another, the terminal being the larger envelope the lower ones, the whole forming a sort of bunch.

Darwin records an interesting fact about the sleeping of the common garden nasturtium. This 
has peltate leaves, and usually makes them stand as nearly as possible at right angles to incident light. At night the circular blade is placed vertically; but, if any leaves have not been well illuminated by day they do not sleep at night. He says he observed no case, so well marked as this, of the influence of previous illumination on subsequent sleep.

It is hoped that the reader will take every opportunity of noticing the various methods by which plants go to sleep; but in every case the object is to place the blades in a vertical plane and protect, if possible, the upper surfaces especially.

\section{CHAPTER XI.}

\section{CLIMBING WILD FLOWERS.}

ONE of the most interesting books of Darwin's is his "Climbing Plants," in which he describes a great number of instances, to which I will refer the reader for details. The feature I now wish to dwell upon is the admirable way in which this power of climbing illustrates the diversity of methods adopted for one and the same end, whenever it is preferable to use one means rather than another for the purpose.

Climbing plants may be grouped as follows :(1) Those which climb by their stems or twiners, as they are called. (2) Leaf-climbers, and these may climb by their petioles or leaf-stalks; by their leaf-apices running out into a sensitive 
tendril ; or by the mid-ribs modified as tendrils without any true blade being developed at all. (3) By peduncles or flower-stalks. (4) By means of hooks ; these being a reduced form of a branch, spiny or not, or as superficial thorns, as of the bramble and Rattan-cane palms. Lastly (5), the climbing process may be effected by adhesive roots, as in tropical epiphytal orchids and our own ivy.

As an illustration of a stem-climber I will take Darwin's description of the hop. He says that when the shoot rises from the ground, the two or three first-formed internodes are straight, and remain stationary; but the next formed, while very young, may be seen to bend to one side, and to travel slowly round towards all points of the compass, moving, like the hands of a watch, with the sun. The average rate was $2 \mathrm{~h} .8 \mathrm{~m}$. for each revolution. Each separate internode, as it grows old, ceases to revolve, becoming upright and rigid generally. These internodes revolve simultaneously ; with all the plants which he observed, if in full health, two internodes revolved; so that by the time one had ceased, that above it was in full action, with a terminal internode first commencing to revolve. The purpose of this spontaneous revolving motion or circumnutation, i.e. a continuous bending rnovement successively to all points of the compass, is obviously in part to favour the shoot in finding a support; but when this is gained, the motion at the point of contact is arrested; while the free part projecting above continues to revolve, and by the very motion cannot fail to twine itself round the support. 
Darwin tells us that of thirty-nine plants examined by him, twenty-five revolved in a course opposed to, and twelve, with the sun; two revolved both with and against the sun. No instance is known of two species of the same genus twining in opposite directions.

The average rate at which the first circle of revolution is described, is about $6 \mathrm{~h} .10 \mathrm{~m}$., computed from thirty-five different plants ; the longest period being $26 \mathrm{~h}$. $15 \mathrm{~m}$., while the most rapid was $1 \mathrm{~h} .17 \mathrm{~m}$. The average rate of twining plants is $5 \mathrm{~h} .45 \mathrm{~m}$., for five revolutions. It must be borne in mind that young shoots commence slowly, and do not arrive at a maximum time of rotation until they have accomplished several circles or ellipses, as the case may be.

Light has a remarkable power in hastening the revolutions. Thus, Ipomcea jucunda performed its first circle in $5 \mathrm{~h} .30 \mathrm{~m}$; the semi-circle from light, in $4 \mathrm{~h}$. $30 \mathrm{~min}$., and that to light in $1 \mathrm{~h}$. $30 \mathrm{~m}$.; the difference being $3 \mathrm{~h} .30 \mathrm{~m}$. It must be observed, however, that the rate of revolution, in all plants was nearly uniform during night as well as day; hence Darwin iufers the action of the light to be confined to retarding one semicircle and accelerating the other; so that the whole rate is not greatly moditied.

Heat likewise affects the rapidity of revolution, by increasing it; thus, e.g., a plant of a species of Loasa, which moved against the sun, completed its first circle in $2 \mathrm{~h} .37 \mathrm{~m}$. Another plant which followed the sun completed its circle in $1 \mathrm{~h} .51 \mathrm{~m}$. and its fourth circle in $1 \mathrm{~h} .48 \mathrm{~m}$., that being a very hot day in July; whereas its fifth circle, on 
the cool morning of July 12 th was finished in 2 h. $35 \mathrm{~m}$.

Darwin describes a peculiar instance of a natural reversal of movement in Hibbertia dentata. He found that, although its long flexible shoots were evidently well fitted for twining, yet they would make a whole, or half, or quarter circle in one direction, and three in the opposite one. $\mathrm{He}$ could not at first discover for what purpose was this adaptation, until after offering the plant various arrangements of sticks and twigs, etc., he surrounded it with several thin upright sticks; and now the Hibbertia, he says, had got what it liked, for it twined up the parallel sticks, sometimes winding round one and sometimes round several. Though the revolving movement was sometimes in one direction and sometimes in another, the twiring was invariably from left to right. It would appear that this Hibbertia is adapted to ascend by twining and rambling laterally over the thick Australian scrub.

We will now theorise a little as to the original cause of the twining of stems.

As the evolutionary history of wild flowers and their organs, is what I wish to keep in view throughout this book, let us try to discover first, how stems, such as of our bindweeds, hop and honeysuckle have acquired this property of twining.

It is a well known fact that plants growing in shade get "drawn," because the stems are not influenced by the retarding effect of light, which acts especially upon the superficial tissues. The interior tissues on the contrary tend to elongate, 
consequently there is a constant struggle between the outer, "cortical" layers and the "central cylinder" of a stem. To illustrate this fact, if a ring of the outer layers be cut off from a herbaceous stem or thick leaf-stalk as of rhubarb, the interior column at once begins to elongate as soon as the tension is removed.

Now, if seeds of plants accustomed to grow in full sunshine find themselves in deep shade, they germinate and grow up with long, weak stems; the majority very possibly die. Some, however, may be able to resist the want of full light. The stems are "drawn" towards the light, some may reach it, blossom and set seed. These seeds reproduce the adaptations of their parents by living in the same conditions. "Circumnutation" or "bowing around," a common property of all shoots, adds another adaptation, for it increases with the length of the internodes. The stem thus coils round any support it may happen to touch.

In support of the probability of this theory being true, is the fact that many species of plants which normally live in full sun-light and do not climb at all, have allied species in adjacent forests which do so. Thus Fuchsia integrifolia occurs in the mountain forests of Brazil, where it climbs to a height of 10 feet, the stem acquires a thickness of one's arm. Outside the forests of the same region, there are plants of this species on rocky places which form bushes of a man's height. So too, all the species of fuchsia with which we are familiar in cultivation, are bushes and never climb.

It is the same with Convolvulus. In the desert of 
Africa the species of this genus form low, woody, gnarled-stemmed little plants ; but in our cornfields the lesser bind-weed climbs up the wheat-stalks, Conversely, when growing on a sunny bank, it at once assumes the habit of a creeping plant.

Climbing plants may hold the power in abeyance. Thus the dwarf French bean and garden nasturtium, as a rule, make no attempt at climbing; yet one or more plants in a row will revert to the habit. A remarkable instance of this is a large bush or small tree known to botanists as Hiptage Metablota, of tropical Asia. There suddenly appears a long slender shoot out of a thick branch which climbs up any neighbouring plant, as a bamboo, etc. This tree belongs to a family which is characterised by containing many climbing plants ; so that it had abandoned its climbing property for its main stem, but still retains it "potentially" in the boughs. Darwin, in concluding his remarks upon twiners adds a few peculiar cases somewhat like those I have here given. Thus, Combretum argenteum produces two kinds of shoots, several of the first-formed showed no tendency to climb until one appeared from the lower part of one of the main branches, five or six feet in length, differing greatly in appearance, from its leaves being little developed, it revolved vigorously and twined. The genus is mostly a climbing one; so this particular species, like the Hiptage, retained it partially in abeyance. Lastly, Darwin gives a still more remarkable instance of Ipomcea argyrceoides, which in S. Africa, almost always grows erect and compact, from twelve to eighteen inches; whereas seedlings 
raised at Dublin, twined up sticks eight feet high. These facts, says Darwin, are highly remarkable, for there can hardly be a doubt that in the dryer and sunnier provinces of S. Africa, these plants must have propagated themselves for thousands of generations in an erect condition; and yet during this whole period they have retained the innate power of spontaneously revolving and twining, whenever their shoots elongated under proper conditions of life required for climbing.

That shade has been the primary cause is suggested by the fact that if a shoot, as of a potato in the dark, elongate, the leaves are undeveloped and more or less reduced to scales. So is it with tropical climbers called Lianes, and as was the case with the twining shoots of the Combretum observed by Darwin, mentioned above.

Further remarks on the peculiarities of woody tropical climbers will be reserved for the second volume of "The Story of Wild Flowers."

That shade has been the primary cause of the origin of stem-climbers or twining plants has been proved experimentally ; for when plants of buckwheat were grown in the dark from seed, their stems showed similar torsions to those of ordinary climbers, and twisted round neighbouring objects.

I will now give one of Darwin's careful descriptions of a leaf-climber; as it well illustrates the power of putting on extra woody tissue, to meet the strain felt as soon as it begins to help to support the plant. The plant referred to, is Solanum jasminoides, not infrequently grown in conservatories, etc. Some members of the genus are 
stem-twiners, but this one is a true leaf-climber. The potato and many other species of Solanum show no tendency to climb.

A long shoot made four revolutions against the sun, very regularly at an average rate of $3 \mathrm{~h}$. $26 \mathrm{~m}$. In no other leaf-climber was a leaf grown to its full size capable of clasping a stick, though it took several weeks to do it. When a petiole of a half-grown leaf had clasped a support, in three or four days it increased in thickness, and after several weeks became hard and rigid. On comparing a thin, transverse slice of this petiole with one from the older leaf beneath, which had not clasped anything, its diameter was found to be doubled, and its structure greatly changed; for in the petiole, in its ordinary state, there is seen a semilunar band of cellular tissue, slightly different from that outside it, and including three closely approximate groups of dark vessels. Near the upper surface of the petioles, beneath the two ridges, there are two other small circular groups of vessels. But in the section of the petiole, which had during several weeks clasped a stick, the two upper ridges became much less prominent, and the two groups of woody vessels beneath them much increased in diameter. The semilunar band was converted into a complete ring of very hard, white, woody tissue, with lines radiating from the centre. The three groups of vessels, which, though closely approximate, were before distinct, where now completely blended together. The part of the new ring of woody vessels formed by the prolongation of the horns of the original semilunar band 
was thinner than the lower part, and slightly different in appearance, from being less compact. The clasped petiole had actually become thicker than the stem close beneath it; and this was chiefly due to the greater thickness of the ring of wood, which presented, both in transverse and longitudinal sections, a closely similar structure in the petiole and axis.

As a more familiar instance of a leaf-climber, and one which can readily be observed in many parts of England, is the traveller's joy. ${ }^{1}$ The leaf consists of two pairs and one terminal leaflet. The petioles are all very sensitive to touch, and are easily excited to bend in response to a very slight pressure; so that they will even coil round a blade of grass. If they catch hold of a twig in growing over a hedge, they soon coil firmly round it. Had they not done so the leaves would fall off in winter; but if the petioles have coiled round a shoot, they remain permanently attached to it.

An allied genus of S. Asia and the Indian Archipelago ${ }^{2}$ differs from the clematis in having leaves and perfect tendrils; but a British wild flower, the climbing corydal ${ }^{3}$ also shows us how one is derived from the other; for the first formed leaves of this plant are not modified at all. The next has the terminal leaflets smaller. The leaves contain several groups of leaflets, varying from five to three in a group; but now the end ones are very much diminished in size, till there is nothing left but the mid-rib, which then forms a true tendril.

1 Clematis Vitalba. ${ }^{2}$ Naravelia.

3 Corydalis claviculata. 
We will now consider a case where the tendril is composed, not of a leaf, but of a metamorphosed flowering branch. The American Virginian creeper ${ }^{1}$ is admirably described by Darwin, and it is so common that everyone must be familiar with its tendrils adhering by adhesive disks to a wall. But it will be noticed that if a plant climbs up a wire-work trellis, it climbs like other tendrils by twisting round the wire; so that it can adopt both methods according to circumstances. The tendrils end at first with little hooks, and it is not until these have caught the irregularities of a wall that the disks are developed.

In the Japanese species, ${ }^{2}$ however, it will be seen that the disks appear on the tendrils before any contact has taken place, showing that the disks, though originally the result of a merely mechanical pressure, have become hereditary in this species. This is not a sole instance, for similar disks are formed on contact, ${ }^{3}$ or are hereditary ${ }^{4}$ in plants of quite different orders.

The vine, being so easily observable, may be also described. Like the tendrils of the Virginia creeper and passion flower, that of the vine is a metamorphosed flowering branch. It is of great size and thickness, bearing two branches, which diverge equally from it like the letter $Y$. One branch has a scale at the base, and is the longer and often forked. After a tendril has clasped any object it contracts spirally. The two branches of the tendril can readilv be compared with the

1 Ampelopsis hederacea. 2 A. Veitchii.

3 See Darwin's "Climbing Plants," p. 102, Note.

4 Op. cit., p. 146, Note. 


\section{THE STORY OF WILD FLOWERS.}

flowering shoot, one branch still remaining as a tendril, the other now branches again, and carries the flower buds.

The peduncle increases in length, and loses its sensitiveness in an inverse degree to the number of flower-buds. Thus the fewer there are the greater the length of the peduncle, and the more nearly does it assume the character of a tendril.

Similarly the "flower-tendril" occasionally bears flowers, and then in this state it retains its characteristic qualities of sensitiveness and spontaneous movement, but in a somewhat lessened degree. In fact, a perfect gradation may be seen from the ordinary state of a "flowerpeduncle" to that of a true tendril.

The reader should search over a vine plant, and he will soon find all sorts of intermediate conditions between tendrils and flowering branches.

In the passion flower the tendril assumes a totally different form, precisely imitating that of our common bryony. The special feature in both is the curious adaptation to resist a breaking strain. As the tropical woody climbers, or lianas, exhibit various methods to secure the same end, I will reserve any remarks till I have to treat of tropical plants in the next volume on "The Story of Wild Flowers." 


\section{CHAPTER XII.}

INSECTIVOROUS WILD FLOWERS.

THERE are many plants of very different families which have acquired the property of catching insects and digesting the nitrogenous matters of their bodies. According to Dr F. Darwin's experiments with the sundew, it would appear that the chief advantage to such plants is to enhance the reproductive process, and to increase the quantity of seed.

We shall see that this "end" is identical with that of parasitism ; for parasitic plants, by grafting themselves on "hosts," are enabled to absorb nutritious fluids and already prepared food; so that requiring no expenditure of "vegetative" energy, they at once proceed to make flowers and fruit with a prodigious quantity of seed.

British insectivorous plants consist of three species of sundew, representing one family; four species of butterwort, together with five of bladderwort, which make another family. There is also a continental plant, to which I wish to refer on the present occasion, as it involves features from both these two families. I shall reserve some very remarkable. instances of foreign insectivorous plants for the second volume.

The family to which the sundew belongs contains six genera, all being insectivorous, but in remarkably different ways. The sundew itself has 100 species scattered pretty well all over the globe, being most frequent in Australia. 
Three genera have but one species each. One, to which I shall refer, occurs in middle and South Europe, and extends as far as India, and is also found in Queensland. It is called Aldrovandra. There is one in South Africa; one in Florida, the

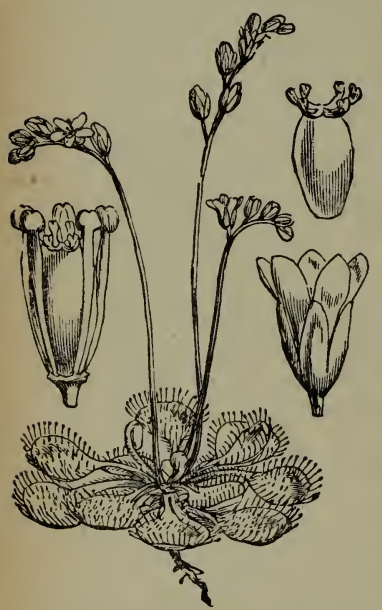

FIG. 33.-Sundew; with complete flower on right; stamens and pistil on left; pistil, above. so-called Venus' fly-trap, which I propose describing; a fourth is found in Spain, and the fifth in Australia, where the sundew, or Drosera, has its chief home.

Our sundews (Fig. 33) are little plants growing in wet places among bog-moss. They have very imperfect roots, but the failure to secure much nourishment by them, is compensated for by the facility with which they can catch nutritive insects.

In the round-leaved sun dew, the commonest species, the blade is circular, and provided with "tentacles," as Darwin called them. 'These consist of cellular structures, being short on the middle of the leaf, but.they get longer and longer towards the circumference, where they spread out horizontally. Each carries a clubshaped or globular extremity. The inner tentacles are green but the outer purple, the cells being filled with a coloured fluid; the terminal glands of the tentacles constantly secrete a large drop 
of gummy fluid, which has given the name sundew to the plant.

Whether insects are attracted, or accidentally come in contact with the gum and stick there, is not quite clear; but as many as thirteen dead insects, more especially flies, have been found on a single leaf. Even a dragon-fly has been seen, caught between two leaves.

With regard to the action of the tentacles, I cannot do better than give Darwin's own words. He tells us that if a small organic or inorganic object be placed on the glands in the centre of a leaf, these transmit a motor impulse to the marginal tentacles. The nearer ones are affected and slowly bend towards the centre, and then those farther off, until at last all become closely inflected over the object. This takes place in from one hour to four or five or more hours. The difference in the time required depends on many circumstances; namely, on the size of the object and on its nature; that is, whether it contains soluble matter of the proper kind; on the vigour and age of the leaf ; whether it has lately been in action; and on the temperature of the day. A living insect is a more efficient object than a dead one, as in struggling it presses against the glands of many tentacles. An insect, such as a fly, with thin integuments, through which animal matter in solution can readily pass into the surrounding dense secretion, is more efficient in causing prolonged inflection than an insect with a thick coat, such as a beetle. The inflection of the tentacles takes place indifferently in the light and darkness, and the plant is not sub- 
ject to any nocturnal movement of so-called sleep.

If the glands on the disc are repeatedly touched or brushed, although no object is left on them, the marginal tentacles curve inwards. So again, if drops of various fluids, as of a solution of any salt of ammonia, are placed on the central glands, the same result quickly follows, sometimes within half-an-hour.

The longer and outermost tentacles curve inwards by bending at a point about one-third from the base. If it be simply touched three or four times, or a prolonged contact with organic or inorganic objects and various fluids, it will incurve itself even within one minute. If an object, such as a bit of meat or an insect, is placed on the central part of a leaf, the surrounding tentacles will become inflected, and their glands will pour forth an increased amount of secretion. In fact, the central glands, when strongly excited, transmit some influence to those of the marginal tentacles, causing them to secrete more copiously.

The next point to note is, that the secretion from unexcited leaves, though extremely viscid, is not acid, or only slightly so; but that it becomes acid, or much more strongly so, after the tentacles have begun to bend over any inorganic or organic object; and still more strongly acid after the tentacles have remained for some time closely clasped over any object. The secretion also appears to be to a certain extent antiseptic, as it checks the appearance of mould, thus preventing for a time the discolouration and decay 
of such substances as the white of an egg, etc. It therefore acts like the gastric juice of the higher animals, and the nature of the secretion appears to be allied to pepsin.

Venus' fly-trap (Fig. 34) is a native of Caro-

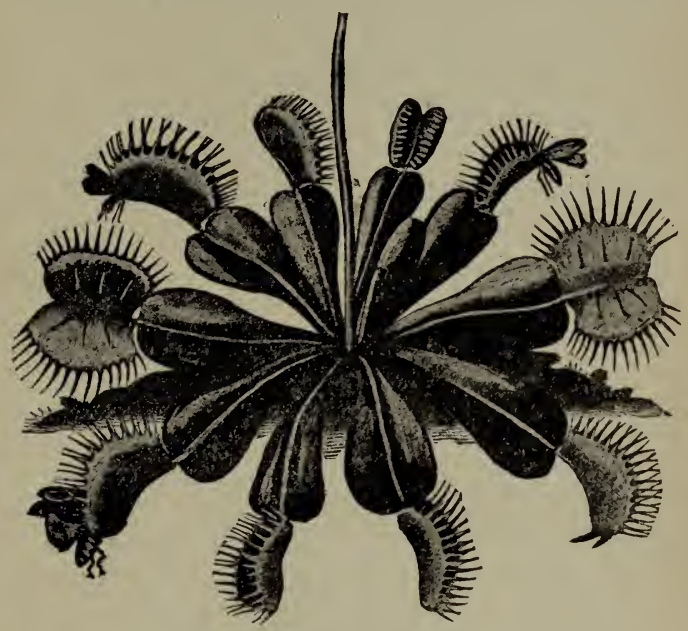

FIG. 34.-Venus' Fly-trap.

lina and Florida. It has a broad-winged petiole, the blade forming the trap. The peculiar feature about this, is that the margin of the two halves are provided with long teeth, while the surface has three bristles on each, and the instant one or more is touched, the two halves close like a rattrap. They are so sensitive that if a piece of cotton be made to touch one of them by dangling it over the bristle, the two halves of the leaf 
immediately close. The motion of the tentacles of sundew is slow, because the insect is retained by gum. Here, there is no secretion; so, in compensation, the trap closes rapidly.

The upper surface of the lobes is thickly covered with small purplish, almost sessile glands. These have the power both of secretion and absorption. They do not secrete until excited by the absorption of nitrogenous matter. The secretion is almost colourless, slightly mucilaginous, and, judging by the manner in which it colours litmus paper, Darwin thought it was more strongly acid than that of the sundew.

Besides the sudden closing of the two lobes of the leaf when the bristles are touched, Darwin discovered that if bits of meat or albumen, if at all damp, were placed on the leaf, they would not only excite the glands to secrete but the lobes to close.

With regard to the digestive power of the secretion, Darwin observes that when a leaf closes over any object, it may be said to form itself into a temporary stomach; and if the object yields ever so little animal matter, this serves as a "peptogene," and the glands on the surface now pour forth their acid secretion, which acts like the gastric juice of animals.

Darwin makes some further interesting remarks upon the transmission of the motor impulse of the bristles. It is sufficient, he says, to touch any one of the six filaments to cause both lobes to close, these becoming at the same time incurved throughout their whole breadth. The stimulus must therefore radiate in all directions 
from any one filament. It must also be transmitted with much rapidity across the leaf; for in all ordinary cases both lobes close simultaneously, as far as the eye can judge. Most physiologists believe that in irritable plants the excitement is transmitted along, or in close connection with the fibro-vascular bundles; but the presence of vessels is not necessary for the transmission of the motor impulse, for it is transmitted from the tips of the sensitive bristles or filaments (these being about the one-twentieth of an inch in length) into which no vessels enter; moreover, experiments showed that there was no necessity for a direct line of communication from the filament which is touched, towards the midrib and opposite lobe. By making longitudinal slits in the leaves between the filaments and the mid-rib, the lobes still closed when the former were irritated. The motor impulse, therefore, travels in all directions through the cellular tissue. The lobes whilst closing become slightly incurved throughout their whole breadth. This movement appears, Darwin suggests, to be due to the contraction of the superficial layers of cells over the whole upper surface. On the other hand, the several layers of cells forming the lower surface of the leaf are always in a state of tension; and it is owing to this mechanical state, aided probably by fresh fluid being attracted into the cells, that the lobes begin to separate or expand as soon as the contraction of the upper surface diminishes: Space will not allow me to quote more upon these interesting plants; but I must refer the reader to Darwin's exhaustive work on Insec- 
tivorous Plants, in which he also attempts to discuss the possible, if not probable, evolution of the Sundew Family.

The Bladderwort (Fig. 35) has a totally different method of seizing its prey. In the first place

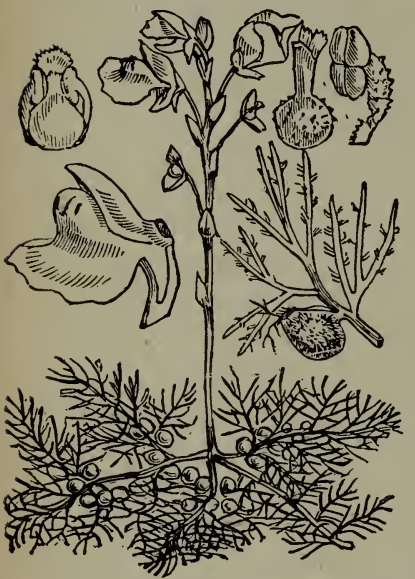

FIG. 35.-Bladder-wort; shewing submerged dissected leaves; one, enlarged with trap; a flower, two stamens and pistil together, on left; separate, on right. it is a submerged plant with finelydivided leaves, as is so commonly the case with aquatic Dicotyledons ; upon these are little bladder-like structures ; they are translucent and green. Their walls are of two layers of cells. 'They are filled with water and bubbles of air.

From three to seven bristles form a sort of hollow cone round the mouth. There is a valvelike lid to the bladder, sloping upwards, and is attached on all sides except the upper or posterior margin, which is sharp, thin and smooth, resting on a collar of the lower or anterior margin which is rigid.

Now for the uses of the several parts in catching small aquatic animals. The interior of the bladder has what might be called bifid and quadrifid processes. These consist of two or four spindleshaped cells radiating freely from a point. When an animal has been caught-and what 
induces them to lift up the lid, enter, and so get imprisoned, it is difficult to suggest-after more or less prolonged struggle, it dies; and when decomposition has set in, the absorbable parts become taken up by these processes. Darwin concluded-from whose observations the preceding is taken - that nitrogen is absorbed by the glands situated near the orifice, as well as by the quadrifid processes.

Unlike the Sundew, the bladderwort only absorbs nourishment from decayed animals. It, in fact, frequents impure water.

Butterworts, the other genus of the same family (Fig. 36), are common in moist

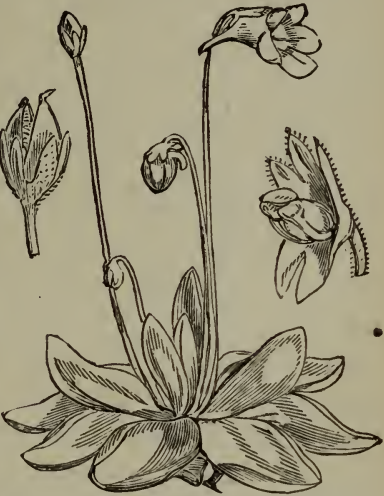
places, especially on the west side of England and Scotland. One species is Alpine, and like our other high mountainous plants is found in $\mathrm{N}$. Europe, N. Asia, etc., and even in Fuegia and Greenland. Though belonging to the same family as the bladderworts they catch insects in a totally different way. The leaves are arranged in a rosette, and are in our British species spoon-shaped, with slightly in-turned margins, the whole surface is covered with button-shaped glands consisting of sixteen cells supported on elongated, unicellular pedicels; 
together with smaller glands of eight cells on shorter pedicels.

The glands secrete a colourless and very viscid fluid. It has been drawn out to a length of 18 inches after excitement.

In an experiment to test the insectivorous properties, a row of flies was placed along one edge ; after fifteen hours it was inrolled by the margin, and all the glands in contact with the flies was secreting copiously.

When a fly was placed in the median line of the leaf, near the apex, both the lateral surfaces grasped it in $4 \mathrm{hrs}$. 20 mins.

Six cabbage seeds caused the margin to infold in $2 \mathrm{hrs}$. $25 \mathrm{~min}$. They yielded soluble matter to the leaf. Inorganic matters, however, have little or no effect on the secretive powers; but induce the infolding of the margins. The shortest time taken to infold the margins completely was two hours seventeen minutes when nitrogenous substances or fluids were given to the leaves.

The average time for unfolding the margins was twenty-four hours.

The advantage of this inrolling movement is to bring the glands near the edge vertically downwards upon the object, so that while it rests on glands below, those above it can add their secretion. Moreover, larger prey that cannot be infolded are pushed to the middle of the leaf where glands abound. The incurved edges also collect, as in a spoon, the superabundant secretion. It is only nitrogenous substances or fluids which cause the secretion to be acid and therefore capable of digesting such food. 
Aldrovandra vesiculosa (Fig. 37) of the Continent, a genus of the same family as the Sundew, is an aquatic plant having its leaves in whorls and the blade bi-lobed like that of Venus' Flytrap, and more or less closed like a half-opened pea-pod, Like the bladderwort it is destitute of roots, but floats freely in water. The lobes of the leaf are formed of very delicate tissue. They open only to a slight degree.

Each lobe rather exceeds a semicircle in shape, and consists of two very different portions; the inner and lesser, or that next the mid-rib, is slightly concave. Fig. 37.-AldroranIts upper surface is studded

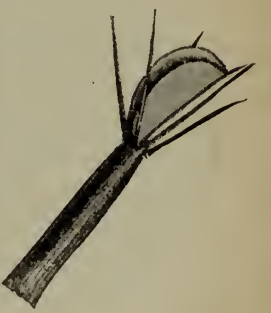
with colourless glands. The outer and broader portion of the lobe is flat and very thin. It bears small quadrifid processes, which curiously resemble those of the Bladderwort, though, as stated, these two plants belong to widely different families (Fig. 38).

The rim is provided with a row of conical, flattened, transparent points, with broad bases, like the prickles of a bramble ; but they are composed of very delicate and highly flexible membrane. They somewhat resemble, but are really totally distinct from, the teeth of Venus' Fly-trap.

On the concave gland-bearing portion of the lobes, and especially on the mid-rib, there are numerous long, finely pointed hairs, which, without doubt, are sensitive to touch, and cause the leaf to close. 
Darwin was unable to carry out sufficient experiments with this plant; but says, that if we may trust to analogy, the concave and inner portions of the two lobes probably close together by a slow movement, as soon as the glands have

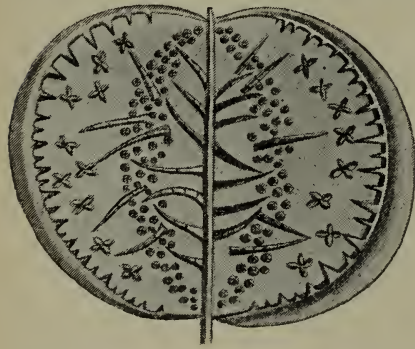

Fig. 38.-Aldrovandra ; leaf pressed flat open (after Darwin).

secrete a true digestive fluid, and afterwards absorb the digested matter.

The interesting feature about this plant is that the form of the trap resembles the leaf of the Venus' Fly-trap, together with its sensitive bristles and glands; but that of a totally distinct plant in the quadrifid processes.

Lastly, there is a species of marsh marigold in the Falkland Islands, off Cape Horn, which has trap-like leaf-blades, with toothed margins, and half-closed, very like those of Venus' Flytrap; but nothing is known of its capabilities of catching insects.

The chief point of interest, from an evolutionary point of view, is seen in the fact that plants of no affinities whatever put on similar structures to gain the same end, when necessary; 
and not only may this be with identically the same organ, as, e.g., the leaf-blades in the above cases; but different organs may assume the same form, as we shall see in the case of pitcher plants of Australia, when we come to consider the peculiar flora of that country in the next volume.

\section{CHAPTER XIII.}

AQUATIC WILD FLOWERS.

THERE are certain peculiar features characteristic of the structures of all aquatic flowering plants, which are, by their universal coincidence, obviously adaptations to a life in water. For, when we observe such to be identically the same in a great number of plants of widely different families, and therefore of no affinity, the conclusion is inevitable that it is the water which has been the prime cause of their existence.

Commencing with roots, we find that when the seeds of aquatic plants germinate, the primary or tap-root is very often soon arrested. This occurs, e.g., in the water-crowfoot and the spear-wort, in the water-chesnut, in the mangroves, ${ }^{1}$ trees growing in the swamps near the mouths of tropical rivers (Fig. 39). After a time

1 These belong to two widely different families, Rhizophorece and Verbenacee, showing how the same habit of growth thas been acquired under similar external conditions. 
the stems of such trees, like those of the screwpines, ${ }^{1}$ among Monocotyledons of a similar habit, terminate below abruptly, often above the level of the ground, but are supported, as already stated, on numerous "adventitious" roots, ex-

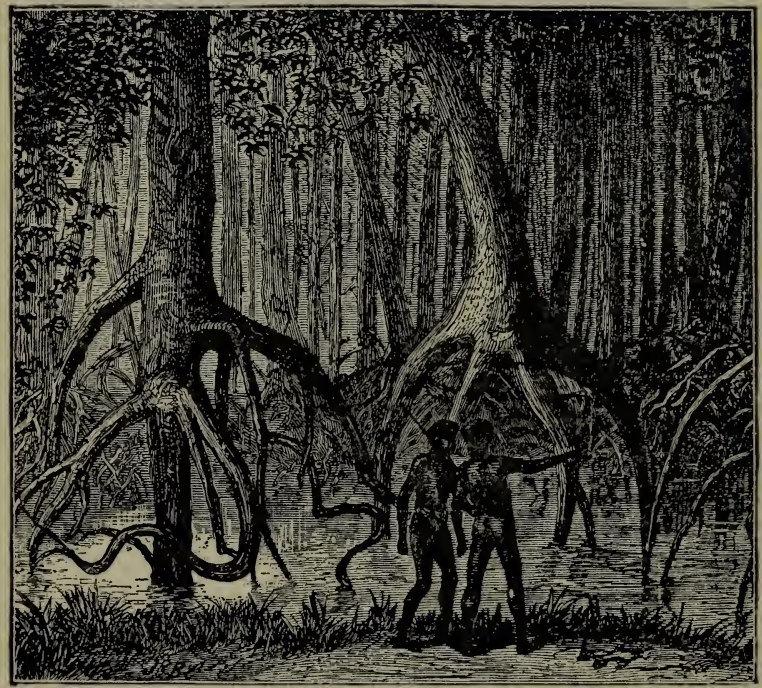

Fig. 39.-Mangroves; supported by adventitious roots.

tending like tent-ropes. These roots are continually being formed in ascending series by their issuing out of the stem, being also often branched. Similar roots are readily observable in a germinating maize plant.

Submerged stems are always characterised by

1 Pandanus. 
having long channels or air-chambers, separated by transverse diaphragms; whereas, the woody tissues necessary for supporting stems growing in the air are almost entirely absent, for the water without, and the air within the stems, keep them erect. Similarly the cortical tissue of aërial stems is compact, but that of submerged stems is lax, and full of air-passages or lacunce, caused by the separation of the cells from one another in places.

The thick rhizomes of water-lilies, which creep along the mud, illustrate another feature of im-

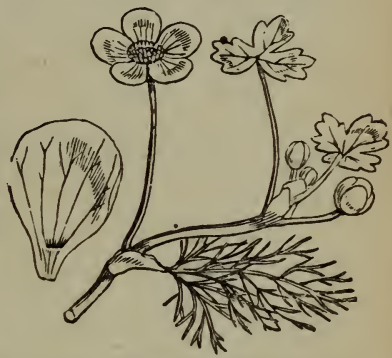

Fig. 40.-Water Crow foot; shewing submerged and floating leaves; also a petal with the nectary at base. portance, for the fibro-vascular bundles or cords of woody tissue, instead of being arranged in definite concentric cylinders, as seen in any cross section of a piece of timber, showing zones of annual growth, these are greatly dislocated and scattered through the fundamental or pith-like cellular tissue. Hence the rhizome of a waterlily has often been compared with and likened to the stem of a Monocotyledon, such as of asparagus or a palm.

With regard to the leaves of aquatic plants, the submerged leaves of Dicotyledons are mostly finely divided, nothing being left of the intersticial tissue between the fibro-vascular bundles or "veins" of the leaf, as in the water-crowfoot (Fig. 40). 
Since terrestrial plants, allied to aquatic ones with divided leaves, have theirs of the ordinary or complete type, we may safely credit the water as being the inciting cause of the dissected character of submerged leaves. ${ }^{1}$ The reader may compare in his mind the water-crowfoot and a field buttercup, the water-violet and a primrose, the bladderwort with the butterwort.

A less number of plants of the class Dicotyledons have ribbon-like leaves when submerged. Such occur in our aquatic species of lobelia, not uncommon in the Welsh Lakes; the only other species in England, to be found in Dorset and Cornwall, has net-veined leaves with a toothed margin. The marestail and water-starwort are other common examples.

The number of plants belonging to the class Monocotyledons, which are aquatic, is far more numerous. In fact, the percentage of Natural Orders or Families, containing aquatic plants, is thirty-three, whereas it is only four in Dicotyledons.

In the enumeration of the most obvious characters distinguishing these two classes, given in Chapter III., it will be seen that the first mentioned refers to the non-existence (as in germinating wheat or barley), or, if it be developed, the carly arrest (as in Indian corn

1 As examples taken from different families, there are the water-crowfoot (Ranunculus family), a watercress (Nasturtium amphibium, of Crucifers), a kind of celery (Apium inundatum, of Umbellifers), the water milfoil (of Haloragea), the water violet (of the Primrose family), the Bladderwort and Hornwort. The above are selected from widely distinct families. 
or the date) of the primary or axial root in Monocotyledons.

The plant is subsequently supported, as already stated, and nourished by adventitious roots, arising in ascending order from the base of the stem. Now, this is universal among Monocotyledons, but it is also far from uncommon among aquatic Dicotyledons.

The stem of a Monocotyledon, as of a palm-tree, or shoot of asparagus, was long ago seen to afford a sharp contrast to that of a Dicotyledon; and since the annual cylinders of wood are formed outside the previous years, as in all our British timber trees; such was called "exogenous" and Dicotyledons were also called exogens, i.e. "begotten without." In Monocotyledons, however, no such cylinders of wood are formed, the fibrevascular bundles, which represent it, pass down the stem from the leaves and outwards again at their lower ends, terminating in the circumference. Through a misconception the younger bundles or woody cords were thought to be always within the others. Hence the term "endogens," i.e. "begotten within," was framed as a synonym for Monocotyledons; but it was a faulty expression. It is only mentioned as it still occurs in our text-books, and in Sir J. D. Hooker's "Student's Flora of the British Isles."

The word "endogenous" is still useful as descriptive of the origin of roots; for these take their rise from a deep-seated active layer of tissue, and issue out of the " mother" root by dissolving out a passage through to the surface of the cortical layers. I say, "dissolves," because the apex 
of the secondary root is provided with a sort of cap which secretes a "ferment." This causes the dissolution of the cortical tissue upon which the young root feeds until it has escaped from the mother-root and penetrates the soil.

The layer of tissue from which the root takes its rise is a very important one, it forms a thin cylinder beneath the cortical tissue over the woody cylinder of roots and stems. It supplies all the secondary and subsequent rootlets.

In the stems of Monocotyledons which have no "cambium" layer beneath the cork, wherewith to form annual layers of wood and bark, as in our dicotyledonous timber trees, this "pericycle" is a substitute, and by its means the stems of Monocotyledons can increase in diameter to a certain extent.

In the flowering stems of herbaceous Monocotyledons, as of the Lily of the Valley and Ixias, it assumes the rôle of supplying mechanical tissues ; as a "stiffening." The reader will perhaps recall the "wiry" character of such flower-stalks. In Dicotyledons it makes the fibres so useful in hemp, flax and many other stems.

Contrary to the nature of roots ; branches, however, are continuous with the trunk and are therefore spoken of as "exogenous" in development.

A similarity between the two classes may often be seen in flower-stalks. In these herbaceous stems the fibro-vascular cords are arranged in one or two circles, but isolated from each other. The flower-stalk of an anemone will be found thus to exactly resemble that of a daffodil ; but the former is a Dicotyledon while the latter is a 
Monocotyledon. Such resemblances point to an original and common origin of the two classes. We have already seen that there are some strong resemblances between the leaves of Monocotyledons and the leaves of certain aquatic Dicotyledons. Let us consider them more in detail.

The almost universal character of submerged leaves of Monocotyledons is to be long and ribbon-like. The reader will recall those of bullrushes, the sweet flag, the flowering rush, and of true rushes, etc. The "insertion" of the leaf in the stem is by a broad and more or less sheathing base, which encircles the stem to a less or greater degree. The fibro-vascular bundles pass out of them and run in parallel courses from end to end, generally united by cross-bars, thereby making square or oblong interstices. Such is the origin of the "parallel venation," regarded as one of the most characteristic features of monocotyledonous leaves.

We have seen that the effect of living submerged causes an arrest of the intersticial parts of the leaves of the majority of aquatic Dicotyledons, reducing them to a finely divided state. A similar effect is often seen in our pond-weeds, in which some of the square interstices are not developed, so the leaf appears to be perforated. In the latticed-leaf plant of Madagascar, all the interstices are thus arrested. ${ }^{1}$

1 Ouvirandra fenestralis. This genus and Aponogeton are the only two of the same family. A. distachyus is hardy in England, and is occasionally grown in ponds. It has a forking flowering-stem; each branch bearing two rows of white bracts and small flowers in their axils. The leaf resembles that of the Lattice-leaved plant, but has no perforations. 
Now there are some members of the Aroidece, now terrestrial, but having large perforations in their leaves, which are hereditary; and it is difficult to account for them otherwise than having been acquired when their ancestors were

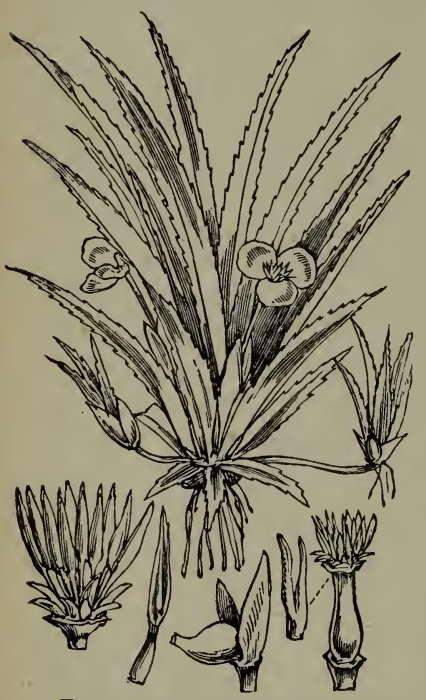

FIG. 41.-Water-soldier; showing stolons; male flower and single stamen (left); female flower, stigmas (right) ; and fruit with 2-leaved spathe (middle). aquatic plants; and so they retained this feature when they finally became terrestrial.

Another type of foliage found among Monocotyledons is that of the African aloë and the "American aloe," really of a different genus and family. These plants now grow in very arid districts where rain rarely falls; so that the leaves have acquired a massive character in order to store up great quantities of water in their internal cellular tissue.

Our British watersoldier would seem to give us an idea of the origin of this type of foliage; for it bears a tuft of rigid and brittle radical leaves with a toothed margin, recalling the marginal teeth of the aloes (Fig. 41).

It may thus, perhaps, represent the original aquatic type of foliage from which the aloes have descended and become terrestrial. 
A better parallel is perhaps to be seen, between the development of leaves of an aquatic Dicotyledon and of Monocotyledons in the evolution of those of the arrow-head. As long as the leaves of the latter are well submerged, they are long and ribbon-like. As the tips come near to the surface of the water, they begin to form an oval blade, and two basal appendages then appear on it, thus forming a spear-shaped blade. The three points elongate and now rise out of the water and take on the permanent form of an arrow-head, giving the name to the plant.

An interesting proof of the effect of water in causing the linear ribbon-like form, is seen in the fact that if a leaf has just commenced to widen out at the top to form a blade, if the water be suddenly deepened, so as to completely submerge it, then the apex sets to work to grow out again into a strap-shaped prolongation.

Sometimes the leaf has already acquired the spear-head form with its two basal points. Then the effect may be that all three points are induced to run out into straps or with ribbon-like extensions.

A large number of Monocotyledons, especially of the family Aroidea, have this arrow-headed form of leaf-blade, as in our common lords and ladies or cuckoo-pint. This plant bears small oval blades at first-just like the first blades of the arrow-head's leaf-then, subsequently, the complete form.

Turning to the water-lily family of Dicotyledons, a similar progression is seen, as, e.g., in the germination of the Great Water-lily of the 
Amazon, known as Victoria regia. The seedlings of this plant, which is an annual, first throw out nothing but flat petioles, then follows the arrowheaded form, and finally the orbicular leaf.

In some plants the basal halves of the lower part of the arrow-headed leaf are united, so that the "peltate" leaf, which it now becomes, is somewhat triangular in shape $;^{1}$ but, as a rule, it is the orbicular or horse-shoe shaped leaf which has the lower edges united, thus forming a circular blade, with the petiole attached to the centre, as in the lotus and the garden nasturtium. This suggests the name "peltate" or shield-like.

We thus see how the foliage of Monocotyledons can be traced to forms assumed by aquatic Dicotyledons; and when the final result is a genuinely reticulated "venation" in the blade, as in the leaf of the cuckoo-pint, black bryony, Paris, Trillium, etc., we seem to recall the ancestral type of Dicotyledons generally.

In describing plants one often has occasion to speak of their degeneracy, and as water is one of the most active agents in causing it, it may be as well to observe that it really means the putting a terrestrial plant in adaptation to, and in harmony with, a watery existence. The stems "degenerate" in the sense of non-development of wood, simply because it is not wanted. It suppresses the stomates on the submerged leaves, because they would be of no use. But the plant is simply in perfect adjustment to its condition of life. 


\section{CHAPTER XIV.}

THE ORIGIN OF FLORAL STRUCTURES OF WILD FLOWERS.

WE have learnt that the typical structure of a flower consists of a calyx, corolla, stamens, and pistil; and we want to know why the parts of these whorls vary in number. Thus dicotyledonous flowers are generally in fours or fives and monocotyledonous in threes.

Then, again, we have seen that a typical flower has the whorls "regular," i.e. with all the members exactly alike, as are the petals of a buttercup. But in many flowers the petals are of different shapes as of a violet and pea-blossom. How has this irregularity come about, since all primitive flowers possessing a corolla are assumed to have been regular?

We will consider these two kinds of differences in flowers in the present chapter.

As all flowers are referable to a leaf-bud, as will be more fully explained in a subsequent chapter, we shall find our clue to the number five, which is by far the commonest among sepals, petals, and stamens, in a very simple way. Take a leafy shoot of a rose-tree or hawthorn, call any leaf No. 1 ; then, it will be observed that if a line were drawn round the stem through the base of each leaf-stalk in succession, it will be a spiral one, and coil twice round the stem before it arrives at a leaf (the sixth) exactly over No. 1. 
The five leaves (No. 1 to No. 5) make a socalled "cycle." Similariy, No. 6 to No. 10 form a second cycle, and so on. Now, suppose the internodes or distances between the leaves to be suppressed, and the leaves of four cycles to be

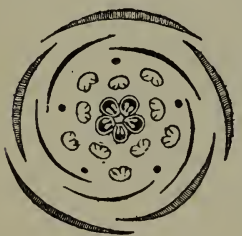

FIG. 42.-Diagram of a complete pentamerous Hower of Geranium.

brought down to one level, we should have what exactly corresponds to four floral whorls of five parts each, except in one particular; and that is, to avoid crowding, Nature shifts each whorl so as to make it alternate with the next. Consequently, the leaves, Nos. $6,11,16,21$ are not exactly over each other, but now lie between those of the whorls above and below (Fig. 42).

This is so general a law in flowers, that if any whorl of a flower is found to be exactly over another, botanists at once know that an intermediate whorl has been suppressed. This occurs in the primrose and pimpernel (Fig. 43), in which the five stamens stand in front of the petals and not between them. A genus known as brookweed, of the same family, has stump-like rudiments of stamens between the petals, as well as five perfect stamens in front of them (Fig. 44); so it illustrates an ancestral condition when two cornplete whorls of stamens were pre-

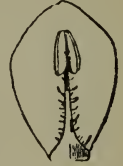

Fig. 43.-A petal and stamen of Pimpernel. sent in alternate positions, the innermost being only present in the primrose. Several of the Incompletoc have stamens in front of the sepals; 
THE ORIGIN OF FLORAL STRUCTURES. 145

because in this group the corolla is generally wanting.

Now let us try to account for flowers which have their parts in twos and fours, as in the enchanter's night-shade, lilac, and fuchsia. If we look at the leaves of these plants we shall find that they are arranged in pairs, each pair being in a position at right angles to those above and below it. If we suppress the in- Frg. 44. - Brookternodes, we get either whorls of weed; part of twos; or if nature takes two menslaid open. pairs to make a whorl, the flower is in fours.

In Monocotyledons we find "threes" to prevail, as in lilies, hyacinth, crocus, etc.

In these plants, it will generally be found that the leaves are so arranged that the fourth leaf stands on the spiral line over the first, so that three leaves only now make a cycle. Hence the whorls are in threes.

Sometimes the number of parts is so great (more than twelve) that it is called "indefinite." This occurs in the stamens and carpels of a buttercup. A close inspection shows that they are spirally distributed, so that they are referable to the prevailing type of arrangement of leaves. Thus, then, we can account generally for the various numbers of the parts of floral whorls. Exceptional cases occur, when one or more parts are wanting, as in Labiates, though the sepals and petals are five each, there are in nearly all cases only four stamens, because the posterior or fifth stamen is suppressed.

Of the two kinds of arrangement of leaves in 
plants, viz., the one with "opposite" pairs of leaves, and the other, when there is only a single leaf at a node or "alternate," the question arises, how does the latter issue from the former? Because, if we go back to seeds of Dicotyledons, we find they all (allowing for rare exceptions) start with a pair of opposite leaves or cotyledons, as seen in germinating mustard and cress. But, it often happens that a shoot will have opposite leaves below and alternate above, as on the stem of a willow-herb, and, as especially worthy of study, is that of the Jerusalem Artichoke.

It will be found that the first step in the change is a separation of the pair of leaves by a very short joint or internode; and as the stem elongates, the leaves of the successive pairs become further apart and at the same time, so to say, shift their positions, they are no longer opposite to one another. This process will be illustrated by the following scheme, in which, however, the leaves are placed, as if remaining opposite in pairs, viz., 1 and 2, 3 and 4, 5 and 6 , etc., constituting the original opposite pairs.

The arrows indicate the order in which they will occur up the stem, when they have become alternate and stand singly on a spiral line as already explained.

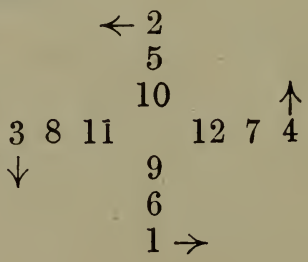


THE ORIGIN OF. FLORAL STRUCTURES. 147

The sixth leaf is then over the first.

The next point to consider is how irregularities have come into existence in flowers.

To answer this question, first, and then to prove it, I might say that they are the actual result of the habitual visits of certain insects, which come to them for honey.

In other words, the living protoplasm of the flower responds to the irritations, pressures, etc., set up by the insect alighting on the flower; so that it gradually (i.e. through successive generations) assumed the irregular form now existing, in special adaptation to its visitor.

This is, of course, a theoretical explanation, because, we cannot induce a regular flower to become irregular; but the theory is based on innumerable coincidences, which render it highly probable. Space will not permit of much illustration but the following examples will show the line of argument.

The calyx of the furze and sage will be observed to be two-lobed, 2 sepals forming the posterior, and 3 the anterior half in the former while in labiates, to which the sage belong, the numbers are reversed. In sages the calyx is tubular and often possesses a number of stout ribs. Suppose we represent them as follows :- $d$ (dorsal) stands for the original mid-ribs of the 5 coherent sepaline-leaves. $m$ (marginal) occurs where the sepals are united by their edges, $s$ (supernumerary rib) in front. 


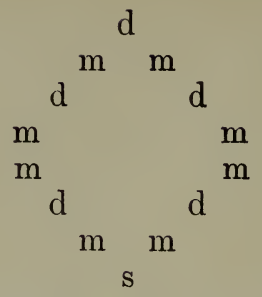

What is the interpretation of this arrangement? The weight of the bee is all on the front part of the flower; as she alights on the enlarged front petal or lip of the corolla. The tube of the latter is sheathed by the calyx-tube; so that the pressure is all on the front part of the calyxtube. This tends to tear the calyx across, and accounts for two-lobed form. To resist this, strong cords are run up in the weakest places; only one $(m)$ occurs between each sepal at the back, as the strain is least there; but two $(m, m)$ are at the sides, two more together with an extra cord $(s)$ are in the front, just where the strain is greatest.

The whole structure of the calyx with its distribution of cords is seen to correspond exactly with the mechanical pressures and strains brought to bear upon it.

In Salvia or sage, we see how extra ribs are added to the anterior or front half of the calyxtube ; but if we examine the flower of the woodsage in which there is no posterior hood to the corolla, we shall find that the corolla lip hangs vertically, and in a cultivated species (which shows the details somewhat better, called Tencrium [Teucris] orientale, Fig. 45) the corolla is split at the back and hangs in a vertical direction, the 
stamens and pistil being erect. The insect hangs upon the corolla, so that the whole weight of the insect is so much to the front, that the leverage will be at a considerable disadvantage, much more so than when the insect stands more directly over the tube of the corolla. To meet this difficulty the pedicel is curved over at the top, as may be readily seen in our common wood-sage, and forms a spring; while hypertrophy has attacked the posterior side of the calyx, so that it now carries two extra marginal ribs, one on either

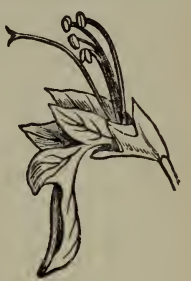

Fig. 45.-Teucrium. side of the posterior dorsal one, as shewn in the accompanying diagram. This is exactly the reverse of what occurs in Salvia and others which $\mathrm{d}$

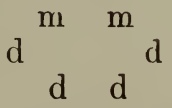

are much more strengthened on the anterior side, when the insect stands more directly orer the centre of the flower.

Irregularities occur most frequently in corollas, so that "lips" are very common ; as in the violet or pansy, the labiates, many of the snapdragon order, most orchids, etc., and as they are always in front, where an insect alights, the coincidence. strengthens the theory, that here too, there has been a direct cause and effect in their production.

In many orchids the flower has become inverted, either by the twisting of the pedicel as 
in twayblade; or of the ovary, if sessile, as of Orchis $;^{1}$ or again, the flower may bend over to the opposite side of the stem, without any twisting at all, as in the "Bee-ophrys." In all cases, however, it is really the posterior petal which forms the lip in front, instead of being a true anterior one. So that these very exceptions add additional reasons for accepting the theory. There is yet another coincidence with regard to irregular flowers. They are almost invariably situated close to the stem in the form of a spike; so that an insect has no alternative in coming from the front. On the other hand, regular flowers are either terminal as a tulip, or if on a raceme as the currant and lily of the valley, there is nothing to prevent an insect resting on any part of it when alighting from any direction. It is not at all uncommon to find the terminal flower on a spike of aconite, larkspur, or horse-chesnut to be quite regular. M. Vilmorin has succeeded in fixing this peculiarity in the foxglove ; which, besides its row of flowers of the usual form, is surmounted by a large bell-shaped one at the summit. It not infrequently happens that the flowers of labiates, as of the salvia, are accidentally quite regular (Fig. 46). The fifth stamen is sometimes also restored.

Now let us note a fact about stamens. In the majority of flowers the corolla forms the landing place. Sometimes, however, there is no strictly anterior petal, so that the insect visitor cannot alight on a single enlarged petal, but stands on

1 The twisted inferior ovary, which causes the reversed position of the flower of Orchis, can be seen in the figure No. 22, in Grant Allen's book, p. 126. 
THE ORIGIN OF FLORAL STRUCTURES. 151

the stamens instead. When this is the case, they all, together with the style, bend down, forming a sort of horizontal and elongated $S$, thus $\sim$. This gives them sufficient strength to carry the bee. It occurs in the horse-chesnut, rhododendron, some lilies, amaryllis, etc. The $\forall$ stamens are said to be "declinate."

Sometimes there is a petal below the stamens, but the insect has found it more convenient to stand on the latter, and as nourishment now seems to be withdrawn from

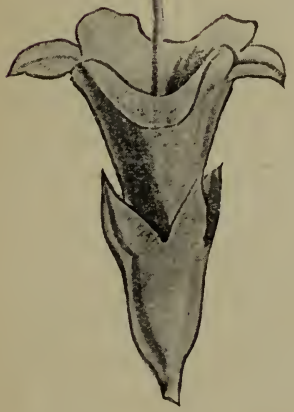

$a$

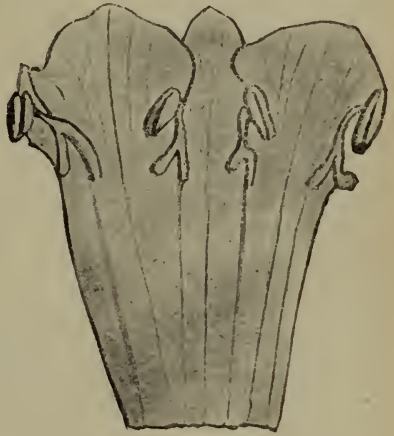

$b$

FIG. 46.-Regular Salvia ; $a$. complete flower; $b$. corolla laid open, show ing four perfect stamens (the fifth, not developed).

below to strengthen the filaments, the anterior petal becomes dwarfed and reduced in size, as in Amaryllis and Speedwell, or vanishes altogether, as in the blossom of the horse-chesnut.

In some flowers the bee hangs on to the stamens, 
as in Rosebay, and the side petals being, so to say, in the way, have got dislocated, and look as if they were pushed aside.

This occurs in many flowers, besides the rosebay, as Dictamnus (Fig. 47), and Clerodendron.

Now it may be asked, what evidence have we that flowers can respond to mechanical irritations,

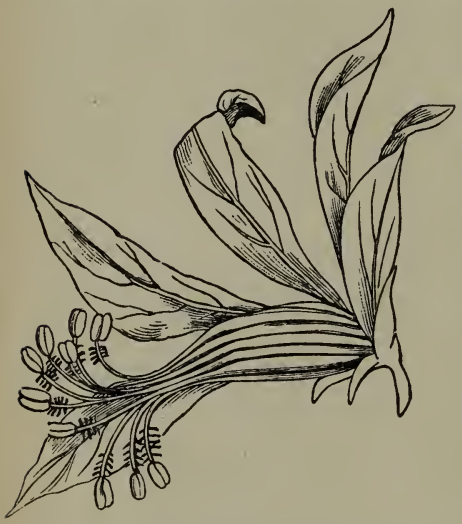
and so build up floral structures in adaptation to insects. Well, it is not altogether a speculation. First, we have seen how leaves and stems respond to strains, and put on mechanical tissues to meet them. Thus tendrils completely alter their forms and structures under

FIG. 47.-Dictammus: showing declinate tensions, as of the stamens and "dislocated" petals.

Virginia creeper. At first it consists of slender branching threads, but as soon as it has its hooked tips in contact with the roughnesses on the surface of a wall, the tips develop adhesive pads or discs, while the branches of the tendril become corkscrew-like, and greatly thickened.

Irritability of protoplasm, with responsive action, are general phenomena in the vegetable kingdom, so that one can draw conclusions based on numerous probabilities, which is practically equivalent to a demonstration. 
THE ORIGIN OF FLORAL STRUCTURES. 153

Moreover, we must remember that the correlations between the flower and the insect are not confined to one particular only, for they run through all parts of it. Thus, we have seen how the calyx and corolla of sage are in agreement; and the stamens are so placed and constructed as to strike the bee with the anthers in a certain place. Then, again, the stigmas are so situated, that they must hit the bee precisely where the pollen had been previously deposited.

Lastly, the position of the honey-gland is exactly where it should be for the bee to have ready access to it.

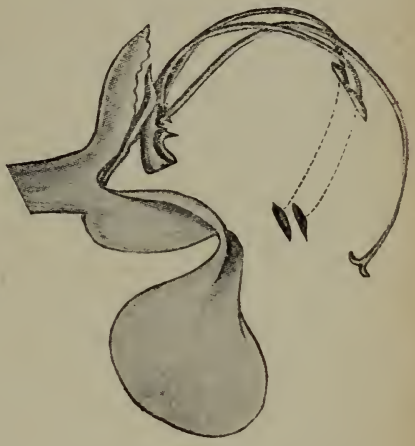

Fig. 48.-Salvia. Hood of Corolla removed, to show stamens and their action.

I will here illustrate two cases of "closefitting" adaptations, if I may so call it. First let us take the sage or salvia. There are only two stamens, supported on very short filaments (Fig. 48), but the "connective," which unites the anther-cells, is extraordinarily developed into a curved rod, which moves up and down as on a pivot. The uppermost anther has pollen, but the lower one has none. When a bee enters the flower her head strikes the spoon-shaped empty anther-cell, so that she sets the connective moving, which, then, brings the polleniferous anther down upon her back (Fig. 49). 
The other flower is called Duvernoia, and the accompanying figure No. 50, will explain matters. Looking at the left hand figure, $a$, one might ask, For what use is this great irregularity of the corolla; and why and how has it come into

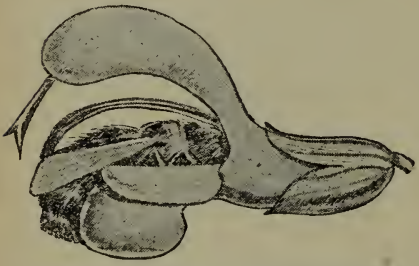

Fig. 49,-Salvia. Bee within Corolla, and connectives depressed.

existence? And no answer is forthcoming. Now, turning to the right hand figure, $b$, we see one use at least. The weight of the bee must be very great; and the curious shape of the lip, with its lateral ridges, is evidently not only an excellent landing-place, but is so constructed as to bear that weight. Moreover, the two walls slope off, and are gripped by the legs of the bee, so that it evidently can secure an excellent purchase, and can thus rifle the flower of its treasure at its ease.

There yet remains to be briefly considered the converse of the preceding facts. If the adaptations to insects in a flower have been brought about by the insects themselves, then, if the irritations be not kept up, in consequence of insects ceasing to visit them, it would be not unreasonable to suppose that they would revert to some less complicated form. And this is precisely what appears to be the case. Innumerable flowers are now very inconspicuous, but they still retain a corolla, which was formerly the attractive organ, as in such weeds as shepherd's 
THE ORIGIN OF FLORAL STRUCTURES. 155

purse, hedge-mustard, chickweed, etc. These have become more or less adapted to pollinate themselves. Consequently they have no fear of not setting seed, as is the case with most orchids, which are absolutely dependent upon visitors. Their degradations are seen in the minute size of the flowers, and in a number of peculiarities, which will be summarised in another chapter.

Lastly, being independent of

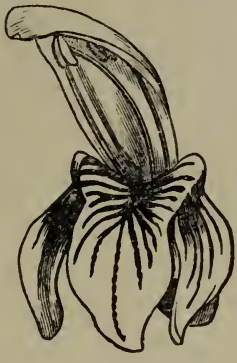

$a$

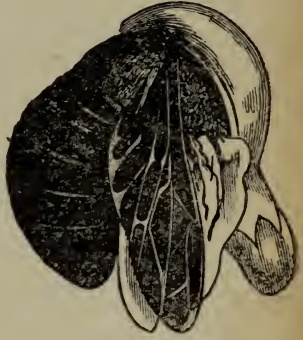

$b$

Fig. 50.-Duvernoia. insects, they are more widely dispersed than are insect-fertilised plants. Many of our common weeds have become cosmopolitan, being scattered over the southern hemisphere as well as the northern. 1

The theory advanced in this chapter may be applied in explanation of "mimetic" flowers. These are of many different families, but imitate one another in their general appearance, though the structure, when examined in detail, is very different. A few of the following have been referred to in another connection, but may be

${ }^{1}$ If the reader desires to read more of the subject of this chapter, he will find it in the author's "Making of Flowers" (S. P. C. K., 2s. 6d.), and also "The Origin of Floral Structures" (K. Paul \& Co., 5s.). 
here quoted in illustration of the peculiarity of mimicry.

First, with regard to bracts as imitating petals and collectively a corolla. They are often coloured as in the winter flowering, familiar decorative plant, Poinsettia, in which the true flowers are very minute and quite inconspicuous were it not for the brilliant scarlet leaves or bracts. The Everlastings supply another instance in which the coloured bracts of the involucre are often mistaken for a corolla. In the cornel, there are four white bracts in some species surrounding numerous minute flowers, rendering the inflorescence exactly like a white flowered clematis. A species of greenhouse spurge, known as Euphorbia jacquiniceflora, has a little cup with five scarlet projections on the rim exactly like a bright little scarlet-petalled flower. But the cup is of the nature of an involucre like that of the French marigold, and contains both male and female flowers within it.

The familiar pea-blossom is imitated by several plants of no relationship whatever. Thus the milkwort has been called "falsely papilionaceous;" the latter term means "like a butterfly," and has been applied to the corollas of the Leguminous family.

If we turn to the Labiates, and examine the common white dead-nettle, the four stamens will be found erect under the posterior hood; but in some foreign genera, as in the genus plectranthus, grown in greenhouses, either for its coerulean blue flowers or coloured foliage, the stamens lie horizontally, concealed in a boat-like lip; but of 
course the corolla is really gamopetalous, and not polypetalous as in the pea.

There is also a genus in the Fox-glove family, often grown in gardens as an annual, called Collinsia bicolor, which has a flower precisely constructed as the last mentioned of the Labiates. It thus closely mimics a pea-flower. Some kinds of S. African Pelargoniums also are not at all unlike blossoms of the Pea family.

There is an orchid of $\mathrm{S}$. Africa known as Disa Cooperi with upturned spurs, so that the spike of flowers might easily be mistaken for one of larkspurs.

Among Monocotyledons, the familiar form of a flower of the crocus is imitated in other families than that to which it belongs; as, e.g., the Colchicum, which is actually called, though wrongly, the autumn crocus. In a third family is a plant with a yellow flower looking like a crocus growing in the east of the Mediterranean regions called Sternbergia lutea.

When we compare the structures of flowers of plants belonging to the Labiate family with many of the Fox-glove family, there are very close resemblances. Thus, for example, the four erect stamens of the dead-nettle standing up under the posterior hood is paralleled by the stamens in the snap-dragon, fox-glove, toad-flax, etc. In both is the landing-place or lip present, and the honey-gland in front just where the insect will find it.

Yet the structure of the pistil is so totally different, yet uniform in each family respectively, that the conclusion is inevitable that all the genera 
have differentiated from two distinct stocks since the pistils characteristic of each family had been evolved.

I have already called attention to the great number of plants of many distinct families in which the stamens are declinate. Now all these facts conspire to prove that they have come about because more or less similar insects have repeatedly visited widely distinct plants of many orders. Then the flowers presumably responded, and within the limits permissible by their structures, have acquired certain resemblances which render them imitative of one another.

It may be here added that mimetic flowers are only one instance of this peculiarity in the vegetable kingdom. I shall have occasion to show that it occurs abundantly in leaves and other organs of plants, but in every case the principle is the same, that the resemblances of structure have been brought about by the plants having lived for many generations under the same external conditions, to which their living protoplasm has responded, and so built up structures best suited for them under the circumstances.

I have alluded to the fact that when flowers are habitually visited on one side, then such flowers are always irregular; but that if they come from all points of the compass then the flower is regular. I have also called attention to the fact that terminal flowers of spikes bearing normally irregular ones are sometimes regular.

Now we cannot make an irregular flower out of a regular one. Nature probably required many generations of the same insect-visitors to 
THE ORIGIN OF FLORAL STRUCTURES. 159

effect this change ; but flowers normally irregular in nature not infrequently have re-acquired regularity under cultivation. In other words, in the absence of the native insects of the country from which the flowers have come, they have reverted to the ancestral form. This is, of course, only of the nature of negative evidence, but of importance as far as it goes.

Dr Masters observes, in his work on "Teratology" (i.e. on the monstrous changes undergone by flowers, about which I propose to add a chapter), that in cultivated pelargoniums, the central flower of the truss frequently retains its regularity of proportion, so as closely to approximate to the normal condition of the allied genus geranium. This resemblance is rendered greater by the fact that, under such circumstances, the patches of darker colour characteristic of the ordinary flower are completely wanting, the flower being as uniform in colour as in shape. Even the nectary, which is adherent to the upper surface of the pedicel in the normal flower of pelargoniums, disappears, sometimes completely, at other times partially. The direction of the stamens and style, and even that of the whole flower, becomes altered from the inclined to the vertical position. In addition to these changes, which are those most commonly met with, the number of the parts of the flower is sometimes augmented, and a tendency to pass from the verticillate, or whorled to the spiral arrangement is manifested.

All the differentiations in an ordinary lateral blossom of pelargonium brought about by insect 
agency are, in the above instances, reversed, in consequence of the flower assuming a terminal position.

A more complete illustration of the effect of manner of growth and the distribution of nutrition could not well be given, showing how all the features of irregularity acquired by the ordinary form must have been induced or impressed upon the flower when growing laterally and easily visited, but from the front only; but that they are readily lost, as soon as the sap can be distributed radially, and so cause the parts to grow symmetrically round the now vertical axis.

Besides the occasional appearance of one or more terminal and regular flowers among a truss of irregular ones, it is the object of florists to induce all the blossoms of many irregular flowers to become regular. Thus cultivated pelargoniums, gloxinias, azaleas, pansies, etc., which are normally irregular, tend to become regular and quite circular in outline under cultivation, and so lose all their characteristic features.

In all these cases, I am inclined to recognise negative evidence in favour of the theory advanced; in that, presuming the characteristic irregularities to have been brought about by the agency of insects, and through the crossing of distinct flowers by these creatures, and that the irregularities have arisen under the various pressures, etc.; then, under cultivation, though they may be repeatedly crossed by man-the process, however, not being effected in the same way as by insects, and consequently the causes of irregu- 
THE ORIGIN OF FLORAL STRUCTURES. 161

larity being wanting-the flowers now revert to their ancestral forms, while ample supplies of nutriment doubtless play an important part in the process.

A good illustration of this reversion is seen in the cultivated gloxinias. These have pendalous tubes, with an irregular border to the corolla, and four stamens; but in 1842, one flower appeared with an erect tube, symmetrical border, and five stamens, a perfect reversion to regularity. This has now become a constitutional affection; for when the flowers of a drooping blossom are fertilized with their own pollen, a large number of the seedlings will bear the erect, regular form of flower.

As a remarkable illustration of the sensitiveness of the living protoplasm to external mechanical irritation, the following case in which regularity was reacquired may interest the reader. Clerodendron is a plant often cultivated in which certain caterpillars take up their abode within the tubes of the corolla. 'T'he irritation induced by their presence brings about a hypertrophy of the corolla, which now assumes a regular form, while the filaments and style are likewise affected, becoming thicker than in the normal, irregular flower.

An irregular flower may become regular, not by reversion, but by increasing the irregularity, which belongs, it may be to one petal only, till all the petals are alike; so that regularity is restored, but not the primitive form of the flower. This peculiarity is particularly common in the calceolaria, toad-flax, and snapdragon, as 
well as other plants. Linnæus, who observed it, called it "Peloria," a word signifying "monstrous."

We have seen how terminal blossoms are often regular; and it will be found that when snapdragons assume this pelorian form, they occur as the middle flowers of three-flowered groups instead of a raceme, of which the central one is regular, while the lateral ones are normal and irregular. Though often sterile, Darwin succeeded in raising sixteen plants of a pelorian variety of snapdragon, artificially fertilised by its own pollen, all of which were as perfectly pelorian as the parent plant.

That peloria is due to hypertrophy is also seen in the fact that it always arises by multiplication of the normally enlarged organ. Thus, in toad-flax and snapdragon, all the petals are spurred or pouched; in pelorian larkspurs and aconites, it is the spurred and hooded sepals which are repeated; and in papilionaceous flowers of the Leguminous family, it is the standard which is multiplied five times, etc. Moreover, an abnormal increase in the number of petals and stamens often occurs in pelorian pelargoniums, horse-chesnut, eta. 


\section{CHAPTER XV.}

ADAPTATIONS FOR POLLINATION OF WILD FLOWERS.

THE ancients knew of the necessity of pollinating the date-palm and some other trees of which the sexes are separated; for Pliny thus wrote in the first century, A.D., copying from Theophrastus of the 4th, B.C._-"The more intelligent inquirers into the operations of nature state that all trees, or rather all plants belong to either one sex or the other; and this manifests itself in no tree more than in the Palm." The Persians also fertilised the Turpentine tree. But they often called two varieties or species of a plant male or female, without any reference to the structure of the flowers, whatever; so that in the case of Mercury the real male plant was called female and vice versa!

The knowledge of the true functions of the stamens and pistil appears to have been lost or at least unknown in the middle ages; though Bacon being familiar with Greek and Roman literature quotes the above suspicion that all plants were sexual. It was recorded of Sir T. Millington, Professor of Botany in Oxford, that he was the first since Bacon's time to point out the true functions of the stamens and pistil. Even cross-fertilisation had been previously suspected, as Perdita in "The Winter's Tale" speaks of "streaked gilliflowers, which some call Nature's Bastards." Prof. Bradley of Cambridge, in 1725, describes varieties which 
were fertile when crossed, but he thought hybrids between two species, like mules, were always infertile. He describes the inflorescences of the hazel, which he rightly thought was pollinated by the wind; while bi-sexual flowers he regarded as being always self-fertilised. Insect agency in pollinating was not perceived until Sprengel published his work full of interesting illustrations in 1793. The pursuit of this subject was not followed until Darwin took it up and published his work on "The Fertilisation of Orchids," in 1862 ; and subsequently, his "Cross and Self-Fertilisation of Plants," in 1876.

Here, unfortunately, he was led to misinterpret certain facts. Self-fertilisation was formerly thought to be universal ; but Darwin drew a precisely opposite conclusion and said that "Nature abhors perpetual self-fertilisation." Mr Grant Allen, following Darwin, says in his "Story of the Plants," of plants which fertilise themselves:"Such flowers are almost always poor and degenerate kinds, the unsuccessful in the race, the outcasts and street arabs of plant civilization." 1 This is really so misleading that I must try to explain the true state of the case; I will then illustrate the disadvantages to flowers in having to depend upon the capricious visits of insects, and the great advantages in being independent of them ; for all idea of "injuriousness" arising from self-fertilisation, as Darwin imagined, is without any basis of fact.

${ }^{1}$ P. 91. For various methods of pollination of flowers, I must here refer the reader to his chapters on "Marriage Customs." 
The first thing to be noticed is that flowers specially adapted to be crossed are conspicuous or scented or attractive in some way or other to these insect visitors. On the other hand regularly self-fertilised flowers are quite unattractive, being minute and devoid of scent and honey. We often call them "weeds," as groundsell, shepherd'spurse, chickweed, black solanum, etc., etc. As to the relative abundance, these latter far surpass the former : and if such weeds be allowed to grow in a garden, they soon prove to be masters of the situation and smother the others. They are often annuals and small, and of no beauty; but as a healthy life and to bear plenty of seed is all that concerns plants themselves; it is very easy to see that they are by far the best off.

Crossing acts as a temporary stimulus; consequently it is an invaluable aid to florists, who raise "finer " plants, more beautiful and variously coloured flowers, etc., thereby rendering them more marketable : but they cannot hold their own in a severe struggle for life with the selffertilising weeds. Common experiences have shown that Darwin was quite wrong in this respect. Moreover, Darwin's experiments, carried on in a few cases for some years, proved that the stimulus of crussing might enhance the size and fertility for a time; but it gradually lessened till the self-fertilised plant (i.e. artificially so pollinated) beat the "intercrossed" in every way. Thus, for example, with Ipomcea purpurea (called Convolvulus major by gardeners), taking 100 to represent the heights of the "crossed plants," 1

${ }^{1}$ I.e. plants raised from the seeds of crossed plants. 
they were in the second year as $100: 76$ for the self-fertilised, and in the third year the proportion was as 100:68. But when we take the nine years in groups of three each, and get triennial averages; the result was as follows:-100:74; $100: 78 ; 100: 82$. Hence the average ratio was becoming approximately equal to unity as the generations went on.

Similarly with fertility. The first two generations were as $100: 93$; the next two as $100: 94$; the fifth gives $100: 107$, and the eighth as 100 to 114. Hence self-fertilisation is better than intercrossing in the long run. We shall see that there are other features corroborating this.

Now for a few words on the inconveniences connected with specialized flowers. Flowers well expanded and visible to insects, with the honey exposed, as might be anticipated, receive most visitors. But the aconite, with a very irregular flower, is visited by humble-bees only ; whereas the buttercup is visited by more than sixty species of insects. Moreover, while the former cannot fertilise itself, for the stamens have shed their pollen before the stigmas are ready, the latter can do so. Again, most orchids are so constructed that the pollen-masses cannot reach the stigma spontaneously at all; and they set no seed if unvisited. A Dendrobium, growing wild in Australia, bore 40,000 blossoms, but only one pod was produced. Yet those orchids which are adapted to fertilise themselves, as our own Beeophrys, set seed abundantly.

The ordinary flowers of the violet do not set seed : but numerous "buds" which never open 
are formed on runners concealed beneath the leaves. These set an abundance of seed, and are therefore called "cleistogamous," a word signifying " concealed unions." They have stamens and a pistil, but no corolla.

Lastly, tracing the distribution of plants over the world, the regularly insect-visited plants of Great Britain and Europe are more or less restricted in range through the northern hemisphere; whereas numerous weeds are well nigh cosmopolitan, even throughout the southern hemisphere.

Now Darwin admitted that he had neglected to study these insignificant looking weed-like plants, so that we must reverse his dictum, and look upon them with a more favourable eye, and not be misled by what may seem to us to be "fine" and "beautiful," and therefore necessarily must be the best thing for plants to be.

Mr G. Allen has given so many examples of "marriage customs" among flowers that I do not wish to trespass on his grounds, but rather to fill up one or two gaps. One is to show how, in making flowers adaptable to insects, Nature has brought into play ordinary mechanical forces; the other point is to give a few instances of special adaptations to secure self-fertilisation, as these are often as interesting as those for crossing.

As one of the many examples of "springs" we may take the stamens of the Lucerne. ${ }^{1}$ The little pea-like flower offers, as usual, the keel-petals and wings, which are firmly locked

1 Any other species of Medicago to which this belongs will do. 
together, as a landing-place, as they project horizontally forwards; but the moment a bee alights the tension of the spring is overcome, and the petals drop; at the same time the included stamens rise up forcibly and dash the pollen on to the bee.

In a tropical genus of orchids known as Catasetum the pollen-mass has a curved stalk held in position till a bee comes. She liberates it, when it immediately flies out and is fixed by a gummy disk at the base on her back. If released artificially it will fly off to a distance of two or three feet. It might be called "the catapult action."

Levers occur frequently. The "third" kind, as it is called, is seen in declinate stamens of the horse-chesnut and rhododendron, as described in the last chapter. The weight of the bee on the projecting ends of the filaments is similar to a weight held out at arm's length in the hand. This is by far the commonest arrangement.

The "first" kind of lever is best illustrated by the stamens of the sage, ${ }^{2}$ described in the last chapter; and some species of Calceolaria; ${ }^{3}$ in which there are only two stamens; the filament is very short; but the "connective" between the anther cells is drawn out into a short rod, the upper end carrying one cell, and the lower end, the other. This connective oscillates in a vertical plane. The two connectives thus form

1 This is described and figured in Darwin's work, "The Fertilisation of Orchids."

${ }^{2}$ Any species of Salvia to which the sage belongs will show it.

3 Calceolaria Pavonii. 
two levers. When a bee alights on the "slipper," her head depresses the lower arm; the upper arm then swings forward and brings the polleniferous anther down upon her back, where the stigma will first strike it, and so receive the pollen from a previously visited flower.

In the scarlet-runner we find a lever and a screw combined. The keel petals instead of being straight, have a rectangular bend, and their extremities twisted spirally. The pistil, which is included within them, has its style coiled in a corresponding manner. Just beiow the stigma is a tuft of hair upon the stylt. On looking at an expanded flower from the frunt, it will be noticed that the wing petal on the left is smaller than the right one, and that the orifice of the spirally coiled keel projects over the left or smaller of the two wings. The bee alights upon the smaller, her weight depresses the keel, thus acting like a lever, the spirally-twisted style passes up the screw, sweeps out the pollen, and deposits it on the bee. The reader must take an early opportunity of examining a flower; the process is easily imitated if he raise and depress the left petal with his finger and thumb, when the stigma will protrude and retire as he depresses and raises the wing petal.

With regard to special adaptations to secure self-fertilisation, this is best seen in cleistogamous buds, as of the violet balsam, and woodsorrel; but many flowers become self-fertilising in inclement weather, as the chickweed, which then often fails to open its buds, though in fine weather the little white flowers are fully expanded. 
Self-fertilisation is often secured by an inflection of the style, so as to bring the stigma into actual contact with the anthers. Buttercups illustrate one of the many cases of flowers being both capable of being crossed, but equally able to fertilise themselves on the other hand.

The stamens may at first spread away from the pistil ; but afterwards bend over it; so that if it have not been crossed the flower can be assured of self-fertilisation, as with the hawthorn, etc.

A very common result in conspicuous flowers usually visited and crossed by insects, is that the stamens are stimulated more rapidly into maturity than the pistil. The consequence is that the pollen is mostly or entirely shed before the stigma is ready to receive it as in Aconite. Such flowers are called "protandrous" (i.e. males first). This is obviously another great disadvantage to such flowers, in case the insects fail to come.

Now various causes may reduce the time between the maturation of the anthers and the stigmas. When this occurs, the flower at once becomes perfectly self-fertile. In some cases, indeed, the pistil matures first, and so is in readiness to receive it, as soon as the pollen escapes. Such a flower is called "protogynous" (i.e. female first). Another hindrance to a ready fertilisation in the absence of insects is a dimorphic condition ; the plant having two kinds of flowers, as has the primrose, the blossoms on different plants being called "thrum-eyed" and "pin-eyed." In the former the five anthers protrude from the corolla-tube, in the latter the globular stigma is 
only seen at the orifice. In the former the style is very short, and so are the stamens in the latter. ${ }^{1}$

If an insect visit either kind, the pollen is caught at a particular spot on the proboscis, which is touched by the stigma of the other kind.

Under cultivation, and sometimes when wild, the flowers become "bomomorphic," i.e. of the same form ; the anthers now standing at the level of the stigma. The difficulty of pollination is overcome and self-fertility ensues.

In the species of wood-sorrel which was sent to Malta in 1806, the flowers are trimorphic; but only one of the three forms arrived. It has never been known to set seed in the northern hemisphere at all; but has overcome the difficulty by propagating itself by little bulbs. By this means it has spread all round the Mediterranean Sea as already observed.

Our purple loosestrife is another instance of trimorphism. The stamens and styles are of three lengths in as many flowers, and always on separate plants, respectively. Each pistil has two sets of stamens to match it. Darwin found that the "mid-styled" form was the most fertile, but when the tallest pistil (long-styled form) was artificially fertilised by pollen from the shortest stamens or vice versa, little or no seed was produced.

Though this common species of Lythrum is trimorphic, another is dimorphic, and a third is homomorphic and self-fertile.

'For further details, see Grant Allen's "Story of the Plant," p. 107. 
In a species of Dead-nettle, ${ }^{1}$ the flower in summer is usually completely expanded; but it often happens in early spring that the corolla does not open. When this is the case the forked stigma is curled back and lies between the anthers and is readily self-fertilised. The same thing occurs in some species of sage.

In the deserts near Cairo, insects are exceedingly rare. The consequence is that the flowers of such plants as grow in the dry watercourses are all self-fertilising; though belonging to families, which, in other countries have conspicuous flowers and plenty of insects to visit them.

Thus the genus Cassia, the leaves of some species of which constitute the drug, Senna, belongs to the Pea-family and usually has large yellow flowers adapted to receive the visits of insects; but there is a species, C. obovata, the flowers of which are very inconspicuous, greenish and rarely open. There is a long style which is doubled back upon the ovary, the stigma lying among the anthers. The flower is, in fact, almost cleistogamous.

The general conclusion arrived at by a study of the plants of the desert, is, that flowers which have been adapted to insects, and therefore endowed with conspicuous and brightly coloured, often irregular corollas, honey and other details, have to a great degree lost these features by a degenerating process. For if those structures which are correlated with insects were originally brought into existence by these visitors themselves, as I have endeavoured to prove, and if

${ }^{1}$ Lamium amplexicaule. 
they be not "kept up" by the constantly applied stimulus of their visits, then the protandry, so general in conspicuous flowers, gives way, homogamy follows, and self-fertilisation is the final result, coupled with numerous degradations in all the floral organs.

I must now add a few remarks upon honey glands which attract insects.

Bees and other insects visit flowers for tne sake of the honey or pollen or both ; the pollen being made into "bee-bread" for the grubs to live upon, as it is a highly nutritious substance; but with regard to honey the question might be asked why is it formed at all? It has been suggested that it is an excretion of superfluous matter; but it is a purely carbonaceous substance being only a mixture of glucose or non-crystallizable sugar, and of the crystallizable cane sugar. Now sugar is the material into which starch, when made in the leaves, is converted to render it transmissible over the plant. As soon as it arrives at the growing parts it is converted into cellulose of which the cell-walls are constructed ; so instead of honey being a waste product, it is really a valuable building material.

I have already observed that the honey-glands in a flower are always situated just where an insect can best reach them. If the flower be regular then the glands are situated regularly round the flower; e.g. one on each petal of the buttercup, five glands on the receptacle of geranium ; a regular circular honey-trough in the raspberry, etc. But in irregular flowers it has particular sites only, usually on the anterior side, if a flower 
is visited from the front, as may be easily seen in the dead-nettle or other labiate, Orchids, etc.

Secondly, when a flower reverts to self-fertilisation, the honey may be no longer secreted at all. The honey-secreting buckwheat may be compared with its ally the honeyless knotgrass.

The conclusion is, that the honey-glands have resulted from the irritation of the proboscis of insects; for they still probe flowers for juices even when they do not secrete honey, as in the spurs of our common orchids; and flowers which produce no honey in England, may do so in other countries. Thus we are told that the laburnum has produced a honey-gland outside the closed staminal tube in Germany, and that they are developed on the sides of the carpels of the marsh marigold. Here, however, there is nothing of the sort, these flowers not being visited by bees as they are on the continent.

Honey-glands, or nectaries as they are called if on floral organs, may be situated anywhere. Thus, each sepal of the lime blossom forms a little boat-shaped structure, which becomes full of honey. In the buttercup family, it is the petals which are more or less modified to form nectaries, as the spurred petals of larkspur, and "crosiers" in the aconite, little tubular honeypots in hellebores, etc. In violets, the honeysecreting organs are two appendages to the front stamens only. In rhododendrons it is the base of the ovary which secretes it. In the majority of instances it is the floral receptacle which bears the glands. If the ovary be inferior, as in umbellifers, then the summit of the ovary 
becomes the honey-secreting organ. Such is also the case in Canterbury bell, in which the broad bases of the filaments form a dome over it.

It may be mentioned here that honey is not confined to organs in flowers, for it may be secreted by leaf-stalks and stipules. Bees and flies may be seen very actively engaged in sucking honey from two glands at the base of the leaf-stalks of the common laurel; while beans, vetches, and species of begonia secrete it by their stipules.

That they may have been caused by irritation is countenanced by the fact that insects have been seen to probe between the sepals and stamens of the wood anemone, which secretes no honey, for the sake of the juices wherewith to moisten the pollen for which they come, so that it is feasible to think that this procedure was the actual cause of the origin of nectaries, the result of a wound constantly repeated and kept up, being a flow of a sweet secretion, which has thus attracted insects, and induced them to repeat and perpetuate the process.

Several facts indirectly support the above conception; thus the little adhesive dises at the ends of the tendrils of the Virginia creeper are not formed till contact has taken place with a wall, when the secretion is made to fix them. But the tendency to secrete at these spots is hereditary.

In the other species from Japan of this same genus, the discs are actually formed before contact. In the case of a mutilation, when it has been once made, the place heals over, and there 
is an end of all special vital action at the place. If, however, the same place be induced to secrete by constantly repeated irritations, as the same flower is repeatedly visited over and over again before it fades, and the flowers of its offspring have to undergo the same process, year after year, generation after generation, it is at least a reasonable surmise that there will at last be caused a permanent flow of fluid to the place, with a corresponding modification of structure, and so the nectary becomes established and an hereditary feature.

If, however, from any cause the flowers become neglected, then the nectaries and glands degenerate, and cease to secrete honey, and it may be ultimately disappear.

One of the important adaptations to insects resides in the colours of wild flowers.

When we notice the immense variety and shades of colours in wild, and still more in cultivated, flowers, the questions arise-How did they get them? what was the most primitive colour? and if they have been evolved, what was the order of their evolution?

When we remember that the spore-cases and spores of the Club-mosses are yellow-and it was from members of some of these higher types of Cryptogams that Gymnosperms were evolved -and that the anther-cells of Cypress, and the whole anther scale of pines, as well as all the pollen-grains of Gymnosperms, are yellow ; again, when we come to Dicotyledons, and find the prevailing tint of stamens is the same, we seem to gather probabilities in support of the view 
that, after green, yellow was the primitive colour.

Nature next, it is believed, introduced reds, and only lately, so to say, succeeded in manufacturing first, purples, and lastly blues, if we may judge from the comparative rarity of that colour. Moreover, when flowers individually change from red to blue, as many of the Borage family do, such as the lungwort and some species of forget-me-nots, etc., it is always in that order. It may even start with yellow, as in the case of Myosotis versicolor.

Conversely flowers may revert; and when that is the case, yellow is the usual colour adopted, as in Chrysanthemums. This is the original colour of the wild chrysanthemum of Japan or China, a small flower about an inch in diameter.

Pale tints, or a total absence of colour, may seemingly occur as a variety of any plant. It is often a concomitant of habitual self-fertilisation, in cases where the variety or species is a degradation from some conspicuous and brightly coloured insect-visited form. White-flowered individuals often appear as "sports" among seedlings, and have a peculiar importance to cultivators. For it has been found that it is useful as a starting-point when great variation in the colours of flowers is required. Thus, the late M. Vilmorin says, that "in ten examples of variegation, which were produced under my own observation, the course was always the same. The original plant, with flowers whole-coloured, gave in the first instance a variety of flowers 
entirely white; afterwards variegations were produced from this white variety on its returning towards the coloured type. By careful selection the pure white type can be fixed. It is only among the white varieties not completely fixed that the variegations make their appearance; at first they exhibit narrow pencillings, the coloured portion being only one-tenth, and sometimes only one-twentieth of the whole surface; but then, in the following generation, the coloured portions begin to predominate, variegation never coming direct from the coloured original."

The value of a white variety is seen in another way, in that it seems to induce variations of colour by crossing. Thus no hybrids were raised from the old bronze-red and striped flowers of Abutilon until a white variety appeared, when, by crossing it with this, pale and dark pink, pale orange, bright carmine, salmon, orange red colours, etc., appeared among the flowers of seedlings.

An analogous feature occurred with Mr Veitch in treating his Rhododendrons from the East Indies. R. Javanicum has orange coloured flowers, but those of the species called $R$. jasminiflorum, from the long, tubular jasmine-like corolla, are pure white. When the former was crossed with the pollen of the latter, the offspring bore rosecoloured flowers. On another occasion, by crossing an orange-coloured hybrid with a white flowered one, a pure yellow flowered offspring was obtained. Hence, one effect of crossing a mixed colour, as orange with white, is to exterminate one of the colours. 
But many other forms have been raised of all sorts of shades of red and yellow, as well as salmon, etc.

Starting from a primitive yellow, subsequent colourations, especially under cultivation, appear to be a matter of nutrition, though we cannot yet explain how they arise, and we may infer that the prevalence of brighter colours in conspicuous flowers, which are regularly visited by insects, is due to the stimulating effects which they have produced, thereby causing more nutritious fluids to pour into the attractive organs.

Besides, however, this general result of brilliant colouring, there are those peculiar and special displays of bright tints distributed in spots and streaks in certain and definite places only. In regular flowers they are symmetrically distributed on every petal alike, especially at the base, so that, as in the Forget-me-not, while the limb of the corolla is blue the throat is bright yellow; but in irregular flowers these markings have been especially called " guides," for they are invariably over and in the direction of the honey-glands, being located on one side of the flower only. Thus spots commonly occur on the lip, if present, but in rhododendrons they are on the opposite side, where the insect must thrust its proboscis.

So that if my theory be true, all these effects are simply the direct results of the insects themselves. The guides are always exactly where the irritation would be set up; and they would, therefore, seem to be a result of a more localised flow of nutriment to the positions in question.

With regard to certain correlations which exist 
between colours and insect visitors, it has been observed that beetles affect yellows, as, for example, the meadow-rue, the ladies-bedstraw, and the yellow stamens of the rose ; wasps and carrion insects appear to prefer the dull reddish-brown flowers of Comarum of the Rose family, and the Helleborines and Figworts; while the more intelligent bees, etc., delight in purples and blues; and it has been thought that their selective agency has determined the survival of such special colours as they prefer. This has been probably the case, but we still want to know what is the immediate cause which induces one colour to change or give place to another.

As an illustration of the relative effects of crossing and self-fertilisation respectively on the production of colours, Darwin tells us that the flowers produced by self-fertilised plants of the fourth generation of carnations were as uniform in tint as those of a wild species, being of a pale pink or rose colour. Analogous cases occurred with the monkey-flower and convolvulus major of gardeners. On the other hand, the flowers of plants raised from a cross with a fresh stock which bore dark crimson flowers varied exceedingly in colour. The great majority had their petals longitudinally and variously striped with two colours. The reader will recall Perdita's observations on "striped gilliflowers," quoted above.

Uniformity and paleness are thus correlated with self-fertilisation; and since, whenever the latter process is persevered with, an increase of fertility follows, it is not surprising to find that 
such tints are usually accompanied by ân increased power of seed-bearing. Thus Darwin found that the proportional number of seeds per capsule produced by the plants of carnations of crossed origin to those by the plants of self-fertilised origin was as 100:125. Again, of snapdragon, the relative self-fertility of red and white varieties was as $9 \cdot 8: 20$; of the yellow and pale varieties of monkey-flower, the same comparison gave the ratio of $100: 147$. Lastly, pale flowered varieties of the scarlet geranium (Pelargonium) are notoriously great seeders.

Enough has now been said, it is hoped, to convince the reader that self-fertilisation is after all the most serviceable process to plants. If it be asked why have flowers become so wonderfully adapted to insects, the answer is that they cannot help themselves. The living protoplasm acts automatically and is compelled by its innate powers of adaptation to respond to the insect visitors, and the best result possible follows.

Man derives the benefit, for it has opened out an unlimited source of joy to him in vastly enhancing the beauties of nature; but, as we have seen, the "ends" of plant-life have been somewhat sacrificed for the result.

The adaptations to secure self-pollination are quite as curious as those for intercrossing, though they are often the results of degradation, as the process can be traced from intercrossed and showy flowers. I will here enumerate their principal features of degradation :-

1. The inconspicuousness of the flowers, even when fully expanded. 
2. The caly $\mathrm{x}$ and corolla are often only partially expanded, or not at all.

3 . The white or pale colours of the corollas, while specially coloured streaks, specks, "guides," and "path-finders" peculiar to intercrossed flowers are more or less reduced, if not absent.

4. The partial or total arrest of the corolla.

5. The mature stamens of the expanded flower retain in many cases the incurved, i.e. an arrested position which they had in bud; the anthers thus remaining in contact with the stigmas.

6. The stamens are often reduced in size and number, and the pollen in quantity.

7. The pollen-tubes may often be seen to be penetrating the stigmas, either from grains within the anther-cells or evidently derived from those of the same flower.

8. The partial arrest of the corolla and stamens in their rates of development, allows the pistil to mature with comparative rapidity.

9. The consequent early maturation of the stigma, so as to be ready before or simultaneously with the dehiscence of the anthers.

10. Little or no scent.

11. Decrease in the size or total absence of honey-glands, with consequent little or no secretion of honey. 


\section{CHAPTER XVI.}

FREAKS OF WILD FLOWERS,

I HAD occasion to speak of the origin of petals out of stamens, as shown by water-lilies, in which a perfect transition always occurs from one to the other.

Our garden plants and sometimes wild flowers are what is called "double," that is to say the stamens and carpels or both may be all replaced by petals, and in addition it is usual for them to be multiplied. Thus the wild stock has four petals, six stamens and a pistil of two carpels; but in a double flower of this plant, I have counted fifty-two petals and others which were still undeveloped in the middle. The flower, in fact, had tried to change from a "flower-bud" to a "leafbud," but consisting of petals instead of leaves. However, flower-buds can take on a further stage backwards and actually have all their members green. In such flowers the corolla may remain of exactly the same shape as when normally coloured, but quite green. It is then called "virescent." Such is not infrequently the case with blossoms of the honeysuckle which come out late in the season, when the weather is cold. A greater change occurs when the various organs, carpels, stamens, petals and sepals become actually replaced by true green leaves, though small in size. This is the case with the "green rose," sometimes cultivated as a curiosity, for it cannot 
boast of any beauty. The alpine strawberry has the same metamorphosis.

It often happens that the change is not completed, so that a stamen for example, may be replaced by a narrow green leaf still carrying a yellow anther along one side of it; or a carpel may be leaf-like above, but resembling an open pea-pod below, etc.

These abnormal cases indicate attempts at a reversion to primeval conditions; for it is an accepted doctrine that sepals, petals, stamens and carpels are really "homologous" with true leaves. That is to say, they and leaves are fundamentally the same thing, only each has grown up into the special organ required where it issues from the stem.

Now, among the freaks of flowers, any organ can, we might almost say, try to assume the form and function of any other. They do not always do it successfully, especially when sepals and petals make an abortive effort to turn themselves into stamens and carpels, for all they can effect is the production of abortive pollen and ovules.

Thus, to give a few examples, the calyx, being the outermost whorl of a flower, and the pistil the innermost, it would seem to be a difficult thing for the former to imitate the latter and bear ovules. A few instances have been met with, however, as in a certain garden pea, the five points on the top of the coherent calyx-tube grew out into styles and stigmas, while the lower part bore rudimentary ovules on the open edges; there being no attempt to close it up like a pod (Fig. 51).

The corolla coming next to the calyx seems an 
easier organ to imitate. Indeed some such freaks are cultivated. Thus in campanulas, the so-called "cup and saucer" variety is one in which, while the cup is the usual corolla, the saucer is a "petaloid" 1 calyx.

The monkey-flower, primrose and a form of Azalea are others which bear, what the gardeners call "hosein-hose" flowers. apparently have two perfect corollas one within the other; but in reality the outer is the calyx assuming all the characters, colour and shape, of a second corolla.

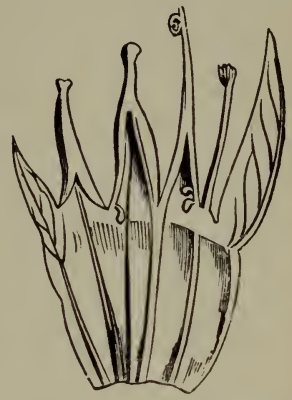

FIf. 51.-Pistiloid Calyx of Garden Pea.

We have seen that petals were originally formed out of stamens; because the first flowers had only stamens and pistils, and no corolla at all. In some freaks the corolla tries to turn itself back into stamens. Thus a fox-glove instead of having its usual tubular corolla, this was split up into ribbon-like pieces, all united below, each piece bearing an anther at the top (Fig. 52). Another case occured in a Campanula; while the tubular honey-bearing spurs of a columbine have been known to produce pollen.

A still stranger attempt at metamorphosis occurs when stamens actually become carpels. Thus, where wallflowers are extensively grown for the London market, there is always a number of "rogues" in the fields. These are useless for 1 That is "petal-like." 
sale, as they bear no corollas and remain like unopened buds ; but there is a curious malformation, in that the six stamens are all changed into carpels, being mostly more or less united together and bearing rudimentary ovules; these, however,

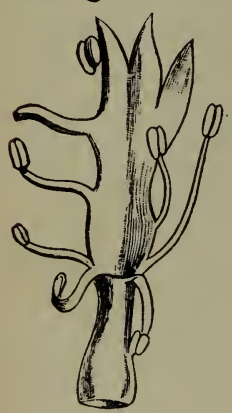

FIG. 52. - Staminiferous corolla of Foxglove. never appear to ripen into seeds. It is very doubtful if they could ever be fertilised; so too, poppies which have numerous stamens and a gobular pistil in their midst not infrequently bear a ring of abortive, miniature carpels round the central pistil. They are really metamorphosed stamens. Lastly, all sorts of abortive attempts can be found in Begonias. Sometimes the anthers are partially converted into stigmas; or petals will bear anthers or ovules; sometimes both on the same petal, which may still retain its normal colour, etc.

Pistils which are composed of one or more carpels, can be sometimes replaced by other structures, as petals or leaves, as stated above; but even the ovules can put on strange alterations; thus, those of a passion-flower have been known to contain pollen instead of an embryo; or anthers may replace them; as occurs in willows, etc. (Fig. 53) or a complete flowerbud, which, on expansion, splits the ovary, and a tuft of petals emerge. This occurs occasionally in the lady's smock (Fig. 54).

These freaks cannot be explained; we can 
attempt to express it without in the least understanding the "how," by saying that the life of a plant expends its energy normally, in different ways, as in making roots, leaves, and flowers. Of these last, some energy is deputed to make sepals, other to make petals, stamens or carpels, respectively. But, by some inexplicable cause, the "special energy" required for, say, petal-making gets confused with that required for making something else, and the two seem to clash and so spoil the work between them! Thus, in doubleflowers, the petalmaking energy overpowers that for making stamens, invades its territory and makes the initial protuberances

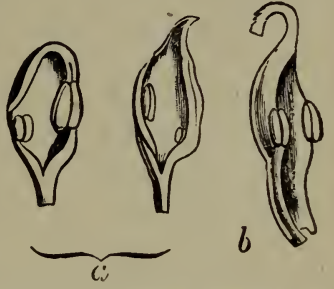

Fig. 53.-Unclosed ovaries with anthers instead of ovules. $a$. Willows ; $b$. lesser Celandine.

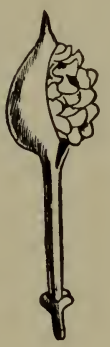

a

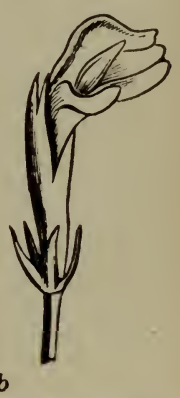

$b$ grow up into petals Fig. 54.-Petals replacing Ovules. instead of stamens.

An interesting case $a$. Lady's Smock ; $b$. Rhododendron.

occurred in the production of double rhododendrons. Mr Heal, Mr Veitch's assistant, who raised a large number of double forms, observed a single flower in a certain truss on a plant to have one anther only slightly petaloid. $\mathrm{He}$ im- 
pregnated the pistil of the flower with pollen from the other anthers of the same flower, this process being strict self-fertilisation. About fifteen seedings were raised, which bore quite or partially double blossoms.

Sometimes the "colouring-energy," as we may call it for want of a better expressiom, which as a rule undertakes the enhancement of the conspicuousness of the corolla, spreads to the calyx and so we get the "hose-in-hose" flowers. It may go further and influence the bracts below the flower. Hence in some scarlet-flowering salvias, corolla, calyx and bracts are all scarlet. In the cactus family (as in epiphyllum) there are numerous small coloured bracts outside, tracing them inwards, they seem to get larger and larger till the true petals are reached. There is no break between the series until we arrive at the stamens which introduce a sudden change of form. In several members of the buttercup family, there is no corolla at all, the calyx assuming its rôle is large and brilliantly coloured. Such is the case in clematis, anemone, winter aconite, and the marsh marigold.

In all these instances it will be observed that the transference of colours (of course, other than green) is a normal condition of things; but it is a freak in the case of the "hose-in-hose" varieties, and the "cup and saucer" campanulas. - In some plants the flowers are very minute, and would, both individually and collectively, supply little or no attraction to insects. Nature has often massed them together into a "head" and then rendered it more conspicuous by en- 
larging the outermost or "ray" florets. This is the common method in the great family of Composites, as seen in the daisy, with its white "ray" florets and small yellow "disk" florets."

In some instances of aggregation of minute flowers the outside bracts or "involucre" answers the purpose. Thus in the familiar "everlastings," it is the dry or "scarious" bracts surrounding the heads of florets which are white or coloured, and so supply the attractive organ. There are species of cornel which have very small flowers in a dense cluster, but are only discoverable by means of four large white petal-like bracts (Fig. 55). Again, Darwinia

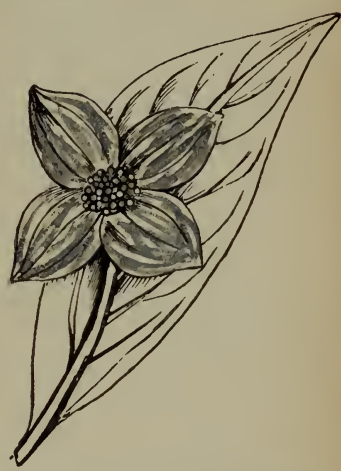

Fig. 55.-Species of Cornel with white bracts and minute central flowers. tulipifera (Fig. 56), a plant of the Myrtle family grown in conservatories, is so called, because it might be thought to bear tulips by the appearance of the flowers. These, however, consist of many striped-coloured bracts, yellow and red, within which are about a dozen very minute flowers.

A not uncommon freak is to find the characters of bracts carried down into the leaves. Thus, the large, single, white bract, called a "spathe," of the familiar "Trumpet-lily" is occasionally

$1 \mathrm{Mr}$ Grant Allen has described "How plants club together," in "The Story of the Plants," chapter x. 
accompanied by a second. The fact is that a second leaf has assumed this form.

So too, the actual coloration proper to a corolla may go down to the leaves. Thus a pelargonium happened to bear brilliantly

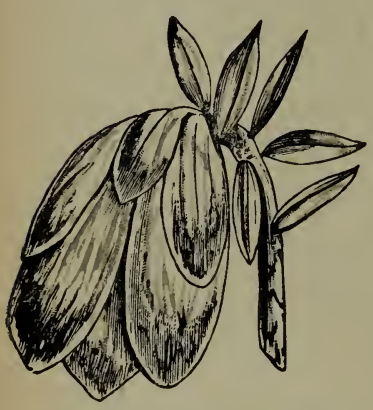

FIG. 56.-Inflorescence of Darwinia. coloured leaves, partly normally green but partly scarlet.

Bracts, being really arrested leaves, may reassume a true-leaf character.

This is often attempted in the common plantains, and occasionally in the umbellifers, etc. What is called the Green Dahlia is a "head" composed entirely of enlarged green bracts, the "florets" being all suppressed.

Similarly the "wheat-eared" carnation consists of the flower-stalks on which the bracts, usually consisting of two pairs at the base of the calyx, are multiplied to excess, the true flower being entirely wanting.

Another peculiar change occurs when an irregular flower becomes regular. One of the commonest plants to effect this alteration is the toad-flax. If now all the five petals become spurred, then the upper part of the flower vanishes, and the "lip" is repeated all round, forming a circular rim. Linnæus called this form "Peloria," a word meaning "monstrous."

This abnormal condition is exactly like the 
normal state of Columbine, all five petals of which are spurred.

But this flower can go backwards, and revert to its primitive condition by abolishng all the spurs; when the petals take the form of an ordinary leaf-like shape. Thus there is a cultivated form of Columbine in which this occurs.

The terminal flower of a spike of larkspur, aconite, snapdragon, horse-chesnut, etc., as has been already observed, not infrequently thus reverts to the primitive form. Sometimes, as in fox-gloves, two or more flowers become fused together and produce a regular bell-shaped structure. The late M. Vilmorin, by selecting seeds from this curious "monster," succeeded in "fixing" it; so that 90 per cent. of the seed came true, with the large "synanthic" 1 flower.

Another instance of a monstrous condition, perpetuated by seed, occurs in a forget-me-not, which has now been cultivated for some years. It was known as "Victoria" and by other names. The petals were more than the usual five, in a whorl, but not "double." So too, the oldfashioned tomato consisted of two or more fruits blended into one, having resulted from a synanthic flower. This was the cause of the fruit being lobed with deep indentations.

Fasciation is the result of the multiplication and branching of the fibro-vascular cords of the flowering-stem or peduncle ; but instead of giving rise to external free-growing branches, they are all included within a common cortical and epidermal tissue. Though excessively common,

1 Grk. syn, "together," and anthos, "a flower." 
especially in asparagus, it is not usually hereditary ; but is perpetuated by seed in the common coxcomb.

Another freak occurs when a normally gamopetalous corolla, as of the Canterbury Bell, or Convolvulus, reverts to freedom by developing the petals separate. A variety of the Hare-bell of our heaths was, and perhaps is still cultivated with a polypetalous corolla. On the other hand a poppy has been known to have its four, usually. free, petals all coherent into a tube.

Another peculiarity of corollas, which has lately afforded an addition to floriculture, is to be "crested." It occurs in cyclamen, begonia, daffodil and primula. It results from a branching of the fibro-vascular cords, which, unlike fasciation, are external to the surface ; and being clothed with tissue produce fringes upon it. Cabbage-leaves, not infrequently have similar excrescences, issuing from the ribs; sometimes they run out into long stalks carrying funnelshaped structures at the end of them.

These fringes are abnormal, but the "cup" or "crown" in a daffodil and jonquil, partakes of the same nature and is normal. The daffodil has all its parts complete, the tube being an extra growth. Indeed, the majority of the plants belonging to the same family, such as the snowdrop and the snowflake, have not got one at all.

The lesson to be learnt from these freaks is, that no hard and fast line can be drawn between "varieties" and "monsters." Both may or may not be hereditary, they may be transient or be- 
PRESENT DISTRIBUTION OF WILD FLOWERS. 193

come fixed, and so constitute a new variety, or if it be preferred a new species.

If it be asked how or why they occur, at presenc no answer can be given to either question.

\section{CHAPTER XVII}

THE ORIGIN AND PRESENT DISTRIBUTION OF BRITISH AND IRISH WILD FLOWERS

Having now considered certain peculiarities of the structure of our wild flowers, the reader may like to know something of their history, and to understand why some are only found in certain places, being often very restricted in their areas. The question is-What is it that determines the local distribution of plants?

Although climate is the most essential element to be taken into account when the distribution of the plants of any flora is to be considered; yet as that of our own country at the present time is so well known, it will be superfluous to describe it in detail. ${ }^{1}$ All that will be necessary is to compare it, or rather contrast it generally, as being insular and maritime, with that of the Continent;

1 The word climate must be taken to represent the aggregate environment of plants included under :-1. Latitude ; 2. Elevation above the sea ; 3 . Maritime or insular or continental position ; 4. Inclination of land ; 5 . Mountainous country or otherwise ; 6 . Character of soil ; 7. Condition of soil, wet or dry, etc. ; 8. Degree of cultivation ; 9. Prevalent winds ; 10 . Rainfall ; 11. Mean summer and mean winter temperatures, etc. 
and then to see what differences may be expected to exist between the flora of Great Britain and that of Europe.

The chief difference between all maritime or insular and continental climates lies in the predominance of moisture ${ }^{1}$ in the air of the former and in the greater degree of dryness in that of the latter. The immediate effect of watery vapour is to moderate the heat in summer by arresting its passage from the sun, and similarly to arrest its radiation at night and in winter. The consequence is that maritime and insular climates are far less subject to extremes of temperature, diurnal or annual, than are places situate away from a sea-board and many miles in the interior of a continent. Another very important agent in affecting the climate is the prevalence of aërial and ocean currents; warm in ameliorating, cold in deteriorating it, as far as the magnitude and vitality of any flora may be concerned. This is particularly the case with the British Isles; for, were it not for the warm currents both of air and water sweeping past us in a north-easterly direction across the Atlantic Ocean, our climate would very likely become as inhospitable as is that between the same latitudes of North America.

${ }^{1}$ As an illustration of the effect of moisture upon the distribution of plants, may be mentioned the fact that tropical forms extend into subtropical regions, if damp; as in South America : e.g., tree-ferns, epiphytal orchids, Myrtacece, etc. Similarly the laurel, fig, and bamboo ascend the humid extra-tropical mountains of Bengal and Sikkhim to 9000 feet; while on the other hand, a temperate flora, consisting of oak, willow, rose, plum, blackberry, pine, etc., descends to the sea in lat. $25^{\circ}$ in India.-J. D. Hook ER. 
PRESENT DISTRIBUTION OF WILD FLOWERS. 195

Perhaps few places could be better chosen to illustrate the above statements than Edinburgh and Moscow, both these places being on the same parallel of latitude. Thus, while the difference between the hottest and coldest months of the year is under $30^{\circ}$ for Edinburgh, it amounts to $60^{\circ}$ for Moscow ; and, it may be added, for Nain, on the coast of Labrador, it is $50^{\circ}$, and for Cape Churchill, on the west coast of Hudson's Bay, the difference is even $80^{\circ}$. All the above places are very nearly on the same parallel of latitude. Again, if we take winter and summer temperatures, we find that for July the mean at London is over $62^{\circ}$; at Berlin, $66^{\circ}$; at St Petersburgh, $64^{\circ}$; and at Astrakhan, $77^{\circ}$. While for January at London it is $37^{\circ}$; at Berlin, $28^{\circ}$; at St Petersburgh, $16^{\circ}$; and at Astrakhan it is $13^{\circ}$.

Now, the most obvious effect that such differences of temperature have on plants is that a continental climate is favourable to annuals and a maritime to perennials; for in places where a summer temperature rises high, plants, whose whole life-history is comprised in a few months or even weeks, may easily, therefore, survive; while the intensely cold winters of the same place would annihilate many perennials that would flourish in a less rigorous climate. Hence evergreen shrubs of South Europe, such as the laurustinus and bay laurel, will survive our winters, which are rarely excessive, yet the climate in summer and autumn is quite insufficient in its degree of heat to ripen efficiently the grape or Indian corn; for the summers are as equally tempered as the winters. 
The British flora, as might, therefore, be expected, contains a large amount of perennials, especially, perhaps, herbaceous ones. Many annuals, being weeds of cultivation only, would be probably more or less exterminated if our arable land should cease to be cultivated.

In reviewing our flora, as a whole, in some respects it may be regarded as insular in character, ${ }^{1}$ though in most others it is continental; that is to say, there is no plant which is peculiar to it or "endemic"; and with rare exceptions, every member of it belongs to the neighbouring continent of Europe.

Although our British plants are almost all European, yet they are not equally or at all uniformly distributed over our territory. They have, consequently, been divided into sub-floras or florulo, each being more or less restricted in area. We are indebted mainly to the labours of the late Professor Edward Forbes and Mr H. C. Watson for tracing out these districts. The following is a comparative table of the respective results of these eminent botanists, with their nomenclatures :-

Watson's.

1. British corresponds with

2. English

3. Scottish

4. Highland

5. Germanic (in part)",

6. Atlantic

7. Local or doubtful.
Forbes'.

Germanic.

Alpine. Kentish.

$\left\{\begin{array}{l}\text { Asturian. } \\ \text { Armorican. }\end{array}\right.$

1 The peculiarities of oceanic insular floras will be considered in the second volume. 
PRESENT DISTRIBUTION OF WILD FLOWERS. 197

That entitled Germanic by Forbes is so called because it is identical with the German flora, though the latter contains many plants wanting in England. This is subdivided by Watson into (1) the British, which includes plants found in all his eighteen "provinces"; (2) the English, which includes plants found chiefly in England and not in Scotland; and (3) the Scottish, embracing plants found chiefly in Scotland and the North of England only. The Alpine of Forbes or the Highland of Watson includes a group of arctic plants found on the Scandinavian mountains and on alpine localities, but not in the intermediate temperate lowlands. Watson's Germanic takes in plants found in the east and south-east of England bordering the German Ocean, from whence he derives the name, and includes those plants called Kentish by Forbes, but which do not seem to be deserving of a special name, as they are chiefly, if not always, plants affecting a limestone or chalky soil, and which, in part, occur elsewhere. The Atlantic types of Watson embrace plants found in the west and south-west of England and in Ireland. In these are included the Armorican of Forbes, which is characterised by a group of plants found in Normandy, the Channel Islands, the S. and S.W. of England, extending (in part) some distance along the west coast, and in the south-east of Ireland. The number of peculiar species continually decreases in passing in a north-westerly direction from South Europe through Normandy; so that while several which are in the Channel Islands are wanting in the south-west of England, others 
which reach that corner failed to cross over to Ireland; such as the Tamarix, one species of Rockrose ${ }^{1}$ though another has arrived as far as the south and west ; ${ }^{2}$ a little Hares'-ear ${ }^{3}$ the Strapwort ${ }^{4}$ and the tiny Polycarpon.

A portion of this Atlantic type was separated by Forbes as "Asturian," because the nearest locality on the Continent whence it was presumed by him these plants had come was the Asturian mountains of north Spain. They consist of six species of saxifrage, including our London Pride; two heaths, the strawberry tree, St Dabeoc's Heath and a rock-cress. ${ }^{5}$

Such is an epitome of our present flora with regard to its distribution within our own islands. The next thing is to consider its extension throughout the world. We have already seen that the great bulk of our plants included in Watson's British and English types (containing about three-fifths of the whole flora) is identical with the flora of Germany ; hence Forbes' name of Germanic; while the Atlantic type of Watson corresponds more especially with the Norman flora and that of the Channel Islands, really a fragment of the South European or Mediterranean flora; and if we take note of Forbes' Asturian, we find that small and fragmentary sub-flora on the Asturian Mountains of Spain. There remains, then, the Highland, Alpine or Arctic type. The nearest localities where plants of this group are to be found are the Alps, Pyrenees, Scan-

1 Helianthemum polifolium.

${ }^{3}$ Bupleurum aristatum.

${ }^{2}$ H. gutlatum.

- Arabis hirsuta, Sub-sp. ciliata.

${ }^{4}$ Corrigiola littoralis. 
PRESENT DISTRIBUTION OF WILD FLOWERS. 199

dinavian mountains, and arctic regions generally; though they are mostly or entirely absent from the warmer lowlands which separate such widelysevered districts.

If, however, we now ltave Europe, and endeavour to find any British plants elsewhere, we shall discovir small groups of this last type appearing here and there in many parts of the world. The following numbers will indicate how many British plants have been hitherto found in the several localities, and will also illustrate the fact that the plants of Britain, like His Majesty's dominions and subjects, are world-wide in their dispersion. Travelling eastwards from the Ural Mountains, Siberia contains about 750 British plants, and within the area included between the River Obi and Behring's Straits, and bounded southwards by the Arctic Circle (lat. $66 \frac{1}{2}^{\circ}$ ), there are 111. Kamtskatka contains 140. In Northrast Asia, including the area from Behring's Straits to South Japan, there are 325 , of which Japan has 156 British species.

Next, regarding the extension of our plants eastward's along the southern line of mountains, Hooker and Thomson give a list of 222 British plants which reach India. ${ }^{1}$ These appear to have travelled eastwards from Europe, finding means of transit along the Taurus, Caucasus, and western hilly or mountainous regions; and the above authors remark that "the key-stone to the whole system of distribution in Western

1 “Flora Indica," p. 109 (1855). Though others may have been discovered since; the relative proportions probably remain much the same. 
Asia does not rest so much upon a number of 'representative' species as upon the fact that not only are a large proportion of annual and herbaceous species of each common to Western India and Europe, but of shrubs and trees also. Those of Northern Europe inhabit the loftier levels of the Himalayas, where they blend with the Siberian types." The following British trees and shrubs occur in India :-Barberry, bird cherry, gean, blackberry, alpine blackberry, hawthorn, cotoneaster, white beam, gooseberry, black currant, ivy, box, elm, two species of willow, the yew and juniper. It may be added that European types disappear eastwards gradually at first, but rapidly after reaching Kumaon. Few species enter Nepal, and still fewer reach Sikkhim. Of the plants which cross the Indian mountains and appear in Tropical Asia (i.e. India south of the Himalayas, the Khasia mountains of Eastern Bengal, together with the mountains of both peninsulas of India, Ceylon, and Java), the number, as might be expected, is much reduced, only 23 species being found there.

The next distributions to be considered are along the three greatest lines of extension of land into the southern hemisphere-Australia, lasmania, New Zealand, and the islands to the south; secondly, from Europe, through Africa and the islands near the coast to the Cape; thirdly, from Greenland and arctic America to Cape Horn ; lastly, the isolated spots in Polynesia, which can boast of a few representatives of the British flora.

I. Of the first of these extensions South Australia contains 100 indigenous plants common to 
PRESENT DISTRIBUTION OF WILD FLOWERS. 201

Great Britain, in addition to which a large number have become naturalised; Tasmania contains 56, New Zealand has 92, and Kerguelen's Land, 8; while Auckland and Campbell Islands possess 6. A curious fact worth notice is that in Southeastern Australia, European species form $\frac{1}{27}$ th nearly of the whole flora; but in South-western Australia they constitute $\frac{1}{100}$ th only; while in Tasmania they amount to ${ }_{15}^{-1}$ th. In Tasmania the following British plants occur, which are not found in Australia: Water-Crowfoot, Blinks and Holy Grass. On the other hand, the Victoria Alps of Australia contain fifteen European species not found in Tasmania, and all but one are British plants.

II. With regard to the extension of British plants from Europe to the Cape, commencing with Morocco we find 344 present there, while in northern Africa generally, which is largely "Mediterranean" in character, there are 420 British plants. North-east Africa and Abyssinia appear to yield about 90 British species. On the west coast of Africa, the little island of Fernando Po in the Gulf of Guinea was found to contain, on "Clarence Peak," at above 5000 feet elevation, 76 species of plants, of which number 56 species of 45 genera belong to a temperate flora. Their affinity is curiously much more with the plants of Abyssinia and of the Mauritius than with those of the adjacent west coast of Africa! Of the temperate flora a large proportion are European, and the following seven are British :-A yellow flowered wood-sorrell, wood sanicle, cleavers, mudwort, tufted aira, wood-rush, and slender 
false-brome grass. Of the South African flora, including the portion of land from the Tropic of Capricorn to the Cape, 27 species are British.

III. In the third great extension of land, Greenland contains 210 (Iceland has 335), while British plants abound in arctic British America, as in Siberia, even Parry's Island ( $76^{\circ}$ North latitude) containing 32. The number decreases as the warmer regions are reached ; thus $\mathrm{Mr}$ Drummond ${ }^{1}$ records only 40 British plants in the Western States. In tropical America (including the temperate and alpine regions of the Cordillera from Mexico to Peru) there are 35 British plants, of which the following eight are common with tropical Asia :- hairy bittercress, wood starwort, chickweed, ceratophyll, persicaria, polygonum, toad-rush, lake scirpus, and common reed. In extra-tropical South America, however, there are no less than 64 British species, while in Fuegia and the Falkland Islands there are 24. Of the British plants common to these three greatest extensions of land there are common to Australia, etc., and Africa, 17; common to Australia and South America, 35 ; common to South Africa and South America, 19; common to all three extensions, 15. Lastly there have been found a few British plants in islands of the Pacific Ocean. Thus, the Society Islands contain 3 ; the Sandwich, 5 ; and Fiji, 16 species.

If now we attempt to find an explanation to the fact of so many plants thoroughly establishing themselves in foreign countries, there are two features which strike us as worthy of observance.

1 Hooker's "Journal of Botany," vol. i, p. 185. 
PRESENT DISTRIBUTION OF WILD FLOWERS. 203

One peculiarity is that plants do not always flourish best where Nature has, so to say, made their home, but in consequence of the struggle for existence they hold their position as long as other plants will let them grow, so that the flora of any locality under normal and existing circumstances has, so to say, long ago arrived at a condition of equilibrium of mutual adjustment. If, however, plants be suddenly transported to other countries, they sometimes at once assume astonishing vigour, and for a long time at least gain great ascendency over the native vegetable population. This was conspicuously so in New Zealand, where the English water-cress grows to twelve feet in length, and three-quarters of an inch in thickness ; while a single plant of Knotgrass will cover several square feet, and the little Dutch clover is driving the huge "New Zealand flax" before it ! Similarly does the Canadian Elodea flourish in England, though we possess the female plant only. It would seem, therefore, that the change of climate has somehow introduced new and invigorating elements into their constitution, which the native flora cannot acquire, having been so long adapted to it. This appears to be one cause of introduced plants so readily establishing themselves. Another is that these sporadic plants, being generally inconspicuous annuals and self-fertilising, are independent of insects; so that they survive in the struggle for existence over their more showy brethren, which cannot propagate fully by seed unless habitually visited.

In a previous chapter on the "Fertilisation of Plants" I have shown how this is the case $\cdot$ but 
would just illustrate it by mentioning a few of the most widely dispersed of our British plants. The hairy Bittercress is found in north-east Asia, tropical Asia, Hong-Kong, Kamtskatka, Chili, South Australia, Auckland and Campbell's Islands, Falkland and Fuegia, Tasmania, South Africa, New Zealand, Madeira, etc. Similarly is the Mouse-Ear Chickweed dispersed over the same area. The black Solanum is also found in California, South Australia, Tasmania, New Zealand, Society Islands, Andaman Isles, North China, Japan, Galapagos Islands, etc.

Having now considered the present distribution of the British Flora, we have to account for it as far as possible ; and here theory must supplement facts. In looking back to discover a historical or rather geological origin of our present flora, we soon find that there have been very remarkable changes in the characters of successive floras that peopled our country. Going no further back than the Eocene periodfor attempts at deductions as to climatal conditions become more and more uncertain in proportion as the faunæ and floræ are more remote in time from and unlike their living representatives-we find tolerably certain evidence that the climate of England at that time was tropical, at least so far as palms, Mimosce, Nipadites, on the one hand, and turtles, crocodiles, and large water snakes on the other, justify us in drawing such a conclusion. This period, then, could not have seen the origin of our present temperate and arctic floras. The next epoch, the Miocene, likewise fails to furnish any members of it. The 
PRESENT DISTRIBUTION OF WILD FLOWERS. 205

flora of this period was subtropical, but probably became less and less so as the next-the Plincene epoch-drew near. The Miocene flora is remarkable for its great extent. Not only are remains of plants to be found in England, as at Bovey Tracey in Devonshire, but at many places on the Continent; and what is still more remarkable, it is found to have extended all over the Arctic regions-as at Disco Island, Greenland, arctic North America, etc. In all these places such plants as vines, custard apples, figs, cinnamons, the lotus of the East, water-lilies, and the ubiquitous "Wellingtonia" 1 are to be found. This shows, therefore, that there must have been a very different state of things in the Northern hemisphere then from what obtains now. The preceding flora had its day, flourished, and then passed away for ever, A colder period drew on. This is signalized in our country by the celebrated Cromer Forest, and the peat or lignite beds on the north coast of Norfolk. ${ }^{2}$ These are overlaid by a steep cliff of "glacial deposits." The flora of these beds is identical with the existing one; that is to say, the Scotch fir, accompanied by the Norway spruce (now extinct, but re-introduced), both our water-lilies, the buckbean, alder, etc., then flourished, but with

1 This genus is better known to botanists as Sequoia, and the species $S$. Couttsioe is found at Bovey Tracey; two species only now exist, $S$. sempervirens (red-wood) and $S$. gigantea, both being confined to California.

${ }^{2}$ Whether the temperate period indicated by these plantbeds preceded the "Glacial" epoch, or represent interglacial milder periods, is perhaps at present undecided by geologists. 
the strange companions of Elephas meridionalis, many Cervi, the Rhinoceros, the great Bos primigenius, the Irish elk, and other extinct animals.

The reduction of temperature (for the forestbeds indicate as temperate a climate as our own), seen by comparing it with that of the preceding Miocene period, was the antecedent condition to an arctic or glacial state of things shortly to follow, or "the Great Ice Age." The evidence of this, as derived from plants, is seen in the presence of an arctic willow, Salix polaris, found in a deposit over-lying the subtropical Miocene beds at Bovey Tracey.

Now, as England is at present temperate, and an arctic flora reigns over high latitudes simultaneously with it, so does it seem probable that such was the state of things, if not before, at least soon after the close of the Glacial Epoch; that when the Cromer Forest flourished, an arctic flora prevailed simultaneously with it in high latitudes. As however, the ice continued to increase southwards, and the land in all latitudes was encroached upon and rendered unfit for such plants to inhabit, they were driven southwards down every meridian, from the arctic regions. The long line of mountains in America, forming an unbroken bridge of transport, enabled many to cross the tropics and so reach the extra-tropical regions of South America. Mr Belt discovered signs of "glaciation" in Nicaragua down to 2000 feet above the sea, apparently showing that there was a "cooling" going on at least locally in the tropical regions, which would seem to dispose of the difficulty of arctic plants crossing the torrid 
PRESENT DISTRIBUTION OF WILD FLOWERS. 207

zone. Similarly in the eastern hemisphere, assuming the land to have been continuous, and there are solid reasons for believing it to have been so, the arctic flora would have been able to find a passage from the Himalayas, through eastern China and the Celebes, to Australia, New Zealand, and Tasmania.

Another suggestion is that the Australian forms came from South America to New Zealand, then Tasmania, and finally Australia; for the New Zealand flora is strangely like that of South America in some respects, and it has been shown above that Tasmania has more British types than Australia. ${ }^{1}$

Thus is it supposed that the arctic flora has been driven over all the world, and on the close of the Glacial Epoch the plants situated on what are now tropical plains perished, or else retired up the mountains where we now find them, as on Clarence Peak in the island of Fernando Pu; while in the northern hemisphere many retreated back again into arctic regions perhaps accompanied

${ }^{1}$ Hooker thus sums up his observations on this dispersion, in his Introductory Essay to the "Flora of Tasmania," p. 103 :- "When I take a comprehensive view of the vegetation of the Old World, I am struck with the appearance it presents of there being a current of vegetation (if I may so fancifully express myself) from Scandinavia to Tasmania ; along, in short, the whole extent of that are of the terrestrial sphere, which presents the greatest continuity of land. In the first place, Scandinavian genera, and even species, reappear everywhere from Lapland and Iceland to the tops of the Tasmanian Alps, in rapidly diminishing numbers, it is true, but in vigorous development throughout. They abound on the Alps and Pyrenees, pass on to the Caucasus and Himalaya, thence they extend along the 
by other plants of the countries they had previously invaded.

With reference to our own islands, there is reason to believe that the Atlantic type of Watson, or the groups including the Asturian and Norman or Armorican of Forbes, are very ancient. This is inferred, first, from their fragmentary character; secondly, from their isolation; and thirdly, from the fact that boulders have been found stranded on the south coast of England, implying that these islands were severed from the Continent, at least on the west, and south-west, during the Glacial Epoch, and that, therefore, these plants owe their origin to a much earlier connexion with the Continent; for, as already remarked, the nearest continental site of the Asturian plants is to be found in Spain; while the Armorican doubtless came from Normandy. With regard to the Arctic and common English and Scottish types, many of which are to be found in the arctic regions, they appear to have travelled from the north, or from the Scandinavian regions across

Khasia Mountains, and those of the peninsulas of India to those of Ceylon and the Malayan Archipelago (Java and Borneo), and after a hiatus of $30^{\circ}$, they reappear on the Alps of New South Wales, Victoria, and Tasmania, and beyond. Then, again, on those of New Zealand and the Antarctic Islands, many of the species remaining unchanged throughout. It matters not what the vegetation of the bases and flanks of the mountains may be; the northern species may be associated with Alpine forms of Germanic, Siberian, Oriental, Chinese, American, Malayan, and finally Australian Antarctic types ; but whereas these are all more or less local assemblages, the Scandinavian asserts his prerogative of ubiquity from Great Britain to the Antipodes." 
the plain of the German Ocean: ${ }^{1}$ but on the subsequent depression of the land below the sea, and with the elevation of temperature to its present state, the more arctic types would be confined to the tops of our mountains, while the rest would people the plains, and the floras would thus be gradually established in our islands in the conditions in which we now find them.

\section{CHAPTER XVIII}

EDIBLE WILD FLOWERS ; ${ }^{2}$ OR THE EVOLUTION OF OUR VEGETABLES

In treating of wild flowers, we must not forget to tell the story of our garden vegetables; for they are all domesticated wild plants, which have been "improved" by the cultivator's skill. Several are natives of the British Isles, and the rest come from various parts of the world.

Let us begin with those which provide us with roots; and then proceed to consider others which supply us with edible stems, leaves, flower-buds and fruits.

1 There appear to have been four well-marked periods at least in the Glacial Epoch : (1) a period of elevation at the time of Cromer Forest ; (2) one of great depression, so that Great Britain became an archipelago; then (3) reelevation, when the German Ocean was land ; and finally a last depression to its present condition.

2 The following brief account of our common garden vegetables is partly taken from my article in the "Journal of the Rl. Hor. Soc.," vol. xvii. 
TuRNIP-This and the rape as well as cabbage are all members of the genus Brassica, of the order Cruciferce. Authors are not all agreed upon the differences between the first two being "specific." Pliny writing in the first century, A.D., said "the turnip is pretty nearly of the same nature as the rape." Gerarde in his "Herball," 1597, united the two and the late Prof. Jas. Buckman considered them as identical. The difference between them probably arises, as stated in Chapter $\mathrm{V}$. from the object and method of cultivation. For if the seed be selected for its oil, then, by the law of compensation the root will not assume the enlarged form. If the turnip-root be the object, then the oil is deficient.

With regard to the geographical distribution of the wild turnip and its kindred, they are all of European and Siberian origin; and are still to be seen wild or half-wild in some form or other.

The turnip was well known to the ancients. Pliny described several sorts; but some may refer to the radish. In the fifteenth century it was known to, and much grown by, the Flemings. The first turnips that were grown in England are believed to have come from Holland in 1550 .

RADISH.-This also is of the order Cruciferce M. Carrière raised a variety of forms from our wild radish, which is distributed over N. Europe, N. Africa, N. and W. Asia to India. The radish has been grown from the earliest historic times, from Europe to China and Japan. Herodotus, writing in the fifth century, B.C., speaks of the radish as being eaten by the builders of the Great Pyramid, built probably between 3,000 and 
4,000 years B.c. The radish is also figured on the walls of the temple of Karnak in Egypt. The present indigenous variety in Egypt is a large white sort with long tapering leaves. Gerarde, 1597, figures two varieties which he calls the "round " and the "pear-fashioned." It is noticeable that both these are represented as having only two-seeded pods. This feature agrees better with that of the seaside species of radish, a plant found from the Clyde southwards, and is commoner on the continent; so that it is pretty certain that this and not the so-called "wild radish" was the true origin of the cultivated one.

With regard to the forms of the roots, M. Carrière found that when seed was sown in a loose soil, a greater proportion of long-rooted forms were produced; while the round or turniprooted forms prevailed in a stiff soil. Pliny records a very similar fact, for he says of the rape:- "The Greeks have distinguished two principal species of rape, the male (turnip-rooted) and the female (long-rooted); and they have discovered a method of obtaining both from the same seed, for when it is sown in a hard, cloggy soil, the produce will be male." Again, he writes: "Some authors have mentioned a plan of making a hole with a dibble and covering it at the bottom with chaff, six fingers in depth. Upon this the seed is put, and then covered over with manure and earth. The result of which is that radishes are obtained fully as large as the hole is made." Prize parsnips are made to-day in much the same fashion. 
ParsniP. - Of the order Umbelliferce. It occurs wild from Durham and Lancaster southwards. It is common on the limestone of Gloucestershire and on the chalk of Dorset, etc. It ranges from Europe to Siberia.

The Greeks and Romans cultivated parsnips and carrots, which the former confounded under the name Staphylinos. It appears from Pliny that "the wild parsnip was eaten after having been transplanted, or from seed; but it preserved its strong, pungent flavour, which it is found quite impossible to get rid of." This seems to imply that the ancients did not know how to improve wild plants by gradual and prolonged selection.

As an example of modern, experimental "ennoblement by selection" of the parsnip, that of the late Professor Jas. Buckman may be mentioned. He sowed seeds of the wild plant in the botanic garden of the Cirencester Agricultural College in 1847 ; and raised a garden form by selection, which he called "The Student." Giving it to Messrs Sutton \& Sons in 1851, that firm improved it, and finally issued it. It still remains after half a century, the best parsnip in the trade.

Carrot. - Also of the order Umbelliferce. This plant is found wild from Europe and N. Africa to N. and W. Asia and India. It is very common in England.

That the cultivated form is derived from our wild annual species has been proved by $M$. Vilmorin and others. M. Vilmorin sowed seed of wild plants, and found that they flowered 
successively through the summer. Collecting the seed from the latest to flower and sowing this again late in the following season, he encouraged the enlargement of the root. By this means the carrot was induced to flower permanently in the second year of growth. Hence the garden form is now a biennial, this acquired habit having become hereditary.

The long and short "horn" forms of carrots have the same origin as the radishes mentioned above.

The carrot is supposed to have been introduced into England as a vegetable by the Dutch, about 1558. It is said to be first grown about Sand wich.

BeEtroot.-Of the order Chenopodiacece. It is a common perennial wild flower round our coasts and a native of Europe, N. Africa, W. Asia and India. The garden-beet, sugar-beet, white-beet or chard and mangel- wurzel are all derived from the same plant. The earliest cultivation would seem to have been from 300-400 B.c. The sugar-beet first began to be cultivated for sugar in 1747.

Chard, or the central, blanched leaves, especially the mid-ribs was the edible part with the ancients. Thus red chard is noticed by Aristotle, 350 B.c. Theophrastus (fourth century B.C), knew of two kinds the "white " and "black," Pliny also describes them, and says that they were eaten with lentils and beans; but the root was only used for its supposed medical virtues. Beet-root was introduced into England in 1570 .

Of plants yielding stems which are edible, the most important is the- 
Potato. - Of the order Solanacece. It is a native of the higher ground of Peru. It was first introduced into Spain and Italy by the Spaniards at the close of the fifteenth century, who found it already cultivated in S. America. It was then called "Battata," from which the word Potato is derived. Gerarde received it from Virginia in 1584, and called it Battata virginiana and Papus hyspanicus. ${ }^{1}$

Jerusalem ArtichoKe-This plant is a native of the N. United States of America. It was cultivated by the Indians of Huron and New England at an early date, and was introduced into England in 1617 as "Battatas de Canada." It is allied to the Sunflower, an annual plant of Mexico. The word "Jerusalem" is a corruption of the Italian word "Girasola" meaning "turn to the sun." The word "Artichoke" is derived primarily from the Arabic "Kharchoûf," which appears as "Alcachofa" in Spanish, corrupted into "Articocco" in Italian, and hence our word "Artichoke."

AsParagus. - This occurs wild on the coasts of Wales, Cornwall, Dorset and the Channel Islands. In the southern parts of Russia and Poland the waste steppes are covered with it, and it is there eaten by horses and cattle as grass. It was highly esteemed by the ancient Greeks and Romans, 200 B.c. It has long been cultivated in England. Gerarde, 1597, figures five kinds, one only, however, being the true garden asparagus. It is one of the few vegetables which have re-

${ }^{1}$ In the portrait, given as a frontispiece to his "Herbal," Gerarde is represented as holding a flowering branch of the potato in his hand. 
mained true to the wild form for upwards of two thousand years of cultivation.

The next to be considered are plants grown for their foliage as food.

CABBAGE.-This is a native of the coasts of England and Wales, of the Channel Islands, and of W. and S. Europe. Theophrastus (300 B.C.) knew of three kinds only-the loose broad-leaved, the closely-packed, and the crisped leaved. Pliny in the first century A.D. mentions several varieties, and says that they were the most highly esteemed of all garden vegetables. Eighty-seven remedies were credited to the Cabbage. He tells us that "small shoots throw out from the main stem, of a more delicate and tender quality than the Cabbage itself, were cut in spring." Pliny also, alluding to the "Arcinian Cabbage," says: "Beneath nearly of all the leaves there were small shoots peculiar to this variety." It would seem from the description that this form corresponded with the kind described and figured by Gerarde, viz., No 7, Brassica prolifera, "the double Colewort." He says : "Double Colewoort hath many and large leaues whereupon do grow heere and there other small iagged leaues, as it were made of ragged shreds and iaggs set vpon the smooth leafe, which giueth shewe of a plume or faune of feathers." It somewhat resembles the "crested" Primroses and Cyclamen flowers, and appears tc be due to hypertrophy coupled with a multipli. cation of the fibro-vascular cords of the mid-ribs, etc. In one kind of this prolification the excrescences take the form of funnels at the extremities of the ribs. A few years ago nearly every 
plant in a bed in the garden of Sir J. B. Lawes at Rothampstead was characterised by this peculiarity.

The following are varieties of the Cabbage.

Kohl-rabi. - This is remarkable for its swollen stem. It appears to have been introduced into Germany from Italy about 1558, and into Tripoli about 1574 . It was known to Gerarde (1597), but it is not clear whether it was known to Pliny. His description of the "Corinthian" Turnip seems to agree with it, of which he says: "The root is all but out of the ground: indeed this is the only kind that, in growing, shoots upwards, and not as the others do, downwards into the ground." It is a common food in Malta.

The Brussels Sprouts.-These were commonly grown in Belgium in 1820, and also in French gardens, but not generally known in England before 1850 .

The Broccoli. - The earliest notice of this variety appears to be in Miller's Dictionary, 1724, where it is called the "Sprout Colliflower." It seems to have originated in Italy. Being sown in September there, as in Malta, it is cut in April or May.

The Cauliflower was earlier known, being mentioned by Dodonæus 1553 or 1559, and figured by Gerarde, 1597, though it was rare in Parkinson's time 1629. The form is due to a partial suppression of the floral organs, accompanied by a great development of the pedicels, similar to the Feather Hyacinth, Bellevalia comosa.. The following description of its origin is by $M$. Vilmorin :- 
"The Sprouting or Asparagus Broccoli ${ }^{1}$ represents the first form exhibited by the new vegetable when it ceased to be the earliest Cabbage, and was grown with an especial view to its shoots. After this, by continued selection and successive improvements, varieties were obtained which produced a compact white head, and some of these varieties were still further improved into kinds which are sufficiently early to commence and complete their rustic growth in the course of the same year. These last named kinds are now known by the name of Cauliflower."

As illustrating the origin of the many varieties of Cabbage by cultivation, Prof. Buckman raised varieties from the seed of wild plants collected at Llandudno, "some having short petioles and the close-hearting condition of Cabbages, both green and red, the tendency [to vary] being much increased by repeated transplanting. Others, with longer petioles and lyrate leaves, seem to take on the looser method of growth of Kales, \&c." With reference to persistency of form, Prof. Buckman adds: "It may be remarked, as throwing some light on the nature of the changes by which the cultivated varieties of this genus have been attained, that experiments with seeds of plants showing any particular tendency, and especially if repeatedly grown in the same soil, will ever result in an increase of the peculiarity."

SEA-KaLE. - This is a native of various parts of the English coast. It was well known to the

1 "The small shoots," referred to by Pliny called Cyma or "Sprouts," were probably the loose form of the flowering head; as commonly seen now in Malta. 
Romans, who collected it wild, and preserved it in barrels for use during long voyages. "It was called Halmyridia from its growing on the seashore only. Pliny's description of the method of pickling it with oil and salt is very suggestive of an origin of sauerkraut of the Germans.

Unlike the cabbage, which is prone to vary greatly, the Sea-Kale, like asparagus, illustrates "persistence of type." The present cultivated form being that of the originally wild one. It was not cultivated until the eighteenth century, 1767.

SPINACH.-This plant does not appear to be known wild; but it may be a cultivated form of a native species of Persia. It was unknown to the ancient Greeks and Romans, being new to Europe in the sixteenth century. The name is derived from the Arabic " Esbnach," which indicates its Eastern origin. Its cultivation is said to have been common in Nineveh and Babylon. A Spinach figured by Gerarde would seem to be some indeterminable form of Goose-foot or Orache. It is noticed in Turner's "Herbal," 1568, as "an herb lately found and not much in use."

OnIONS.- These species of the genus Allium which are more or less in general cultivation are the following:-The common Onion, Garlic, Shallot, Chives, Rocambole or Sand-Leek and the Leek.

The common Onion is one of the earliest of the cultivated species. It was used as a spell in Chaldea, possibly 5000 B.c. One variety was worshipped in Egypt, and Garlic and Onions were invoked by them when taking an oath. 
Pliny says "There are no such things as wild Onions," but they have been discovered truly wild in Beluchistan and neighbouring countries.

The Spring or Welsh Onion, or Rock Onion of Russia, is a native of Siberia and Russia. It has been grown in England since 1629. Like the Leek, it does not form a bulb.

Garlic is wild in the desert of the Kirghis of Sungari. It is very ancient and widespread in cultivation. Herodotus mentions it as grown in Egypt, upwards of 3000 B.C.

The Shallot, is believed to be the same as the Ascalonian Onion of Pliny, who says "it is so called from Ascalon, a city of Judæa." Theophrastus, however, as also A. de Candolle regards it as a form of the Onion. It is not known wild. It was introduced into England in 1548.

The Chive occupies an extensive area in the northern hemisphere, both in the old and new worlds. It is found wild in some of the northern and western counties of England and Wales. A variety to be met with in the Alps appears to be nearest to the cultivated form.

The Rocambole, or Sand Leek, occurs wild from Yorkshire and Lancashire to Fife and Perthshire, as well as in Ireland. It is not of ancient cultivation, though of European origin, as it is not mentioned by Greek and Latin authors.

The Leek is commonly wild in the East and Mediterranean regions, and especially Algeria. It is naturalised in England. It was well known to the ancients. Pliny observed that the Emperor Nero used to eat Leeks and oil to improve his voice, and that the best came from Egypt. It is 
usually a non-bulbous form under cultivation; but the ancients used to make it produce bulbs by transplanting and cutting off the green tops, as described by Pliny. Gerarde's figure of the Leek shows a decided tendency to produce a bulb. I have found it wild and always bulbous in Malta.

RHUBARB.-The leaf-stalks of species of Rheum, natives of N.E. Asia and China.

LETTUCE.-This salad-plant is a native of $\mathrm{S}$. Europe and occurs from the Canary Islands to E. Asia. The wild form is to be found in many counties of England but it is a rare plant. It was cultivated by the ancients as a salad-plant and was also used as a sedative. Lettuce appears to have been the "opium" of the physician Galen, who lived about 200 A.D.

ENDIVE.-This is probably a Mediterranean plant. It is described by Pliny more especially for its supposed medicinal qualities, and he speaks of two kinds, the cultivated and the wild, known as Cichorium or "Spreading Endive." He refers to its growth in Egypt, where the true Endive still occurs wild in the fields and is sometimes cultivated. There are two forms in present cultivation-the curled-leaved, which was unknown to the ancients, and the broad-leaved or Batavian. The "curled" appears to be first alluded to by Camerarius in 1586 .

Pliny makes the remark that "the general opinion is that those only will admit of being blanched which are produced from white seed ... care being taken to tie up the leaves as soon as ever they begin to come to any size."

CHICORY.- This differs from the endive in 
being perennial. There are two kinds in cultivation, the "Barbe de Capucin" and the "Witloof" or Brussels Chicory. It occurs wild throughout England, bearing flowers like those of the Dandelion, but of a bright blue colour, on a tall wiry stem. It is cultivated for the sake of the root near York. This is roasted and ground to powder.

CELERY.-This is not uncommon in ditches and especially near our coasts; remarkable for its strong smell, and is dangerous to eat raw in the wild form. In Italy, Malta, etc., it is not blanched, but the green leaves are used for soup, etc. Gerarde described it as "water parsley" or "smallage." Indeed, the word "celery" is a corruption of Selimon the Greek word for parsley. In Gerarde's time, 1597, it was the custom to transplant it from the ditches into gardens just as Pliny says the parsnip was in his day.

PARSLEY.-This is allied to celery and a native of S. Europe and the Levant. English gardeners received it in 1548, but it was used in medicine in the fourteenth century and doubtless earlier. It has naturalized itself in England, and delights in rocks (petros being the Greek for "a stone ;" and petro-selimon being the scientific name), as e.g., over the Avon at Clifton, where it is wild. Parsley was used by the ancients for garlands, as it retained its colour. It was also eaten as an antidote to the effects of wine.

Of fruits used as vegetables, the most important are the following.

HARICOT OR KIDNEY BeAN.-This plant was for a long time supposed to be of Indian origin; 
but the discovery of beans of dwarf haricots in certain tombs of Peru in 1880 countenances the view that it is of $\mathrm{S}$. American origin.

On the other hand, it is said to have been cultivated in France in the time of Charlemagne, 800 A.D. ${ }^{1}$

BEAN.- Varieties of the broad bean have been found in the ruins of Troy, and in the Swiss lake dwellings of a prehistoric period. Herodotus speaks of the bean as never being cultivated in Egypt," and if it grows they do not eat it. The priests cannot even endure the sight of it; they imagine that this vegetable is unclean." It was early known in Italy, as it was an ancient Roman rite to put beans in the sacrifices to the goddess Carna. Beans are mentioned with lentils in 2 Sam. xvii. 28, as being brought to David. It is believed to have been found wild south of the Caspian Sea and in Algeria. M. de Candolle, however, doubts the statement.

Of leguminous plants "the honour," says Pliny, "must be given to the Bean." In speaking of it as food, he says that it was mixed with flour and made into bread. It was also use 1 for feeding cattle. Bean pottage occupied a place in religious services. Pythagoras believed that the souls of the dead are enclosed in the bean, hence they were used in funeral banquets. A remark-

${ }^{1}$ Gerarde, 1597, figures twelve sorts of beans called Phaseoli Brasiliani, or "kidney beanes of Brasile." This, therefore, seems as if he had been aware of a S. American origin. He also calls the "English kidney beane, French beane." The scarlet runner is probably a variety of this species. 
able statement of Pliny's is that "it fertilises the ground in which it has been sown as well as any manure." We now know the cause of this fact, that certain kinds of microbes invade the roots, giving rise to tubercles, and that by some unknown method they can obtain nitrogen from the air. Consequently leguminous crops, as a rule, do not require nitrogenous manures, and the haulms of peas and beans should be always chopped up and dug in the ground while still green if possible, as the decay is more rapid then.

PEA.-This plant is not known wild. Some botanists have thought it may be a cultivated form of the Field Pea wild in Italy. It was cultivated in the time of Theophrastus, and it has been found in the lake dwellings of Switzerland. It was not known in ancient Egypt nor in India, the so-called Mummy Pea ${ }^{1}$ having nothing to do with Egypt. The pea was probably cultivated in England early in the sixteenth century, as Gerarde figures and describes it.

CuCUMBER.- The origin of this plant is now thought to be C. Hardwickii. This is wild from Kumaon to Sikkim. It has been cultivated in India for 3000 years, and introduced into China, 200 B.c. The ancient Greeks cultivated it under

${ }^{1}$ The Mummy Pea was "sent out" by $\mathrm{Mr}$ Grimstone as a new pea about 1840, accompanied with the story that it had been found in a mummy case. It is a "fasciated" form, and as there is both a white and a purple-grey variety, it is suggestive of having been a cross between Pisum arvense and $P$. sativum. The reader will find it described in the Gardeners' Chronicle, 1849, p. 115 ; and 1873, p. 44. 
the name of Sikuos. The "cucumber" mentioned in Numbers xi. 5, appears by the name in Hebrews to have been some other plant; no trace has yet been found of the cucumber in ancient Egyptian literature.

VEgETABLE MARROW.-This is believed to be a cultivated variety of the pumpkin. This species has been supposed to be indigenous to S. Asia and America. The nearest approach to it seems to be a kind found growing on the edges of thickets by the Guadaloupe, and apparently an indigenous plant. Gerarde's figure of Cucumis ex Hispanico semine natus or Spanish cucumber might very well represent the vegetable marrow.

Tomato.-This was first brought from Santo Domingo to Philadelphia in 1798 . It was . at first cultivated as an ornamental plant; and not used as food in New Orleans till 1812. It appears to have been introduced into England in 1596. The name is derived from the Mexican word "Tomatl." Of the numerous forms of the fruit in cultivation, the small species cerasiforme or cherry-like form is probably the mearest to the original type. 


\section{A P P E N D I X}

FOREIGN WILD FLOWERS IN THE GARDEN

WHEN wild flowers are introduced into gardens where they find a much better soil with more abundant nutriment, etc., than in their natural conditions, they often begin to change in many respects. Thus spiny plants lose their spines as the sloe changed into the plum, and the wild pear into the garden pear-tree. In such, the sharp-pointed aborted shoots develop into leafy branches. Much hairiness vanishes and the cultivated descendants may become quite hairless; as the smooth-leaved garden parsnip, which was raised from the wild hairy species. Flowers become much larger and varied in their colouring, as in wallflowers, sweet peas and snap-dragons, and they often become "double" by the multiplication of their petals.

Many wild flowers, however, resist all or most efforts to induce them to change; so that they are still after many years of cultivation almost if not quite like their wild ancestors from which the present plants were descended.

Besides many of our own native wild flowers which have been "improved" by cultivation, as the old forms of garden pansies, daisies, etc., the Continent and especially South Europe has supplied a large number of our old favourites, some 
of which were introduced in the middle ages, as the wallflower; but more especially from the sixteenth century and onwards. But the whole world has helped to furnish our gardens and greenhouses.

Florists, however, have not been content to let plants change at their own sweet will, by merely providing them with various soils, etc., thereby inducing them to vary their colours, etc.; for they have, during this present century, adopted the practice of hybridizing flowers, so that perhaps the majority of our present cultivated flowers were never wild at all; for they are the progeny of two or more species combined. This subject, however, would require to be treated by itself. At present we are only concerned with "cultivated wild flowers."

As people interested in garden flowers often wish to know from what country some particular plant comes, I have drawn up the following list of the more familiar garden plants, giving the native country and the dates as far as is approximately known when they were first introduced.

They are alphabetically arranged so that any plant can be referred to at once. The dates are supplied from Paxton's "Botanical Dictionary."

\section{A}

ABIES-Some twenty species of Fir are in cultivation. The Norway or Spruce was once indigenous but is extinct now. The White Spruce, Canada; the Black Spruce, N. America ; the Douglas Fir, N.W. America; the Hemlock Spruce, N. America ; the common Silver Fir, Central Europe ; the Cephalonian, 
Greece; the Balsam or Balm of Gilead Fir, N. America; these are some of the most familiar. Mostly imported during the eighteenth and last centuries.

Abronia-Two species, California (1823), allied to the Marvel-of-Peru.

Acanthus-A. mollis, S. Europe (1548).

ACER-The False Sycamore from C. Europe and W.

Asia ; the Curled (1656), the Sugar (1735), and the Snake Maples (1755), N. America. A. polymorphum, with variously dissected leaves, Japan (1860). Aconitum - The Aconite, Monkshood or Wolf's-bane, (A. Napellus), C. Europe (1596).

Adam's Needle-and-'Thread-Yucca filamentosa, from

Virginia (1675).

Asculus-The Horse-chesnut (AE. Hippocastaneum),

reached Europe from Asia in 1530. It was rare in

England in 1597.

Agapanthus-African Lily (A. umbellatus), C. G. H.

(1692).

Agave-The American Aloe, S. Amer. (1640).

Ageratum-A. Mexicanum, Mexico, (1822).

Ailanthus-A. glandulosa, Japan, China (1751).

Allium-A. Moly (1604) and A. roseum (1752), S.

Europe. Numerous other species are cultivated. Almond-See Amygdalus.

Aloysia-The Lemon-scented Verbena (A. citriodora),

Chili (1794).

Alstremeria - A. aurantiaca, Valparaiso (1831).

ALTHAA-The Holyhock (A. rosea), Levant (1573).

Amaranthus - Love-lies-bleeding ( $A$. caudatus), E.

Ind. (1596) ; Prince's Feather (A. hypochondriacus),

Virginia (1684); the Cockscomb (A.cristata), Asia (1570).

Amaryllis-A. Belladonna, S. Africa (early in 17 th century). This is the only species; but the name is given to florists' hybrids of the genus Hippeastrum.

AMELANCHIER-A. vulgaris, S. Europe (1596).

Ampelopsis-The Virginian Creeper (A. hederacea), N.

America (1729), and A. tricuspidata (Veitchii), Japan (1868). 
AMYGDALUS-Almond (A. communis), Barbary (1548), Peach and Nectrine are "Sports."

Anagallis-Pimpernel (A. Indica), Nepal (1824); $A$. Monelli, Italy (1648).

Anemone-Hepatica (A. Hepatica), C. and S. Europe

(1573). Poppy Anemone (A. Coronaria), S. Europe

(1596); Star Anemone (A. hortensis), Pyrenees

(1596); A. Japonica, Japan (1844).

AntirRhinum-Snapdragon (A. majus), S. Europe (probably in Middle Ages).

ANTHERICUM-A. ramosum, etc., S. Europe (1570).

Apocynum-Dogbane (A. androsamifolium), N. America (1688).

Aquilegia-Columbine (native); A. Canadensis (1640); $A$. alpina, Switzerland (173i). Other species from Siberia, S. Europe, etc.

Araucaria - Puzzle-monkey, Chili (1796). A. Bidwillii, Morton Bay (1840).

Aristolochia - Birthwort (A. Clematitis), Europe

(16th century?); Dutchman's Pipe (A. Sipho),

N. America (1763).

Ash, Flowering-See Fraxinus.

ASPHODELUS-Asphodel (A. fistulosus and A. ramosus,

S. Europe (1550).

Aster - Michaelmas Daisy (A. Tripolium and $A$.

Tradescanti), N. America (1633). Numerous other

species are grown, chiefly North American. Astilbe (Spircea Japonica)-Japan (1830).

Astrantia-A. major, occurs wild near old Roman

quarries, in Stokewood (Shropshire) and the Malverns. Possibly introduced accidentally by them. Aubrietia-A. deltoidea, S. Europe (1710). A бсUвA-A. Japonica, Japan (1783). A uricula - See Primula.

Azalea-A. Pontica, Turkey (1793). A. Indica (1808) and $A$. Sinensis (A. mollis), China (1823).

\section{B}

Balsam-See Impatiens.

Balsam Fir-See ABIEs.

Barberry-See Berberis and Mahonia. 
Bastard Balm-Melittis.

Berberis-B. Daruinii, S. Chiloe (1847).

B. aristata, Nepal.(1820), B. ilicifolia, Terra del Fuego (1719).

Bгта-B. (Thuya) orientalis, Japan (1860).

Birth-root-See Trillium.

Bladder-nut-See STAPHYLEa.

Blessed Thistle-See CARDUUS.

Blue Daisy-See Catananche.

Borago-Borage (B. officinalis), S. Europe.

Box-See Buxus.

Box-Thorn-See Lyciom.

Broom, Spanish-See Spartium.

Buck-eye, red-Pavia.

BUdDleia-B. globosa, Chili (1774).

Bulbocodium-B. vernum, C. Europe (1629).

Buxus-Box (B. sempervirens); Native on Box-hill, etc.

C

Calceolaria - C. corymbosa and C. integrifolia (1822); C. purpurea and C. arachnoides (1827); and C. crenatiflora (1831), all S. American. Modern garden forms are hybrids.

Calendula-Marigold (C. officinalis), S. Europe (1573). Callistephus-China Aster ( $C$. hortensis), China (1731). Calochortus-Several species, California (1826-1836). Calycanthus-Carolina Allspice (C. floridus), Carolina (1726).

Campanula-Canterbury Bells (C. Medium), C. Europe (1597); C. persicifolia, Europe (1596); C. Carpatica, Carpathian Alps (1774); C. pyramidalis, Carniola (1594).

Candy-tuft-See IBERIS.

CanNa-Indian Shot (C. Indica), India (1570).

Canterbury Bells-See CAMPANULA.

Cape Gooseberry-See Physalis.

Caper-Spurge-See Euphorbia.

CarduUs-Blessed Thistle (C. Marianus), S. Europe.

Carnation-See Dianthus.

Castanea-Sweet or Spanish Chesnut (C. vesca), was introduced into Europe from Asia Minor. 
Catalpa-Indian Bean ( $C$. bignonioides), S. States of America (1726).

Catananche - Blue Daisy (C. ccerulea), S. Europe (1596).

Castor Oil Plant-See Ricinus.

Ceanothus-C. Americana, N. America (1713).

Cedar, Japanese-See CrYPTOMERIA.

Cedorus - Cedars ; C. Libani, Lebanon (1683); $C$. Atlantica, Atlas Mts. ; C. Deodara, Nepal (1822).

Centaurea-C. montana, Austria (1596).

Centranthus-Red Valerian (naturalized).

Cercrs-Judas Tree (C. Siliquastrum), S. Europe and

W. Asia (1596).

Cepralotaxus - C. Fortunei, China and Japan (1848).

Cerastium-C. tomentosum, S. Europe.

Chaste-Tree-See VITEX.

Cheiranthus-Wallflower(C.Cheiri), S. Europe (Middle Ages).

Cherry, Winter-See Physalis.

Chesnut, Sweet-Seo Castanea.

Chesnut, Horse-See ALsculus.

China Aster-See Callistephus.

Chinese Pink-See Dianthus.

Christmas Rose-See Helleborus.

Chrysanthemum-C. Sinense and Indicum, China (1790);

C. coronarium, S. Europe (1629); C. carinatum,

Barbary (1796).

Crstus-C. ladaniferus, Portugal and Spain (1629);

C. Cyprius, Greece (1800), and others.

Clatrkia-C. elegans, California (1832); C. pulchella, N. America (1826).

Clematis-Virgin's Bower (C. Viorna), N. America $(1730)$; C. azurea, C. cervlea, Japan ; C. Fortunei, C. lanuginosa, China (1851).

Совда-C. scandens, Mexico (1792).

Cockscomb-See Amaranthus.

Collinsia-C. bicolor, California (1851).

Colutea-C. arborescens, France (1548).

Columbine-See AqUILEGIA.

Convolvulus-C. tricolor (minor), S. Europe (1629);

C. althoeoides, S. Europe (1597); C. mutabilis (major, 
or Ipomoea purpurea), the American "Morning Glory," S. America (1629).

Coreopsis-C. tinctoria, N. America (1820).

Cornus-Cornelian Cherry (C. mas.), Austria (1596); C. alba, Siberia (1741); C. florida, N. Am. (1731);

C. (Benthamia) fragifera, Nepal 1825 ; C. Canadensis, Canada (1774).

CORYDALIS-C. lutea (naturalized).

Cowslip, American-See Dodecatheon.

Crab-See Pyrus.

Cratagus-C.Pyracantha, S. Europe (1629); C. coccinea,

N. America (1683) ; C. Crus-galli, N. Am. (1691).

Crocus-C. vernus, Europe (16th century?); Saffron C.

(C. sativus, naturalized) ; C. luteus, Turkey (1629);

C. variegatus, Levant (1829), etc.

Crown Imperial-See Fritillaria.

CrYPtomeria-Japanese Cedar (C. Japonica), Japan (1846).

Cupressus-Cypress (C. sempervirens), Candia (1548);

C. Lawsoniana, S. Francisco (1852), etc.

Cyclamen-C.Persicum, Cyprus(1731); C. hedercefolium,

C. and S. Europe, naturalized in Kent and Sussex. Cypress-See Cupressus.

CyTisus-C. Laburnum, C. Europe (1596) ; C. Adami, Graft-hybrid (C. L. $\times$ C. purpureus), C. alpinus, Europe (1596).

\section{D}

Dahlia - D. variabilis, Mexico (1789).

Dame's Violet-See Hesperis.

Dammara-Kauri pine (D. australis), New Zealand (1821).

Daphne-D. Pontica, Asia Minor (1759); D. Cneorum, Austria (1752), etc.

Datura-Thorn-apple (D. Stramonium), naturalized; and Purple var., Tatula, N. America (1629). Day-Lily-See Hemerocallis.

DeLPHinidm-Larkspur, Rocket (D. Ajacis), Switzer-

land (1573); Bee Larkspur (I). elatum), Siberia (1597); D. Consolida, S. Europe, naturalized, $D$. grandiflorum, Siberia (1816). 
Devil-in-a-bush-See NigelLA.

Dianthus - Clovepink ( $D$. Caryophyllus), S. Europe, naturalized on old walls, etc ; Pirk (D. plumarius), S. Europe (1629); Sweet William (D. barbatus), C. and W. Pyrenees (1573); Spanish Pink (D. Hispanicus), var. of Sweet William ; Chinese Pink or Indian Pink (D. Chinensis), China (1713), and hybrids.

Dicentra [Misspelt Dielytra]-D. spectabilis, Siberia (1810); D. eximia (1812) and D. chrysantha, both from N. America.

Dictamnus-Fraxinella or Dittany (D. albus), C. and S. Europe (1596).

Diervilla (Weigela $)-D$. rosea, China $(1845)$; D. amabilis, China (1855).

DodeCATHEON-American Cowslip (D. Meadia), Virginia (1744).

Dogbane-See Apocynum.

Dog's-tooth Violet-See ErYthronium.

Doronicum-Leopard's bane(D. Pardalianches), Europe, naturalized.

DracoCephalium-D. peregrinum, Siberia $(1759) ; D$. Argunense, Siberia (1822).

\section{E}

Eccremocarpus-E. longiflorus, Peru (1825).

Echinops - E. sphorocephalus, Austria (1596); $E$. Ruthenicus, Germany (1816).

Eglantine-See Rosa.

Eranthis - Winter Aconite ( $E$. hyemalis), Italy (1596).

ERICA - E. carnea, S. Europe (1763); Bruyère ( $E$. arborea), S. Europe (1658).

ERYNGIUM - $E$. alpinum, Switzerland $(1597) ; E$. amethystinum, Styria (1648).

Erythronium - Dog's-tooth Violet (E. Dens-canis), Europe (1596); Yellow Adder's-tongue (E. Americanum), N. America (1665).

Escallonia-E. macrantha, etc., Chili (1827 to 1847).

Eschscholtzia-E. Californica (1826). 
Eúphorbia-Caper Spurge (E. Lathyris), S. Europe, naturalized.

Evening Primrose-See Enothera.

Everlastings-See HELICHRYSUM.

F

Fair Maids of France-See RANunculus.

Feather grass-See STIPA.

Fennel, Giant-See Ferdua.

Ferdla-Giant Fennel ( $F$. communis), S. Europe (1597). Fir-See A BIEs.

Flax-See Lindm.

Flax, New Zealand-See Phormium.

Flowering Ash-See Fraxinus.

Fraxinella-See Dictamnus

Fraxinus-Flowering Ash (F. Ornus), (1730).

Fritillaria-Crown Imperial ( $F$. imperialis), Persia (1596).

Funckia-Several species, Japan (1790-1840).

GaILlaRdia-G. bicolor, N. America (1787).

GALEGA-G. officinalis, Spain (1568).

Genista-Portugal Broom (G. alba) (1596); G. sagittalis, Germany (1570).

GentianA-Gentianella ( $G$. acaulis), and other species of the Swiss Alps; G. Andrewsii, N. America.

Geranium-Pencilled Geranium ( $G$. striatum), Italy (1629) ; G. phoum, C. Europe, naturalized.

GEUM-G. chiloense (coccineum), Chiloe (1826).

Giant Fennel-See Ferula.

GILIA-Sp. from California (1826-1851).

Gladiolus- $G$. communis, S. Europe $(1596)$; $G$. cardinalis, C. G. H. (1789); G. cuspidatus, C. G. H. (1795); G. floribundus, C. G. H. (1788), etc., and many hybrids.

Godetia-See CENothera.

Goose-herry, Cape-See Physalis.

Grevillea - G. robusta, Port Jackson, Australia (1829). 
GRINDELia-G. grandiflora, Texas (1840).

Gunnera-G. scabra, Chili.

GyNERIUM-Pampas Grass $(G$. argenteum), S. America.

GrpsophiLA-G. paniculata, Siberia (1759).

\section{$\mathrm{H}$}

Hare's-foot Grass-See LaGURUS.

HEDYSARUM - Sulla or Maltese clover ( $H$. coronarium), S. Europe (1596).

Helianthemum- $H$. Algarvense, Portugal $(1800) ; H$. ocymoides, Spain (1800).

Helianthus-Sun-flower ( $H$. annuus), Mexico (1596); H. multiflorus, N. America (1597).

HeLichrysum - Everlastings, Immortelles (H. Stcechas), S. Europe (1629); H.bracteatum and H. apiculatum, Tasmania (1799).

Heliotropium-Heliotrope, Cherry-pie (H. Peruvianum), Peru (1757).

Hellebore-See HELLeborus.

HeLLEBorus-Black Hellebore, or Christmas Rose $(H$. niger), Austria (1596); H. olympicus, Asia Minor (1840); H. purpuruscens, Hungary (1817).

Hemerocaldis-Day-lily $(H$. flava), S. France, and $H$. fulva, Levant (1596).

Heracleum- $H$. A ustriacum ( $H$. giganteum), Europe. HESPERIS -Dame's-Violet or Rocket ( $H$. matronalis), S. Europe (1597).

Hollyhock-See ALTH Æa.

Honesty-See LunaRIa.

Honeysuckle-See LONICERA.

Horse-chesnut--See AEsculus.

HyacinTHUS-Hyacinth ( $H$. orientale), Levant (1596).

Hydrangea-H. Hortensia, Japan (1790).

HYPERICUM-Rose of Sharon, or Aaron's Beard ( $H$. calycinum), S. Europe (1680).

\section{I}

IBERIS-Candytuft (I. amara, I. umbellata, etc.), S. Europe (16th century). 
Ice-plant-See Mesembryanthemum.

Impatiens-Balsam ( $I$. Balsamina), Asia (1808); $I$. fulva, N. America.

Indian Bean-CATALPA.

Ipomaea-See Convolvulus.

IRIs-Flags (I. Germanica), Germany (1573) ; Orris ( $I$.

Florentina), S. Europe (1596); I. Susiana, Persia (1596); I. Xiphium, Spain, (1596).

Ixia-Many species, S. Africa (from 1757).

\section{$J$}

JASMnUM-Jessamine ( $J$. officinale), N. India and China (1548) ; $J$. nudiflorum, China (1844).

Jonquil_See NARCISSUS.

Judas-tree-See Cercis.

Juglans-Walnut-tree (J. regia), Persia (1562).

Juniperus - Common Juniper ( $J$. communis), $J$. chinensis (1804), and J. Japonica, China and Japan; Red Cedar (J. Virginiana), N. America (1664); $J$. Bermudiana, Bermudas (1683); Savin (J. Sabina), S. Europe (1548); J. Oxycedrus, S. Europe (1739).

\section{$\mathrm{K}$}

KaLmia-K. angustifolia, N. America (1736).

Kerria - K. Japonica, Japan (1700).

Kriphofia (Tritoma)-K. uvaria, S. Africa (1707).

KolReUteria $-K$. paniculata, China (1763).

$\mathrm{L}$

Laburnum-See Cytisus.

Lady's Bouer-See Clematis.

Lagurus-Hare's-foot Grass (L. ovatus), S. Europe.

LARIX-Larch (L. Europrea), Germany (1629).

LATHYRUS-Sweet Pea (L. odoratus), Sicily (1700).

Laurel, Common-See Prunus.

Lourel, Common Bay-See Laurus.

LaUrus-Common Bay Laurel (L. nobilis), S. Europe (1561). 
Lavandula-Lavender (L. vera), S. Europe (1568); L.

Strechas, S. Europe (1568).

LEDUM-L. latifolium, N. America (1763).

Lemon-scented Verbena-See ALoysia.

Leopard's-bane-See DoRoNICUM.

LeYCESTERIa - L. formosa, Nepal (1924).

Libocedrus-L. decurrens (Thuya gigantea) California ;

L. chilensis, Andes (1849); L. tetragona, S. America (1849).

Lilac-See Srrivga.

LiLIOM-Lilies ; $L$. bulbiferum, Italy (1596); L. candidum, Levant (1596) ; L. Martagon, Germany (1596); L. pyrenaicum, Pyrenees (1596); L. Chalcedonicun, Levant $(1796) ; L$. lancifolium, Nepal $(1824) ; L$. speciosum, Japan (1833); L. Thunbergianum, Japan (1835); L. tigrinum, China $(1804) ; L$. auratum, Japan, (1860) etc.

Lily-See LILIUM.

Lily, African-See Agapanthus.

Lily, Guernsey-See NERINE.

Lily, Lent-See NARCISSUS.

Limnanthes-L. Douglasii, California (1833).

Linaria-L. Dalmatica, Levant (1731) ; L. purpurea,

S. Europe (1648), etc.

Livem-L. grandiflorum, N. Africa (1820): L. flavum,

Austria (1793); L. campanulatum, S. Europe (1795);

L. alpinum, Austria (1739).

LIqUIDAMBAR-L. styracifua, N. America (1683).

LIRIODENDRON-Tulip-tree (L. tulipifera), N. America

(1663).

Lossa-L. aurantiaca, Chili.

Lobelia - L. Erinus, C. G. H. (1752) ; L. cardinalis, Mexico (1629); L. fulgens, Mexico (1809), etc.

LonicEra-Honeysuckle (L. Periclymenum (native) and L. Caprifolium, S. Europe (naturalized). Trumpet

H. ( $L$. sempervirens), N. America.

Love-in-a-mist-See NIGELLA.

Love-lies-bleeding-See AmarantruUs.

LUNARIA - Honesty (L. Biennis), S. Europe (1570).

LUPINUS-Lupin ; L. polyphyllus, Columbia $(1826) ; L$. mutabilis, Bogota (1819) ; L. tomentosus, Peru (1825) 
L. luteus, Sicily $(1596) ;$ L. virius, S. Europe (1596).

Lycium-Box Thorn or Tea-tree (L. Barlarum), Barbary (1696).

M

Magnolia - M. grandiflora, Carolina (1734); 1 . purpurea, Japan (1790); M. conspicua (Yülan), China; (1789) Umbrella tree (M. tripetala), N. Am rica (1752).

MaHoNia-M. (Berberis) aquifolium, N. America (1824). Maidenhair Tree-See Salísburia.

MaLCoLMIA-Virginian Stock (1I. maritima), S. Europe (1713).

MaLOPE-M. grandiflora (trifida), S. Europe (1808). Máple-See ACER.

Marigold-See Calendula.

Marigold, African and French-See TAGETE:

Marvel of Peru-See Mirabilis.

MatTHiola-Stocks, Brompton and Queen (M. incana),

W. and S. Europe (indigenous); Ten-week S. (M.

апnиа) S. Europe (1731).

May-apple-See PoDophyllum.

MeLrTtrs-Bastard Balm, M. Melissophyllum (grandiflora), indigenous.

Mesembyanthemum - Ice-plant (1. cry-tallinum)

Greece (1775).

Michaelmas Daisy-See Aster.

Mignonette-See RESEDA.

Mrmulus-Musk plant (M. moschatus), Columbia (1826) ;

Monkey-flower (Mf. variegatus), Chili (1831), and M. luteus, Chili and California (naturalized since 1826).

MirabiLIS - Marvel of Peru (M. Jalapa), W. Indies (1596).

Monkey-fower-See MiмuLus.

Monkshood-See Aconitum.

Montbretia-M. aurea, S. Africa.

Morus-Black Mulberry (M. nigra) (1518); White M.

(M. alba), China (1596).

Mulberry-See MoRus. 
MUSCARI - Feathered Hyacinth (M. comosum var. monstrosum), S. Europe (1596); M. botryoides, Italy (1596); M. racemosum, Europe (1780). Musk-plant-See Mrmulus. Myrtus-Myrtle (M. communis), S. Europe (1597).

\section{$\mathrm{N}$}

NARcissus-Jonquil (N. Jonquilla), Spain (1596) ; Hoop Petticoat, N. Bulbocodium. Portugal (1629): Daffudil or Lent lily ( $N$. Pseudo-Narcissus (indigenous), $N$. incomparabilis, S. Europe (Hybrid) 1629 ; N. odorus, S. Europe (1629) ; Polyanthus N. (N. Traetta) from S. Europe to Japan (1759); N. poeticus, S. Europe (sixteenth century?)

Nectarine-See Amygdalus.

NEGUNDO-N. fraxinifolium, N. America (1688).

Nemophila - N. insignis and N. maculata, California (1833-1848).

Nerine-Guernsey lily (N. Sarniensis), S. Africa (1659); N. pulchella, etc., C. G. H. (1820).

Nicotrana-N. affinis, S. America.

NigeLLA - Devil-in-a-bush, or Love-in-a-mist $(N$. Damascena), S. Europe (1570); N. Hispanica, Spain (1629).

Oak-See Quercus.

CEnothera-Evening Primrose (E. biennis, N. America (1629); E. speciosa, N. America (1821); CE. (Godetia) rubicunda, California (1835); EE. (G.) grandiflora, Columbia R. (1841).

Opium Poppy-See PAPAver.

ORNithoGaLdM-O. pyramidale, Spain (1752); 0 . arabicum, S. Europe (1629); O. narbonense, S. Europe (1810); Star of Bethlehem (O. umbellatus), indigenous.

Oxalis-O. rosea, Brazil (1826); O. violacea, N. America (1772); O. Bowiei, C. G. H. (1823); 0 . Deppei, Mexico (1827). 


\section{$\mathrm{P}$}

Panonia-Peony : $P$. corallina (officinalis), S. Europe ; Tree-peony ( $P$. Moutan), China (1789); P. albiflora, Siberia (1548).

Pampas Grass-See Gynerium.

Pancratium- $P$. maritimum, S. Europe $(1597) ; P$. Illyricum, S. Europe (1615).

PaPaver-Poppy; Opium P. ( $P$. somniferum), S. Europe (origin, P. setigerum?); $P$. orientale, W. and C. Asia (1714); P.alpinum, Alps to Lapland (1759); P. nudicaule, Siberia (1730).

Passiflora-Passion Flower ( $P$. corulea), Brazil (1699). PaUlownia-P. imperialis, Japan (1840).

Pavia ( $E s c u l u s)$-Red Buckeye (P. rubra), N. America (1711).

Pea, Sweet-See Lathyrus.

Peach-See Amygdalus.

Pelargonidm-Scarlet P. ( $P$. inquinans) (1714); Zonal

P. $(P$. zonale $)(1710)$; Ivy-leaved P. ( $P$. peltatum)

(1701), all from C. G. H. "Show" and "Fancy"

Ps. are all hybrids for indoor use.

Pentstemon- $P$. acuminatum and $P$. speciosum, $\mathrm{N}$. America (1827), etc.

Petunia-P. nyctaginiflora (1823) and P. violacea (1831), both S. American. All now hybrids between these two species.

Philadelphus-Syringa, or Mock Orange(P.coronarius),

S. Europe (1596); P. grandiflorus, Carolina (1811). Phillyrea $-P$. angustifolia, $P$. latifolia, and $P$. media, S. Europe (1597).

Phlomis-Jerusalem Sage $(P$. fruticosa), S. Europe (1596).

Phlox-P. paniculata, N. America (1732); P. Drummondi, Texas (1835).

Pнокмium-New Zealand Flax (P. tenax), N.Z. (1798). Physalis-Winter Cherry ( $P$. Alkekengi), S. Europe (1548) ; Cape Gooseberry (P. edulis, or Peruvianum), S. America (1772).

Pinus-P. Austriaca, Austria (1835); P. Laricio, Corsica (1814) ; P. Pinaster, S. Europe (1596) ; P. Pinєa, S. Europe $(1548) ; P$. insignis, Oregon (1833) ; $P$. ex- 
celsa, Bhotan (1823); P. Strobus, E. America (1705); P. Cembra, Siberia (1746).

Platanus-Plane: P. occidentalis, N. America (1636); $P$. orientalis, Levant (1548).

Podophyllum-May-apple ( $P$. peltatum), N. America (1664).

Polygala-P. Chamabuxus, Switzerland and Austria (1658).

Polygonum-P. cuspidatum (Sieboldii), Japan ; $P$. orientale, N. India, China (1707).

Populus-Lombardy Poplar ( $P$. pyramidalis, fastigiata, or dilatata), Italy (175s).

Portulaca-P. grandiflora, S. America (1827).

Potentilla-P. atrosanguinea, Nepal (1822), and numerous species, \&c.

Primula - Chinese Primrose ( $P$. Sinensis), China (1820); $P$. Auricula, Switzerland (1596); P. Japonica, Japan, \&c.

Prunus-Common or Cherry Laurel (P. Laurocerasus), Levant (1629) ; Portugal Laurel ( $P$. Lusitanica) (1648).

Pyrus - Siberian Crab (P. prunifolia) (1758); American

Crab (P. coronaria), Virginia (1724); P. Japonica (1815).

\section{Q}

QDeRcus-Turkey Oak (Q. Cerris), S. Europe (1735); Scarlet Oak (Q. coccinea), N. America (1691); Evergreen Oak (Q. Ilex), S. Europe (1581); Cork Oak (Q. Suber), S. Europe (1581).

\section{$\mathrm{R}$}

Ranunculus- $R$. asiaticus, Levant (1596); White Bachelor's Buttons, or, Fair Maids of France $(R$. aconitifolius), Alps (1596).

RESEDA-Mignonette ( $R$. odorata), Asia Minor (?) (1752); I. alba, S. Europe (1596).

Retinospora-R. pisifera, etc., Japan (1864).

Rhamnus-R. Alaternus, S. Europe (1629).

Rhodanthe-R. Manglesii, Swan R. (1832). 
RHODODENDRON-Rose of the Alps ( $R$. ferrugineum and R. hirsutum) (1656-1752); R. Caucasicum (1803); $R$. Ponticum, Asia Min or (1763); R. Catawbiense, N. America (1809); R. Dahuricum, Siberia (1780), etc. and numerous hybrids.

Rhus-Wig-tree or Venetian Sumach (R. Cotinus), S. Europe (1656); Stag's horn Sumach (R. typhina), N. America (1629).

RIBes $-R$. sanguineum, N. America (1826); $\dot{R}$. aureum, Missouri (1812); R. speciosum, California (1829).

Ricinvs-Castor-oil Plant (R. communis), Asia (?) (1548). Robinia-False Acacia ( $R$. Pseud-Acacia), N. America (1610).

Rosa-Provence or Cabbage Rose (R. Centifolia) Caucasus (1596); vars. Musk and Crested, France. R. Gallica, S. Europe (1596); R. Damascena, Syria (1573); Eglantine (R. lutea), Germany $(1596) ; R$. Indica, China (1589); R. Banksiae, China (1807). Rock-rose-See Helianthemum.

Rocket-See HeSPERIS.

Rocket Larkspur-See DeLPHinium. Rose of Sharon-See HYPERICUM.

Rosmarinus - Rosemary (R. officinalis), S. Europe (1548).

RUDBECKIA-R. purpurea, etc., R. Drummondii, $\mathrm{N}$. America (1640-1832).

Ruscus-R. androgynus, Canaries (1731); R. hypoglossum, Italy (1596).

S

SALISBURIA-Maiden-hair tree ( $S$. adiantifolia), China and Japan (1754).

Salvia-S. patens, Mexico (1838); S. verticillata, Germany (1628); $S$. splendens, Mexico (1822), etc., Sage (S. officinalis), S. Europe (1597).

SAPONARIA-Soapwort (S. officinalis), naturalized.

Savin-See JUNIPERUS.

Saxifraga-S. crassifolia, Siberia (1765).

Scabrosa-S. atropur, urea, E. Indies (1629).

Scilla-S. Sibirica, Siberia (1796); S. amona, Levant

(1596); S. campanulata, S. Europe, Spain (1683); 
S. Peruviana, S.W. Europe (1607); S. Italica, Switzerland (1605).

Sedum-S. Sieboldii, Japan (1836) ; S. Fabaria, Japan (1836).

SEquora - Mammoth Tree (S. gigantea), California (1853) ; Red-wood (S. Taxodium or sempervirens, California (1796).

Silene-S. compacta, Caucasus (1823); S. pendula, Sicily (1731); S. fimbriata, Caucasus (1803).

Sisyrinchium - S. Bermudianum, Bermuda (1730); $S$. grandiflorum, N. America (1826).

Skimmia-S. Japonica, Japan (1845).

Snapdragon-See ANTIRRHINUM.

Snowberry - See SYMPHORICARPUS.

Soapwort-See SAPONARIA.

SolANUM-S. giganteum, C. G. H.' (1792), etc.

SParaXIS-S. tricolor, etc., C. G. H., 1789.

Spartium - Spanish Broom (S. junceum), S. Europe (1543).

Specularia - Venus' Looking-Glass (S. Speculum), Europe (1596).

Spider-wort-See Tradescantia.

SPIRÆA-Goats'-Beard (S. Aruncus), Siberia (1633);

Queen of the Prairies (S. lobata), N. America

(1765) ; S. salicifolia, Arctic Europe (naturalized). Spruce-See ABIES.

Staphylea-Bladder-nut (S. pinnata), C. Europe.

Statice-S. elata, Siberia (1820).

Sternbergia - S. lutea, S. Europe (1596).

STIPA-Feather grass ( $S$. pennata).

Sweet Bay-See Laurus.

Sweet William-See Dianthus.

SympHORICARPUS-Snowberry (S. vulgaris), N. America (1730).

Syringa-Lilac (S. vulgaris), Persia (1597).

\section{$\mathrm{T}$}

TAGETES-French Marigold ( $T$. patula) (1573); and African Marigold ( $T$. erecta) (1596); both from Mexico.

TAMARIX-Tamarix (T. Gallica), naturalized. 
Taxodium-Deciduous or Bald Cypress (T. distichum),

N. America (1640).

Tea-tree-See Lycium.

Tecoma-Trumpet Flower ( $T$. radicans), N. America

(1640).

Thorn-apple-See Datura.

Thuja - T. Lobbii (gigantea), N.W. America ; $T$. occidentalis, N.W. America (1595).

Tigridia-T. Pavonia, Mexico (1796).

Tradescantia-Spiderwort ( $T$. virginica) N. America (1629).

TrILLIUM-T. grandiflorum (1799) and $T$. pendulum (1805) ; both N. American.

Tritoma- See Kniphofia.

Troldios-T. asiaticus, Siberia (1759) ; T. caucasicus, Caucasus (1817).

Trop AOLUM--Indian Cress (T. majus), Peru (1686).

TulIPA-Tulips, T. Gesneriana, W. Siberia (1577); T. suaveolens, S. Europe (1603); 'T'. Turcica, Levant ; $T$. Oculus-solis, Italy (1816) ; $T$. procox, Italy (1825).

$\mathrm{U}$

Uvularia-U. grandiflora, N. America (1802).

\section{V}

Venetian Sumach-See RHus.

Venus' Looking Glass-See Specularia.

Veratrum - White Hellebore ( $I$. album), Black $H$. (V. nigrun), both C. Europe (1548-1596).

Verbena-V. Aubletia and V. Chamadrifolia, Buenos Ayres (1827).

VERONICA-V. longifolia, C. Europe (1731); V. speciosa, $V$. salicifolia, $V$. macrocarpa, etc., New Zealand.

Viburnum-Laurustinus (V. Tinus), S. Europe (1596).

Viola-V. Rothomagensis, France; V. grandiflora, Switzerland $(1781) ; V$. calcarata, Switzerland $(1790) ; V$. cornuta, Pyrenees.

Violet, Dog's-tooth-See Erythronium

Violet, Dame's-See Hesperis.

Virginia Creeper-See AMPELOPSIS. 
Virginia stock-See Malcolmia.

Virgin's-bower-See Clematis.

VITEX-Chaste-tree (V. Agnus-Castus), Sicily (1570).

\section{W}

Wallflower-See Cheiranthus.

Walnut-JUGLANS.

Weigela-Diervilita.

Wig-tree-See RHus.

Winter Aconice-See Eranthis.

Winter Cherry-See Physalis.

Wistaria-W. Sinensis, China (1818).

Wolf's-bane-See Aconitum.

$\mathrm{Y}$

YuCCA-Y. gloriosa, America (1596); Adam's Needleand-Thread ( $Y$. filamentosa), Virginia (1675), etc.

$\mathrm{Z}$

Zinnia-Z. elegans, Mexico (1796). 


\section{N D E X.}

A

Acacia, 14, 77 ff.

Achene, 18.

Achlamydea, 36.

Adaptations for pollination, $163 \mathrm{ff}$.

Adaptations for self-fertilisation, $169 \mathrm{ff}$.

Adhesion, explained, 31, Aldrovandra, 131, 132.

Allium, species cultivated, 218.

Aloe, 140.

Alternate leaves, origin of, 146.

Ampelopsis Veitchii, 119.

Analogy, 95

ANGIOSPERMS, 16.

Antheriferous ovaries, 187.

Apple, structure of, 35 .

Aquatic wild flowers, $133 \mathrm{ff}$.

Artificial classification, 40 .

Asparagus, 214.

Assimilation, 11.

B

Bean, 222.

Beetroot, 213.

Bladderwort, 128.

Bracts, 11, 156.

British sub-floras, distribution of, 201

British sub-floras, origin of, $196 \mathrm{f}$.
British wild flowers, origin of, 193.

Broccoli, sprouting, 217.

Brussels sprouts, 216.

Brookweed, flower of, 145 .

Bryony, tendrils of, 80 ,

Buds, developing, $104 \mathrm{ff}$.

Bull's-horn thorn, $77 f f$.

Butterwort, 129.

\section{C}

Cabbage, and varieties of, 215 .f.

Calyciflorce, 32.

Cambium, 138.

Carnation, wheat-eared, 190.

Carrot, 212.

Cassia obovata, self-fertilising, 172.

Cassia, sleep of leaves, 109.

Caulifiower, 216.

Celery, 221.

Chard, 213.

Chicory, 220.

Circumnutation, 99.

Classification, 15, 40.

Cleistogamous, 38 .

Climate, 193 (note).

Climbing plants, $110 f f$.

Clover, leaves sleeping, $107 f f$.

Cohesion, explained, 31 .

Colchicun, propagation of, 60 ,

Colours of flowers, $176 \mathrm{ff}$.

Combretum, climbing of, 115.

Conduplicate leaves, 105. 
Convolvulus, climbing, 114.

Cornel, petaloid bracts of, 189.

Corollizorce or Gamopetala, 30 , 34.

Cotyledons, 16, 42 .

Crested flowers, 192.

Crossing and self-fertilisation, 165,180 .

Crown of Thorns, 80 .

CryṔtogams, 15.

Cucumber, 223.

Cut-leaved forms, $90 . f f$.

\section{D}

Darwinia, petaloid bracts of, 190.

Dahlia green, 190.

Declinate stamens, 151.

Degeneration or degradation, 37.

Degeneration and self-fertilisation, 181, 182.

Dichlamydea, 30 .

DicoTYLEDONS, characters of, 16,40 .

Dictamnus, dislocated petals of, 152 .

Dislocation of petals, 152 .

Distribution of wild flowers, causes and effects of, 202.

Drosera or Sundew, 122 ff.

Duckweed, propagation of, 84.

Duvernoia and bees, 155 .

\section{E}

Edible wild flowers, $209 \not f$.

Egyptian wheat, 45.

Embryo, 42.

Endive, 220.

Endogenous, 137.

Endosperm, 46.

Epigyna, 34.
Evolution of wild flowers $19 \mathrm{ff}$.

Exogenous, 137.

F

FAMILY, 17.

Fasciation, 191.

Fastigiate, 89.

Ferns, vegetative propagation of, 86.

Floral receptacle, $31 \mathrm{ff}$.

Flowers, fertilisation of, $167 \mathrm{fj}$.

Flowers, complete, $35 . f f$.

Flowers, names of parts of, 11.

Foliage of Monocotyledons, 139 .ff.

Food materials in reserve, 46. Freaks of wild flowers, $183 \mathrm{ff}$. Frog-bit, propagation of, 85 .

G

Gamopetalce or Corolliflorce, 30,34 .

Garden vegetables, history of, 209 ff.

Garden, wild flowers in the, $225 . f f$.

Genus and species, $17 . f f$.

Geranium, floral diagram of, 144.

Germination, process of, $47 . f f$. Genista, movernents in flower of, 102.

GLUMIFER

GyMnosperms, 16.

\section{$\mathrm{H}$}

Haricot bean, 221.

Hibbertia, peculiar climbing of, 113.

Hiptage, peculiar climbing of, 115 . 
Homology, 95.

Homomorphic, 171.

Honey - glands, origin of, $173 \mathrm{ff}$.

Honey-guides, 179.

Honey, nature of, 173.

Hor, method of climbing, 111.

Horse-chesnut, buds of, 106 .

Hose-in-hose flowers, 188.

Hypogyno, 34 .

\section{I}

Incompletoe, 36.

Inductive reasoning, 24 .

Insects and wild flowers, 121.

Involucre, 11.

Ipomaa argyraoides, climbing, 115.

Irregular flowers, 35, 147.

Irregular flowers reverting to regularity, 151.

\section{J}

Jerusalem Artichoke, 214.

Juniper, common, 17.

\section{$\mathrm{K}$}

Kaffir-bush, 77.

Kidney-bean, 221.

Kleinia, propagation by internodes, 88.

Knotgrass, forms of, 21.

Kohl-rabi, 216.

L

Lamina, 64.

Leaves and their modifications, $63 \mathrm{ff}$.
Leaves, simple and compound. $64 \mathrm{ff}$.

Leaves, venation of, 64 .

Leek, 219.

Lesser Celandine, origin of, $25 \mathrm{ff}$.

Lettuce, 220.

Lime, buds of, unfolding, 105.

Loasa, climbing, 112.

Lucerne, movements in floral organs of, 103.

Lupin, sleep of leaves of, 109.

M

Mangrove, 134.

Marrow, vegetable, 224.

Mechanical forces in plants, $98 \mathrm{ff}, \mathrm{I} 67 \mathrm{ff}$.

Mimetic flowers, $155 \mathrm{f}$.

Monochlamydece, 36.

MoNOCOTYLEDONS, characters of, 16,41 .

Monocotyledons described, 39.

Monsters, 190.

Movements of organs, $98 \mathrm{ft}$.

Mummy wheat, $42 f$.

\section{O}

Onions, sorts cultivated, 218.

Opposite leaves, 146.

Orchids, inversion of flower of, 149 .

ORDER, 17.

Organs of flowers, \&c., $10 \mathrm{ft}$.

Organs, functions of, $10 \mathrm{ff}$.

Origin of floral structures, $143 \mathrm{ff}$.

Ovary, inferior, $33 f f$.

Ovary, superior, $33 f f$. 
Ovules, petaloid, 187.

Oxalis cernua,spreading of, 84 .

\section{$\mathrm{P}$}

Parsley, 221.

Parsnip, 212.

Pea, 223.

Peloria, 151, 162, 190.

Perianth, 39.

Pericycle, 137 ff.

Petaloid bracts, 189 ff.

Petaloid ovules, 187.

Petaloidea, 39.

Petiole, 64.

Phanerogams, 15.

Phyllode, 71.

Pimpernel, flower of, 144.

Pistil replaced, 186.

Plumule, 42.

Plumule, growth of, $52 f f$.

Polypetala, 30.

Pondweed, 71, 86.

Potamogeton, 71, 86.

Potato, 214.

Propagation, by vegetative organs, $81 . f f$.

Protandrous, 170.

Protogynous, 170.

Protoplasm, properties of, 22. Pulvinus, 65.

\section{$\mathrm{R}$}

Radicle, 42.

Radicle, growth of, $48 . f$.

Radish, 210.

Ranunculus, species of, 17.

Receptacular tube, $31 \mathrm{ff}$.

Regular flower, 29, 150.

Regularity in terminal flowers, 159.

Representative plants, 14.

Respiration of germinating seeds, 47.
Rhubarb, 220.

Roots, $54 \mathrm{ff}$.

Roots, adventitious, 61 .

Roots, contractile, 58 .f.

Roots, mechanical force of, 60.

Roots, propagation by, 62 .

\section{S}

Salvia, action of stamens, $153 \mathrm{ff}$.

Salvia, structure of calyx of, 148.

Saxifraga granulata, bulbs of, 84.

Scarlet runner, flower of, 169. Scotch fir, 17.

Sea-kale, 217.

Sedum, propagated by leafbuds, 83.

Seed, structure of, 42 .

Self - fertilisation, Darwin's mistake on, $164 f f$.

Self - fertilisation compared with intercrossing, $164 f f$.

Self-fertilisation, methods of, $169 \mathrm{ff}$.

Self-fertilising plants, character of, 181.

Solanum Jasminoides, climbing, $116 \mathrm{ff}$.

Species, meaning of, $17 f$.

Spinach, 218.

Sports, vegetative, $89 \mathrm{ff}$.

Stameniferous corolla, 186.

Stamens, declinate, 151.

Stipular zone, 74.

Stipules, origin of, 64, 72 .

Sub-classes, 30.

Subterranean clover, $100 f$.

Sundew, 122.

Survivals, 23.

Synanthic flowers, 191. 
$\mathrm{T}$

Teucrium, structure of flower, 149.

Thalamiflore, 32.

Tissues, mechanical, 66 .

Tomato, 224.

Turnip, 210.

\section{U}

Uncaria, climbing flowerstalk of, 67 .

Uses of floral organs, 10.

\section{V}

Varieties, 19, 178.

Vegetative $81 \mathrm{ff}, 88$.

Venation of leaves, 64 .
Venus fly-trap, 125.

Veronica cupressoides, $92 f f$.

Victoria regia, 142.

Vine, tendrils of, 119.

Virginian creeper, tendrils of 119.

W.

Walnut, leaf of, 106.

Water-crowfoot, 135.

Water-lily, 142.

Water-soldier, 140.

Weeping trees, 90 .

Whorls, floral, $11 \mathrm{fj}$.

Whorls, floral, origin of, $143 t f$.

Wood-sorrel, $10 \tau t$

Y.

Yew, 17, 89. 
PRINTED BY

TURNBULI, AND SPFARS, EDINEURGH 


\section{The Ifbrary of điseful stortes. PRICE ONE SHILLING EACH.}

THE STORY OF ICE, in the Present and Past. By W. A. BREND. With 37 Illustrations.

THE STORY OF ECLIPSES. By G. F. Chambers, F.R.A.S. With ig Illustrations.

THE STORY OF THE BRITISH RACE. By JOHN MunRo. With 4 Maps.

THE STORY OF THE MIND. By Prof. J. M. BALDWIN. THE STORY OF GEOGRAPHICAL DISCOYERY : How the World Became Known. By JosEPH JACOBS. With 24 Maps, etc.

THE STORY OF THE COTTON PLANT. By F. WILKINSON, F.G.S. With 38 Illustrations.

THE STORY OF RELIGIONS. By the Rev E. D. PRICE, F.G.S.

THE STORY OF PHOTOGRAPHY. By A. T. STORY. With 38 Illustrations.

THE STORY OF LIFE IN THE SEAS. BY SydNEY J. Hickson, F.R.S. With 42 Illustrations.

THE STORY OF THE BRITISH COINAGE. By G. B. RAwlings. With ro8 Illustrations.

THE STORY OF THE POTTER. BY C. F. BINNS. With 57 Illustrations of Ancient and Modern Pottery.

THE STORY OF GERM LIFE : BACTERIA. BY H. W. CONN. With 34 Illustrations.

THE STORY OF THE EARTH'S ATMOSPHERE. By DOUglas ARCHIBALD. With 44 Illustrations.

THE STORY OF THE WEATHER. BY G. F. CHAMBERS, F.R.A.S. With 50 Illustrations.

THE STORY OF FOREST AND STREAM. BY JAMES RODWAY, F.L.S. With 27 Illustrations.

THE STORY OF THE CHEMICAL ELEMENTS. By M. M. Pattison Muir, M.A.

THE STORY OF EXTINCT CIYILIZATIONS OF THE EAST. By R. E. ANDERSon, M.A. With Maps.

THE STORY OF ELECTRICITY. BY J. MUNRO. With roo Illustrations.

THE STORY OF A PIECE OF COAL. By E A. MARTIN, F.G.S. With 38 Illustrations.

THE STORY OF THE SOLAR SYSTEM. BY G. F. Chambers, F.R.A.S. With 28 Illustrations.

THE STORY OF THE EARTH IN PAST AGES. By H. G. SEELEY, F.R.S. With 40 Illustrations.

THE STORY OF THE PLANTS. By GRANT ALLEN. With 49 Illustrations.

THE STORY OF PRIMITIYE MAN. BY EDWARD Clodd. With 88 Illustrations.

THE STORY OF THE STARS. BY G. F. CHAMBERS, F.R.A.S. With 24 Illustrations.

** Other Volumes in the Press.

LONDON : GEORGE NEWNES LIMITED. 




$$
86-32704
$$




\section{GETTY RESEARCH INSTITUTE \\ G \\ ||||||||||||||||||||||||||||| \\ 33125014211086}


